\title{
HOW INDIVIDUALS' DEFINITIONS OF CAREER SUCCESS \\ INFLUENCE THEIR DECISIONS ABOUT WHETHER \\ TO SEEK A PROMOTION
}

\author{
by \\ Jessica Eden, BAH

\begin{abstract}
A thesis submitted to
The Faculty of Graduate Studies and Research

in partial fulfillment of the

degree of

Master of Business Administration
\end{abstract}
Supervised by: Dr. Linda Duxbury
Eric Sprott School of Business
Carleton University
Ottawa, Ontario
June 21, 2007

(C) copyright Jessica Eden, 2007 


$\begin{array}{ll}\begin{array}{l}\text { Library and } \\ \text { Archives Canada }\end{array} & \begin{array}{l}\text { Bibliothèque et } \\ \text { Archives Canada }\end{array} \\ \begin{array}{l}\text { Published Heritage } \\ \text { Branch }\end{array} & \begin{array}{l}\text { Direction du } \\ \text { Patrimoine de l'édition }\end{array} \\ \begin{array}{l}\text { 395 Wellington Street } \\ \text { Ottawa ON K1A ON4 }\end{array} & \begin{array}{l}\text { 395, rue Wellington } \\ \text { Ottawa ON K1A ON4 } \\ \text { Canada }\end{array}\end{array}$

Your file Votre référence ISBN: 978-0-494-33781-3 Our file Notre référence ISBN: $978-0-494-33781-3$

NOTICE:

The author has granted a nonexclusive license allowing Library and Archives Canada to reproduce, publish, archive, preserve, conserve, communicate to the public by telecommunication or on the Internet, loan, distribute and sell theses worldwide, for commercial or noncommercial purposes, in microform, paper, electronic and/or any other formats.

The author retains copyright ownership and moral rights in this thesis. Neither the thesis nor substantial extracts from it may be printed or otherwise reproduced without the author's permission.
AVIS:

L'auteur a accordé une licence non exclusive permettant à la Bibliothèque et Archives Canada de reproduire, publier, archiver, sauvegarder, conserver, transmettre au public par télécommunication ou par l'Internet, prêter, distribuer et vendre des thèses partout dans le monde, à des fins commerciales ou autres, sur support microforme, papier, électronique et/ou autres formats.

L'auteur conserve la propriété du droit d'auteur et des droits moraux qui protège cette thèse. $\mathrm{Ni}$ la thèse ni des extraits substantiels de celle-ci ne doivent être imprimés ou autrement reproduits sans son autorisation.
In compliance with the Canadian

Privacy Act some supporting forms may have been removed from this thesis.

While these forms may be included in the document page count, their removal does not represent any loss of content from the thesis.
Conformément à la loi canadienne sur la protection de la vie privée, quelques formulaires secondaires ont été enlevés de cette thèse.

Bien que ces formulaires aient inclus dans la pagination, il n'y aura aucun contenu manquant.

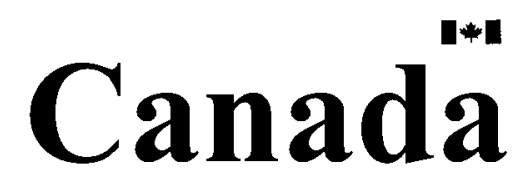




\section{ABSTRACT}

This study aimed to examine the relationship between subjective career success and the decision to seek a promotion. The sample consisted of 40 managers at the Executive level and the feeder group to the Executive level in a Canadian government department, originally interviewed as part of a prior study. A grounded theory analysis was carried out on the interview data, resulting in a model of the influence of subjective career success and of individual and situational characteristics on how public servants make the decision to pursue a promotion.

The results of this research can be useful to researchers, as they extend the scholarly understanding of career-related decision-making and how it is influenced by subjective career success. The results may also be used by managers and HR professionals, facing a succession planning crunch in the public sector, to encourage employees to seek a promotion to the Executive level. 
TABLE OF CONTENTS

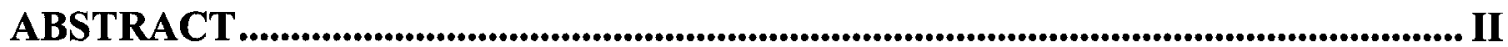

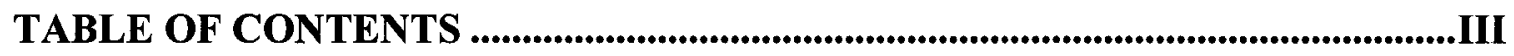

LIST OF TABLES ............................................................................................................................ V

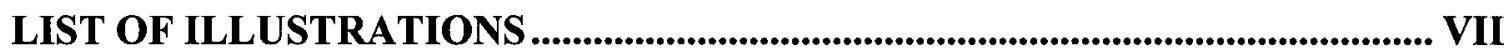

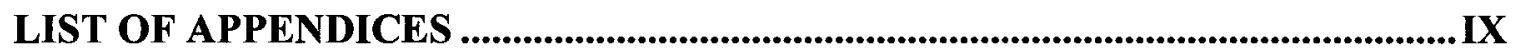

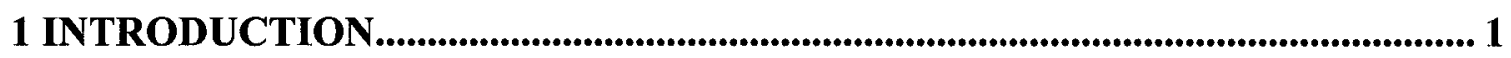

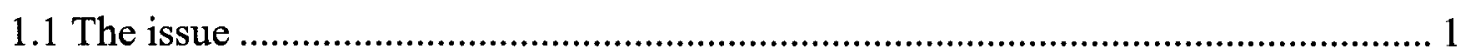

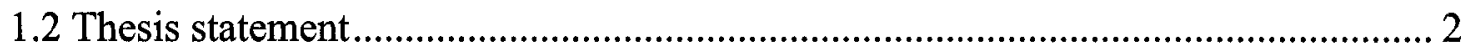

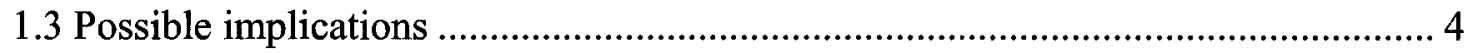

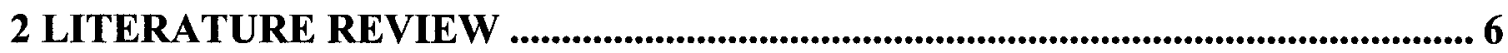

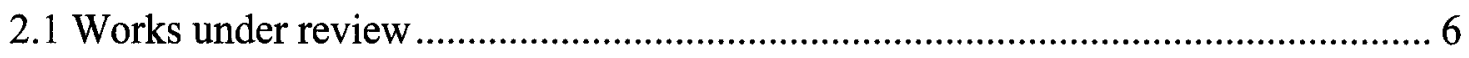

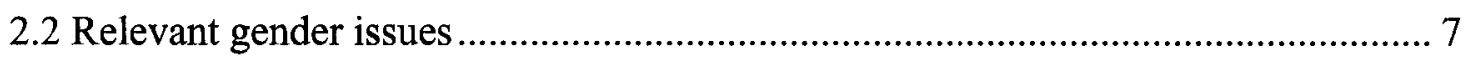

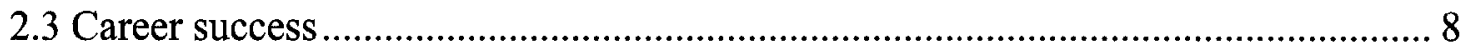

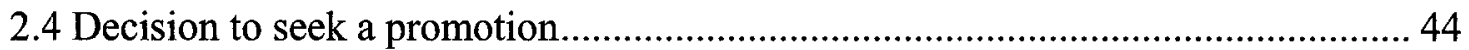

2.5 Linking subjective career success definitions and seeking a promotion ...............64

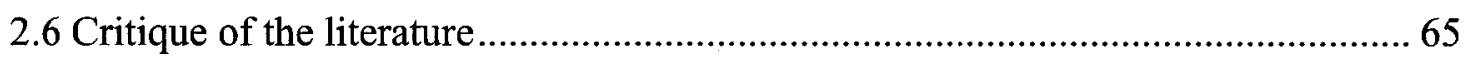

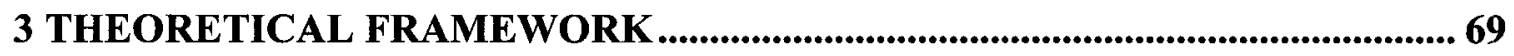

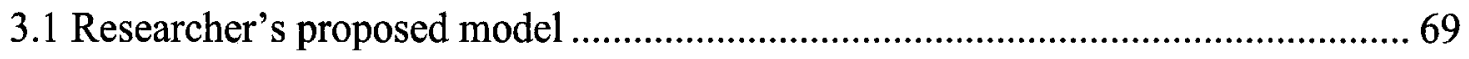

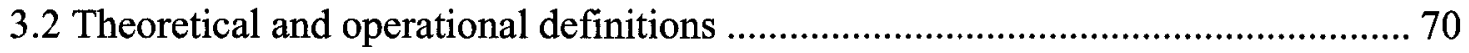

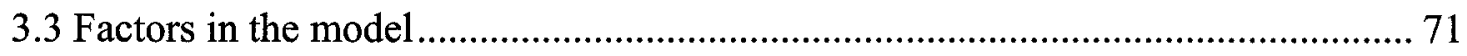

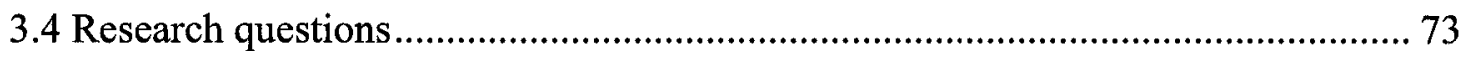

4 RESEARCH DESIGN AND METHODOLOGY .............................................. 75

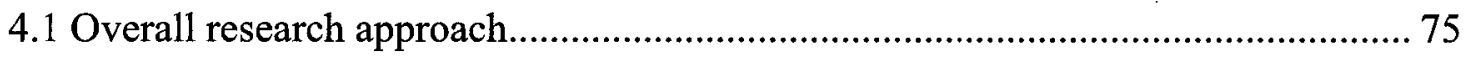




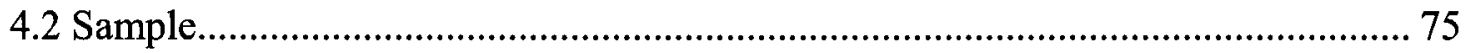

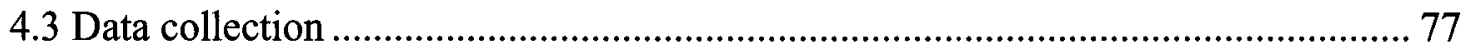

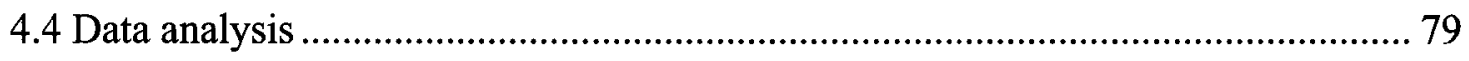

5 DISCUSSION OF FINDINGS .................................................................................92

5.1 How do public servants define career success? ..................................................... 92

5.2 What factors do public servants report taking into account when making the decision on whether or not to seek a promotion? ................................................ 105

5.3 Is there a relationship between a public servant's definition of career success and the factors they describe taking into account when deciding whether to seek a

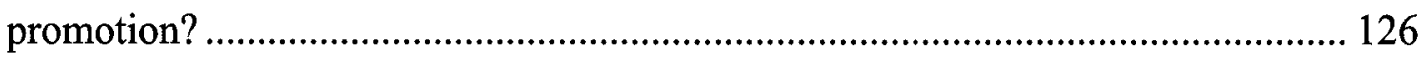

5.4 To what extent do the data bear out the model proposed by the researcher? ....... 139

5.5 To what extent does the relationship between subjective career success and the decision to seek a promotion depend on gender and level? .................................... 150

6 CONCLUSIONS ..................................................................................................................... 165

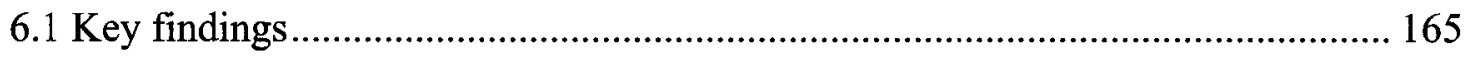

6.2 Limitations

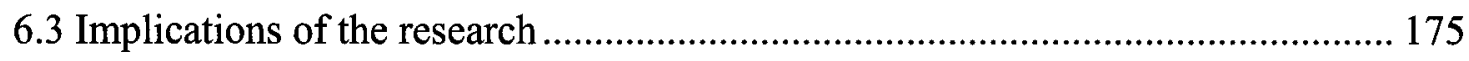

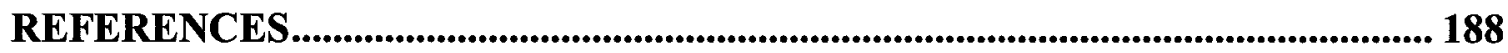




\section{LIST OF TABLES}

Table 2-1: Keywords used for literature search ..................................................... 7

Table 2-2: Comparison of rewards found for men and women .................................. 28

Table 3-1: Comparison of factors in the proposed model with those found in the literature 72

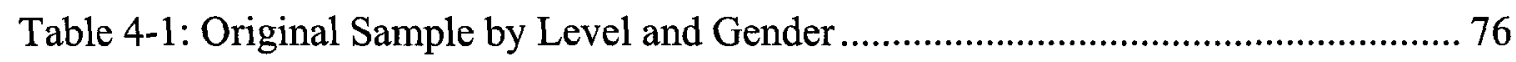

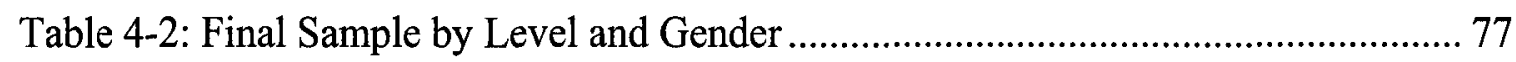

Table 5-1: Frequency of Occurrence of Subjective Career Success Themes and Subthemes

Table 5-2: Frequency of Occurrences of Career Decision-making Themes and Subthemes 106

Table 5-3: Frequency of Occurrences of Theme and Sub-theme Matches. 133

Table 5-4: Frequency of Occurrences of Career Success Themes and Sub-themes by Gender

Table 5-5: Test for Significance of Gender on Themes and Sub-themes in Subjective Career Success Using Fisher's Exact Probability Test.

Table 5-6: Frequency of Occurrences of Career Decision-making Themes and Subthemes by Gender

Table 5-7: Test for Significance of Gender on Themes and Sub-themes in Decision to Seek a Promotion, Using Fisher's Exact Probability Test. 156

Table 5-8: Frequency of Occurrences of Career Success Themes and Sub-themes by Level 160 
Table 5-9: Test for Significance of Level on Themes and Sub-themes in Subjective Career Success Using Fisher's Exact Probability Test.. 161

Table 5-10: Frequency of Occurrences of Career Decision-making Themes and Subthemes by Level. 162

Table 5-11: Test for Significance of Level on Themes and Sub-themes in Decision to Seek a Promotion, Using Fisher's Exact Probability Test. 163 


\section{LIST OF ILLUSTRATIONS}

Figure 2-1: A Conceptual Model of Career Success (Judge et al, 1995)........................ 11

Figure 2-2: A Gender-Specific Model of Career Success (Melamed, 1996).................. 14

Figure 2-3: Heslin's (2003) model of criteria affecting subjective career success........... 33

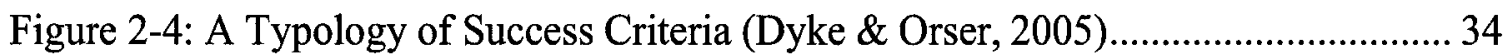

Figure 2-5: An Interactive Model of Career Motivation Components (London, 1983) ... 47

Figure 2-6 : Proposed Model of a Rational Decision-making Process.......................... 49

Figure 2-7: Process Model of Individual Career Decision Making (Mihal, Sorce \&

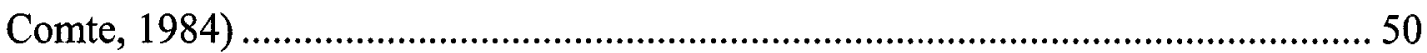

Figure 2-8: Simplified Version of Mihal, Sorce \& Comte's (1984) Model .................... 51

Figure 2-9: Cassirer and Reskin's (2000) Model of Influences on Promotion Aspiration52

Figure 2-10: Powell and Mainiero's (1992) Model of Factors Influencing Women's Careers

Figure 3-1: Proposed Model of a Rational Decision-making Process for PromotionSeeking Decision 70

Figure 3-2: Role of Factors in the Proposed Model of a Rational Decision-making Process .73

Figure 4-1: Comparison of Coded Factors with Hypothetical Examples 90

Figure 5-1: Frequency of Occurrences of Subjective Career Success Themes 94

Figure 5-2: Frequency of Occurrences of Subjective Career Success Sub-themes.... .95

Figure 5-3: Frequency of Occurrences of the Decision to Seek a Promotion Themes... 107

Figure 5-4: Frequency of Occurrences of Decision to Seek a Promotion Sub-themes .. 108 
Figure 5-5: Diagram of the Matched Themes and Sub-Themes................................. 129

Figure 5-6: Example Showing the Proportion of Individuals with Theme Matches ...... 131

Figure 5-7: Comparison of Career Success Factors Found In the Literature To Themes

And Sub-Themes Found In This Study 141

Figure 5-8: Comparison of Career Decision-making Factors Found In the Literature to Themes and Sub-Themes Found In This Study. 146

Figure 6-1: Revised Model of a Promotion-Seeking Decision-making Process 169 


\section{LIST OF APPENDICES}

Appendix A: Comparison of presence of Positive and negative sub-themes 184

Appendix B: Initial Model of Subjective Definitions of Career Success Process Resulting from Axial Coding Phase . 186

Appendix C: Initial Model of Decision to Seek a Promotion Process Resulting from Axial Coding Phase 187 


\section{INTRODUCTION}

\subsection{The issue}

A succession-planning crunch is at hand for the Canadian Public Service. Demographic data shows that approximately $40 \%$ of the Public Service workforce will be eligible for retirement by 2011 (May, 2006). More than half of the Public Service workforce is between the ages of 45 and 64, and, specifically in the top four layers of the executive cadre, most of the workforce is aged 50 to 53 (May, 2006). Furthermore, the Public Service Commission has predicted that 6.8 to $7.8 \%$ of executives will leave annually until 2011 (Public Service Commission of Canada, 2002). These data indicate that succession planning is now critical, as there will be a serious need to promote good candidates to the executive management level.

In order to address this problem, organizations in the Public Service need to encourage individuals with sufficient skills and experience to seek promotion to the managerial level. The Public Service Commission report goes on to note that "while there are many staff who will be available in the feeder groups to possibly replace executives, the primary issue is whether they are capable, ready and willing to replace executives" (Public Service Commission of Canada, 2002, p. 4). Researchers can help organizations tackle this problem by identifying how best to motivate qualified individuals to seek management jobs. Such efforts can be predicated by undertaking research that examines why people decide to seek a promotion to management. 
Popular wisdom says that an individual will always seek, or accept, a promotion if one is available. However, research into women's career choices shows that some women, at least, choose not to seek promotions. Might not some men, as well? Organizations need their best potential managers, both male and female, to apply for these jobs in order to minimize the effect of the forthcoming demographic crunch. Improving our understanding of why employees decide to, or not to, seek a promotion can help organizations motivate these employees to become managers. One sensible avenue for research is to examine how an employee's benchmark for measuring their career outcomes - their personal definition of career success - influences their decisions about seeking promotions.

\subsection{Thesis statement}

This thesis will use exploratory research techniques, including grounded theory methodology, to develop a model that articulates how individuals' definitions of career success are linked to their decisions about whether or not to pursue a promotion. Specifically, this thesis research seeks to answer the following research questions:

- How do public servants define career success?

- What factors do public servants report taking into account when making the decision on whether or not to seek a promotion?

- Is there a relationship between a public servant's definition of career success and the factors they describe taking into account when deciding whether to seek a promotion?

- To what extent does data bear out the model proposed by the researcher? 
- To what extent does the relationship between definitions of career success and the decision to seek a promotion depend on gender or on level in the hierarchy?

A thorough review of the relevant literature will be undertaken at the beginning of the model development process. This review will increase our understanding of what factors influence a public servant's perception of career success and what factors these individuals take into account when making career-related decisions. Our literature review will also examine and identify how gender differences affect both of these elements. The literature review will form the basis for a preliminary model of how an individual's definition of career success influences his or her decision to seek a promotion.

The study will undertake qualitative analysis of recorded, semi-structured interviews, conducted in 2006, from a prior study on career satisfaction and career progression. The 2006 study examined the views of managers in the executive cadre and executive feeder groups in a Canadian federal government department. ${ }^{1}$ While eightyeight individuals participated in this initial study, not all consented to participate in this follow-up study. Qualitative content analysis and some quantitative analysis of the interview data will be used to test the model developed by the researcher and to build on it.

The model development phase consists of several major steps. First, a list of potential factors included in the subjective definition of career success, and a list of the

\footnotetext{
${ }^{1}$ The name of the department studied has been redacted to protect the anonymity of the participants in this study.
} 
factors that may be considered when making a career-related decision will be developed. This list will be included in the model suggested by the literature review, in order to create a preliminary model that will be the jumping-off point for the exploratory analysis. Next, the interview data will be analyzed according to exploratory analysis methods, in order to extend upon or revise the suggested model. Finally, the model will be presented and examined to create suggestions for future research.

\subsection{Possible implications}

Understanding how an individual's definition of career success influences his or her decision about seeking promotion may help organizations, such as the Canadian Public Service, to be more effective in their efforts to encourage employees to seek management positions. In particular, this research may also benefit the organization where the study was conducted, which is attempting to tackle its succession planning challenges. The results of this research may help the organization make management positions more attractive and accessible to its employees. This research can also be useful to human resource (HR) practitioners, in order to help them develop programs and processes (including the promotion process itself) that will encourage qualified candidates to seek promotions.

The development of a model can also help researchers to better understand the relationship between these two constructs, which may point to interesting areas for further research. In particular, it may highlight the question of whether individuals will always choose to seek an available promotion. This is not necessarily the case in today's environment, so it is useful to examine how real people think about this decision. 
Finally, it is useful to study this question in an environment where the choice to seek a promotion passes through a clear application process, in order to develop ideas about how this could be examined in organizations where the promotion processes are less transparent or rules-based. The model developed for the Public Service can then form the basis of research in the private sector where promotion mechanisms are less prescribed.

This proposal is divided into six sections. The first section is the current one, which provides an overview and an introduction to the thesis. The second section presents the literature review, including a review of the career success and career-related decision-making literatures. Section 3 presents the proposed model, including the research questions. The fourth section presents the research design and methodology, including how the research questions will be answered in order to develop the final model. Next, Section 5 presents the results of this study in detail. The final section will present key findings, including the final model, as well as the limitations and implications of this study. 


\section{LITERATURE REVIEW}

This review of the literature will explore the current state of research into career success and career-related decision making, how the one may influence the other, and how gender issues influence and complicate both. This exploration will afford some insight into the relationship between the definition of career success held by an individual and his or her decision to seek a promotion.

The literature review will consist of six sections, which will address the main aspects of the research questions. First is Section 2.1, which sets the groundwork for the review by providing an overview of the works under review and outlining how the review is structured. Section 2.2 presents the reasoning for including gender differences in the literature review and in the study. Since gender issues are so integrated with the individual bodies of literature, they will be discussed concurrently with the next two sections. These sections examine the areas of the literature that bear on the research questions, including objective and subjective definitions of career success (Section 2.3) and the decision to seek a promotion (Section 2.4). Section 2.5 will then address how these two concepts overlap. The final section, Section 2.6, critiques the literature.

\subsection{Works under review}

The articles under review were identified via a search of the scholarly literature using Business Source Complete, Web of Science, and Google Scholar. This search attempted to identify a broad range of scholarly articles touching on the themes of career success and career decision-making, as well as related gender issues. Articles were 
reviewed for relevance to the key topics and appropriate articles (i.e., those with direct relevance to issues under study) were selected for the review. Additional relevant works were identified via snowballing from the citations of selected articles.

Table 2-1, below, shows the keywords used for the literature search. Various synonyms were used in order to find the relevant literature. In addition, for some searches the keywords "career" and "work" were used in order to exclude marketing literature that was returned by the keywords "promotion" and "advancement." These searches (and snowballing of references from articles) resulted in over 340 potentially relevant articles. After reviewing them, approximately 80 works were found to be relevant enough to be included in the literature review. Articles were determined to be relevant by review of the abstract and/or the article itself by the researcher to see if the content touched directly on any elements of the research question.

\begin{tabular}{|c|c|c|c|c|}
\hline \multicolumn{5}{|c|}{ Table 2-1: Keywords used for literature search } \\
\hline Topic & Career Success & Career Decision-Making & Gender & Narrowing \\
\hline Keywords & success & decision² (i.e., decision, & gender & career \\
searched & promotion & decisions, decision-making, etc) & sex & work \\
& advancement & goals & "glass ceiling" & \\
& progression & balance & & \\
& development & management & & \\
\hline
\end{tabular}

\subsection{Relevant gender issues}

One of the objectives of this thesis is to examine how gender affects subjective definitions of career success and the role gender plays in decisions to seek promotion. Several researchers have suggested that women's career experiences are different from

\footnotetext{
${ }^{2}$ The * character represents a truncation wildcard, used to find all words beginning with "decision."
} 
men's. Thus, it is important to consider unique issues of gender when studying careers (Kirchmeyer, 2002).

Because gender issues are so entwined with the analysis in many of the relevant articles (particularly in the decision-making literature) the discussion on impact of gender will be integrated into the main sections of the literature review. It is important to look at gender differences in both subjective and objective career success, as women's different experiences and opportunities in organizations may affect the way they define career success for themselves. In particular, women may be affected by unique work-life balance issues, due to the typical distribution of labour in the home (Hewlett \& Luce, 2005). Finally, it is important to note that when compiling this literature we observed that, while there is quite a bit of research into measuring and understanding the gap between men and women's objective career success, there is relatively little literature examining how this may affect their subjective career success or how women make career-related decisions. This thesis should, therefore, contribute to the knowledge in this area.

\subsection{Career success}

This section will present the literature related to individual definitions of career success. Career success has been defined as "the positive psychological or work-related outcomes or achievements one has accumulated as a result of one's work experiences" (Judge, Cable, Boudreau \& Bretz, 1995, p. 486). Historically, career success has tended to be defined purely as objective career success. More recently, there has been a growing emphasis on subjective definitions of career success (Ng, Elby, Sorensen \& Feldman, 
2005), and researcher's definitions of career success are increasingly taking into account both subjective and objective aspects. For example, Melamed (1996, p 217) defines career success as "the subjective and objective aspects of achievement and progress of an individual through an organization or occupation." In contrast, Seibert and Kramer (2001) defined it as the accumulated positive work and psychological outcomes resulting from one's work experiences, and $\mathrm{Ng}$ et al (2005) follow their definition.

Accordingly, this section of the literature review is broken into two broad categories: objective and subjective career success. Individual definitions of career success (as per the research question) would fall into the subjective career success body of literature. Since objective career success can, however, influence subjective career success, it is useful for this review to examine both. As such, this review will present the theoretical and operational definitions of both objective and subjective career success, and it will also identify factors that researchers have theorized or demonstrated to lead to each type of success.

\subsubsection{Objective career success}

Objective success has historically been the standard by which researchers measured an individual's success in their careers. Since this type of success is intended to measure how an individual has achieved on the organizational totem pole, it is usually assessed in comparison to a reference group (Melamed, 1996).

Objective career success is defined to be verifiable, observable, and measurable (Hughes 1958; London \& Stumpf, 1982; Judge et al, 1995; Heslin, 2005). It is often operationalized as salary, total compensation, salary growth, promotions, or place in the 
hierarchy (i.e. rank). These definitions will be discussed in more detail in the next section.

\subsection{1.a Theoretical models of objective career success}

Three articles have been selected as key to identifying the determinants of objective career success: Judge et al (1995), Ng et al (2005), and Melamed (1996). All three were selected for their rigorous empirical methods and broad scope.

The first of these is Judge et al (1995), which surveyed over one thousand executives from the database of an American executive search firm. These survey results were combined with data from the search database in order to analyze potential predictors of objective career success. They also examined subjective career success, which will be discussed in Section 2.3.2. Judge et al (1995, p. 486) define objective career success as the "observable career accomplishments which can be measured against the metrics of pay and ascendancy." In Judge et al's (1995) study, objective career success was operationalized as compensation (measured using total annual cash compensation) and number of promotions (measured by asking the participants about the number of upward changes in job levels they had received during their careers). Although Judge et al (1995) measured objective career success using both pay and promotions, they reported the results separately for each measure. They found that "the variables predicted number of promotions similarly to how they predicted compensation, although their effects were somewhat weaker in magnitude" (Judge et al, 1995, p. 505).

As shown in Figure 2-1 below, Judge et al (1995) grouped the predictors of objective career success into four areas: demographic, human capital (experiences that 
can enhance an employee's value), motivational (ambition and hours worked) and organizational/industry characteristics. Details on the specific variables in these groupings are discussed in Section 2.3.1.b below. Judge et al also posited that these variables, in combination with objective career success, predict subjective career success (see Section 2.3.2.b)

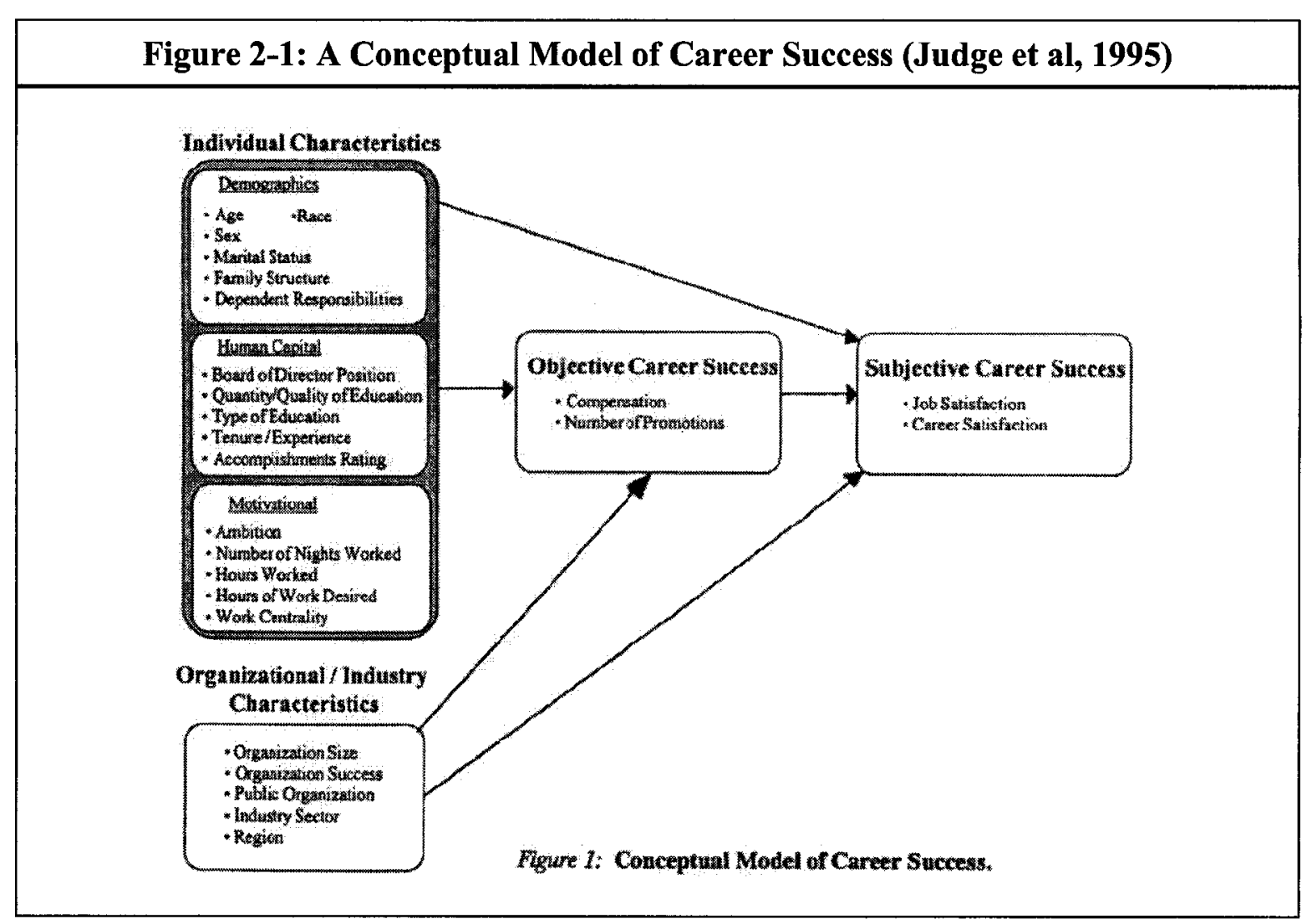

The second key article in this area is a meta-analysis done by Ng et al (2005), which analyzed 140 articles that examined potential predictors of objective career success and subjective career success (see Section 2.3.2.b). Ng et al (2005) operationalized objective career success by looking at two variables: total compensation and promotions. In their analysis, $\mathrm{Ng}$ et al (2005) treated total compensation the same as simple annual salary when operationalizing salary, since the two measures are highly correlated. For 
promotions, they used measures of the total numbers of promotions in an individual's career, and excluded studies that had measured promotion rate from any calculations of the relationship between promotions and organizational tenure.

Although no diagram of the model was presented, $\mathrm{Ng}$ et al (2005) grouped the predictors of objective career success into four areas: human capital, (experiences that can enhance career attainment) organizational sponsorship (assistance by organizations to facilitate career success), socio-demographic, (i.e. demographic) and stable individual difference characteristics (the Big Five personality characteristics, plus some additional variables). Although there is some overlap with the groupings presented by Judge et al (1995), the individual variables have been grouped differently by $\mathrm{Ng}$ et al (2005). The specific variables in these groupings will be discussed in the next section. $\mathrm{Ng}$ et al also posited that these variables, in combination with objective career success, predict subjective career success. The subjective career success element will be discussed in Section 2.3.2.b.

Melamed (1996) is considered the third key article with respect to understanding objective career success. This article discusses two separate, but similar, studies of gender-specific objective career success, using different samples. The first sample is 136 managers from one branch of the British civil service. The second sample is 324 British full-time employees from various organizations and industries. Both groups completed a similar survey, but the second contained more questions than the first. The first study operationalized objective career success as managerial grade, measured using a grading system of 1 to 5 used by the government. The second study operationalized career success as both gross annual salary and managerial level (self-reported on a seven level 
scale). Melamed did not make specific predictions about the relationship between the determinants and objective career success, although these findings were presented. The hypotheses presented in the study were specifically about the impact of gender on these relationships.

As shown in Figure 2-2, Melamed (1996) grouped the predictors of objective career success into three areas: human capital (attributes that can be converted into market rewards), career options (career-related choices and decisions) and opportunity structures (social contexts that determine opportunities). Again, although there is some overlap with the groupings presented by Judge et al (1995) and Ng et al (2005), the individual variables have been grouped differently by Melamed (1996). The specific variables in these groupings will be discussed in the next section. Unlike the other two studies, Melamed did not examine subjective career success. 
Figure 2-2: A Gender-Specific Model of Career Success (Melamed, 1996)

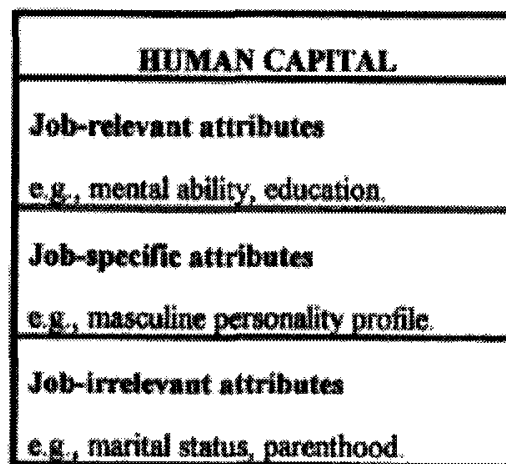

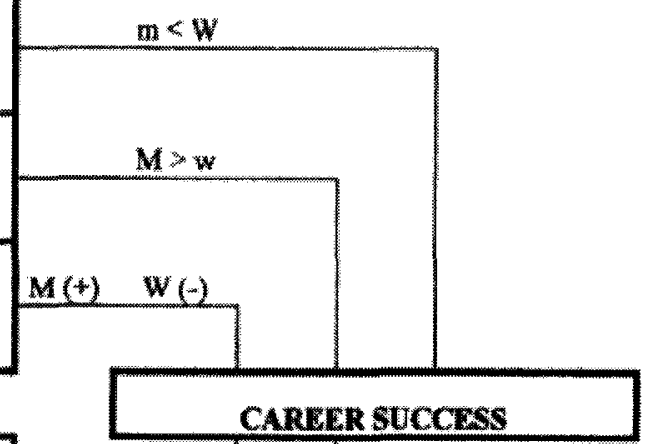

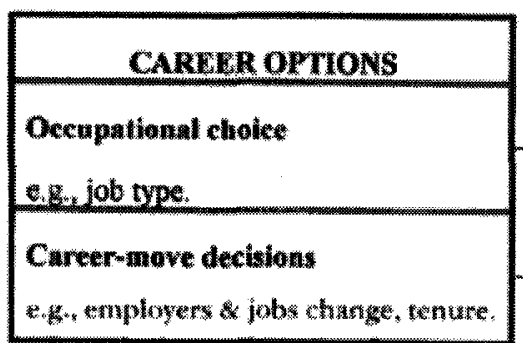

\section{CARGTr SUCCRs}

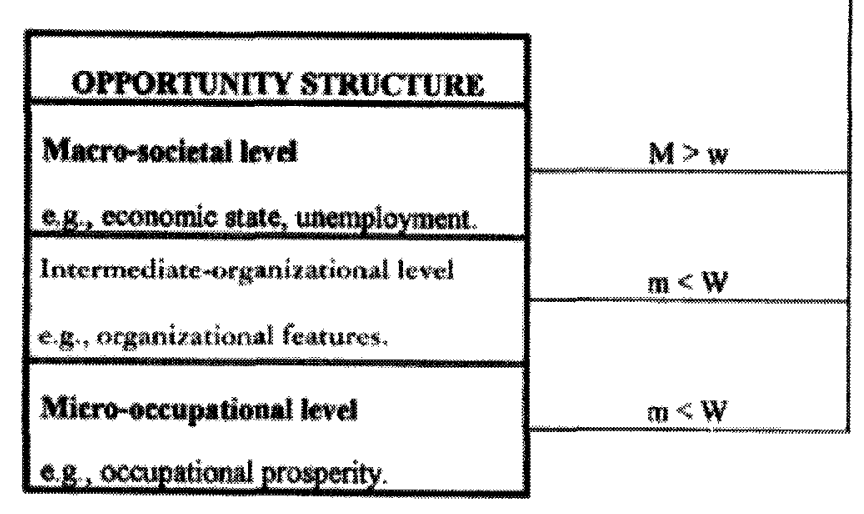

$\mathrm{m}$ m Inen

women

(+) posinive entect

(*) negative effect

\subsection{1.b Determinants of objective career success}

This section presents the groupings of variables and the specific measures used by researchers, their hypotheses, and their findings about the relationships between the various predictors and objective career success. While the focus is on the three specific articles described above, these findings are supplemented by a discussion of key findings from other researchers. 
For the purposes of clarity, some of the groupings have been categorized differently for this review, so that like variables can be discussed together. These categories are Personality, Demographic, Human capital, and Organizational/industrial/regional variables. The groupings used by Judge et al (1995) and $\mathrm{Ng}$ et al (2005) are very similar, so they can easily be folded together. Melamed's human capital grouping, however, contains elements that fall into different categories, so they have been split up in order to offer clearer comparison of findings. Personality variables are called "stable individual differences" by Ng et al (2005) and "job-specific human capital" variables by Melamed (1996). Demographic variables are discussed by Judge et al (1995) under that name, and are called socio-demographic variables by $\mathrm{Ng}$ et al (2005). Judge et al (1995) and $\mathrm{Ng}$ et al (2005) both discussed human capital variables, and Melamed's (1996) job-relevant human capital variables and career options variables are included here. Judge et al's motivational variables are also included in the human capital category. Finally Judge et al's (1995) organizational, industrial, and regional variables are discussed in the same section as $\mathrm{Ng}$ et al's (2005) organizational sponsorship variables and Melamed's (1996) opportunities structure variables.

\section{Personality variables}

Personality variables have been researched particularly in relation to gender differences in objective career success. The empirical data has found that characteristics such as extraversion, independence, self-confidence, masculinity, motivation and organizational commitment have a positive relationship with objective career success (Judge et al, 1995; Melamed, 1996; Tharenou, 2001; Chenevert \& Tremblay, 2002). 
$\mathrm{Ng}$ et al (2005)'s personality grouping included what they called stable individual differences variables. In their model, this was operationalized as the Big Five personality factors (neuroticism, conscientiousness, extroversion, agreeableness, and openness to experience), proactivity, locus of control, and cognitive ability. Conscientiousness, extroversion, proactivity, internal locus of control, and cognitive ability were all expected to positively influence career success. Neuroticism was expected to negatively influence career success. In their meta analysis, $\mathrm{Ng}$ et al determined that these personality variables were generally measured with commonly used scales, such as the NEO-Five Factor Inventory (Costa \& McCrae, 1992) for the Big Five personality factors or Bateman and Crant's (1993) measure for proactivity. Cognitive ability was operationalized by various common mental ability measures such as scores on standardized intelligence tests, aptitude tests, or critical thinking tests.

$\mathrm{Ng}$ et al (2005) reported that neuroticism and agreeableness were negatively related to both salary and promotions (i.e. objective career success). Conscientiousness, proactivity, and extroversion on the other hand were positively related to these factors. Openness to experience, locus of control, and cognitive ability were found to be positively related to only one of the two objective measures of career success studied: salary.

Melamed's (1996) operationalizing of the job specific classification of human capital is very similar to $\mathrm{Ng}$ et al's work. The first study included personality traits in this grouping. Personality traits were measured using Cattell's (1970) 16 Personality Factor model, combined into five general personality characteristics: extraversion, selfconfidence, tough-mindedness, independence and self-control. Study 1 found that 
extraversion and independence were positively and self-control negatively related to one measure of objective career success: managerial level. The second study found that independence and self-control were positively related to one dimension of objective career success, managerial level, while confidence, tough-mindedness and independence were positively related to the second measure of objective career success, salary.

\section{Demographic variables}

Demographic variables considered by Judge et al (1995) include age, marital status, employment status of spouse, time devoted to dependent responsibilities, gender, and minority status. Marital status, age, race, and gender were all collected using information in the database used in the study, while spouse's employment status and hours spent on dependent care were assessed via survey. Being older and married was predicted to be positively related to objective career success. Having a spouse employed outside the home, greater dependent care time, being female, or being a minority, on the other hand, were all expected to be negatively related to objective career success. The study found that while being older, male, married, and having a non-working spouse were all related to a higher level of compensation, being older was the only variable that predicted more promotions (Judge et al, 1995).

$\mathrm{Ng}$ et al (2005) included the following socio-demographic variables in their model: gender, race, marital status, and age. Being married, older, male, and white were expected to positively influence career success. All of these variables showed the expected relationship with salary and, with one exception (race), for promotions 
Finally, Melamed's (1996) job irrelevant classification of human capital also focused on demographic variables. Her first study included marital status and parenthood (both measured as Boolean yes/no variables) in this grouping. Marital status was removed as it was highly correlated with the parenthood variable. The first study did not find a significant relationship between parental status and objective career success. The second study, on the other hand, found that parenthood was positively related to managerial level.

\section{Human capital variables}

Judge et al (1995) and Ng et al (2005) define human capital similarly, as educational, personal, and professional experiences that can enhance an employee's value to an employer (Judge et al) or career attainment ( $\mathrm{Ng}$ et al). Melamed, on the other hand, defines human capital as personal attributes that can be converted "into rewards on the labour market" (Melamed, 1996, p 218). Although this definition is still quite similar, it may explain the very different variables that Melamed included in this grouping, (i.e. variables that the other two researchers defined as personality or demographic variables). These differences are discussed in more detail below.

Various researchers have looked at the impact of human capital on objective career success. A number of variables have been reported to affect objective career success, including education and work experience (Stroh, Brett \& Reilly, 1992; Chenevert \& Tremblay, 2002); job and work variables, such as administrative or budget responsibilities and hours worked (Judge et al, 1995; Melamed, 1996; Chenevert \& Tremblay, 2002); and career variables, such as tenure, job changes, and work 
interruptions. With two exceptions, these relationships are generally positive. Voluntary turnover is negatively associated with objective career success for women, while career interruptions are negatively associated with objective career success for men (Cannings \& Montmarquette, 1991; Melamed, 1996; Chenevert \& Tremblay, 2002; Kirchmeyer, 2002).

Judge et al (1995) defines human capital to include the following variables: level of education; type of degree obtained (business, law, engineering, or other); university quality (including whether the university was Ivy League); job tenure; occupational tenure; international experience; accomplishment ratings; and service on external board of directors. All of these items were obtained from fields in the database used, except for the quality and accomplishment ratings of employees and university quality. University quality was measured based on the Gourman Report (Gourman, 1993) on higher education. Quality and accomplishment ratings of the executives were evaluated by associates at the executive search firm who supplied the database used in the study (Judge et al, 1995).

Judge et al (1995) hypothesized that human capital variables included in their model would positively influence objective career success. The data partially supported this hypothesis. Level of education, type of degree, university quality, attending an Ivy League university, and accomplishment ratings were all found to positively influence compensation. Occupational tenure, international experience, and accomplishment ratings were found to positively influence promotions. Job tenure was found to negatively influence promotions (Judge et al, 1995). 
Judge et al (1995) also discussed motivational variables, which will be included here in the human capital category. Motivational variables in this study included job importance, hours worked, evenings worked, desired work hours, and ambition. Hours worked per week, evenings worked per month, and desired hours of work per week were assessed by the survey, while ambition was measured by the number of levels an executive wished to advance and job importance was measured with an instrument developed by the Meaning of Work project (MOW International Research Team, 1987). All of these variables were expected to positively influence objective career success. Again, this hypothesis was only partially supported. While all of the variables were found to positively influence compensation, only evenings worked per month, desired work hours, and ambition positively influence promotions (Judge et al, 1995).

$\mathrm{Ng}$ et al (2005) operationalized human capital using number of hours worked, work centrality (i.e., job involvement), job tenure, organization tenure, work experience, willingness to transfer, international work experience, education level, career planning, political knowledge and skills, and social capital variables. Work centrality was defined by Ng et al (2005, p. 380) as "the psychological investment in work or centrality of work for self-identity or self-image." This was generally operationalized with self-reported measures of job involvement using measures similar to those used by Judge et al (1995) to measure job importance in the motivational variables category (discussed previously). Willingness to transfer was measured with self-reported openness to mobility opportunities, including job rotations, promotions, and relocations. Career planning was commonly measured using Gould's (1979) scale. Political knowledge and skills was measured as both political knowledge and supervisor-focused political tactics measures. 
Social capital included self-reported measures for the number of people the respondents knew in other functions or levels of the organization, or the extent of networking activities they engage in. These variables were expected to be positively related to objective career success. These hypotheses were supported by the data as all the human capital variables were positively related to salary and with a few exceptions to promotions. The exceptions included the following: the relationship between political knowledge and skills was not significant, and salary and job tenure had a negative association. Finally, there were not enough data to allow conclusions with respect to the relationship between career planning and promotions.

Findings using Melamed's job relevant classification of human capital are also relevant to this discussion. The first study included scholastic mental ability and education level in this grouping. Mental ability was measured with the scholastic mental capacity score of the 16 Personality Factor test (Institute for Personality and Ability Testing, 1972). Education level was measured on a six-point scale by years of schooling. The second study added two measures of mental ability and work experience (measured as the number of years in the current job title). Again, the research found that certain measures of human capital predicted one aspect of objective career success. For example, the first study found that education was positively related to managerial level, while the second study found that numerical ability was positively related to salary.

The career options grouping by Melamed includes elements that were grouped as human capital by other researchers. Career options are defined by Melamed (1996) as choices and decisions made by employees throughout their career, such as occupational choice and career moves. For the first study, three career-move decisions were used for 
career options variables: tenure, frequency of changing employers, and frequency of changing jobs. These were measured numerically by looking at the reported number of employers, job titles, and years of service (tenure). In the second study, two occupational decisions were added: job social class and job type. Job social class was a self-selected choice of one of five groups (i.e., professional, manual, skilled, etc), while job type was measured using standard occupational classifications. Job change was removed from the analysis as it was highly correlated with employer change.

Certain job type and job change choices were expected to be positively associated with objective career success. Frequent job change was found in the first study to be positively related to managerial level. In contrast, in the second study it was negatively related to salary, except in cases where frequent job change was paired with infrequent employer change (which had a positive association). The second study found that professional and high-level jobs were related positively to both salary and managerial level. Finally, the first study found that tenure was positively related to managerial level.

\section{Organizational, industrial, and regional variables}

$\mathrm{Ng}$ et al (2005, p. 371) included organizational sponsorship, or the "extent to which organizations provide special assistance to employees to facilitate their career success" in their model. Organizational sponsorship variables included career sponsorship, supervisor support, training and skill development opportunities, and organizational resources variables. They hypothesized that these variables would all positively influence career success. Career sponsorship was measured as a self-reported extent to which the participant receives sponsorship from others in their organization, 
from any source, such as challenging tasks, exposure, visibility, protection, sponsorship, or coaching. Supervisor support was defined as emotional and work-related social support from supervisors, and was measured by multi-item self-reported measures. Training and skill development opportunities were measured by self-reported perceptions of the extent of such opportunities. The organizational resources variable was measured by organization size, as the number of employees in the organization. All four organizational sponsorship variables were positively associated with salary. Career sponsorship and training and skill development were both positively but weakly associated with promotions.

Opportunities structures-or the "social contexts that determine the progress opportunities open to employees"-was examined on an organizational, occupational, regional, and industrial level by Melamed (1996, p. 222).

For the first study, three regional opportunities structure measures were used: average wage, unemployment rate, and number of vacant jobs in job centres. These values were all obtained from official publications of the British Central Statistical Office. Ultimately, the regional vacancies variable was removed from the model as it was highly correlated with the average wage variable. For the second study, three industry opportunities-structure variables were added: average salary in industry, salary gap between top and low earners, and size of the workforce in the industry. The data was obtained from official publications of the British Central Statistical Office. For the first study, organizational opportunities included the variables promotion opportunities and position power. Promotion opportunities were measured by the ratio of the number of employees between the two adjacent job grades within the respondents' regional office. 
Position power was measured by defining departments as either line or staff departments, and was rated by two independent judges. In the second study, promotion opportunities was dropped due to a low response rate and type of industry (service or manufacturing), industrial sector (public or private) and the size of the workforce within the organization (grouped into eight levels) were added. Study two also included occupational opportunities structures, which was operationalized using two variables: average salary in occupation, and salary gap between top and low earners in occupation. These data were obtained from official publications of the British Central Statistical Office. Regional vacancies, industry wage gap, industry type and occupation wage gap were omitted due to interrelations.

This research showed that organizational variables were associated with some dimensions of objective career success. For example, study one found that promotion opportunities were positively related to managerial level. Study two found that a prosperous region and working in the private sector were positively related to managerial level, while a prosperous region and prosperous occupation were positively related to salary.

\subsection{1.c Gender-based differences in objective career success}

When looking at gender differences in objective career success, it is first important to demonstrate that this difference actually exists. Various researchers have attempted to argue that the difference between men and women's objective career success is not due to discrimination, but rather, can be attributed to gender difference in situational factors (such as educational level, for example). According to this school of 
thought, gender differences in objective career success will disappear concomitant with gender differences in these situational factors (Chênevert and Tremblay, 2002).

Other researchers (Cannings and Montmarquette, 1991; Chênevert and Tremblay, 2002) have attempted to disprove the notion that women are disadvantaged by either covert or overt discrimination in organizations, by statistically eliminating the influence of gender on career progression in their data analysis. Although such studies were able to eliminate the influence of gender on some aspects of career progression, such as the number or speed of promotions, they were not able to counter the effect of gender on other aspects, such as salary and hierarchical level (Chênevert and Tremblay, 2002).

The glass ceiling theory is the most common explanation for women's difficulty in obtaining objective career success, even when situational factors have been accounted for. In particular, this theory accounts for women's poor representation at management levels. The glass ceiling theory suggests that women reach a certain middle management level, above which it is very difficult for women to rise. Studies have found that biases tend to be more pronounced at higher organizational levels (Morrison, White \& Van Velsor, 1992; Auster, 2001). Tharenou (2001) also suggests that in organizations dominated by male hierarchies, there may also be a "sticky floor" below the "glass ceiling" that prevents women from advancing into lower and middle management.

Part of the explanation for this outcome is that either overt or covert biases held by superiors prevent women from being promoted. Employers and superiors may hold stereotypical views of women's lesser attachment to their careers, perceive women as not having the personality traits appropriate for management, or may be concerned about the 
likelihood of career interruption (Bielby \& Baron, 1986; Cannings, 1988; Liff \& Ward, 2001).

Even in equity-friendly organizations, "far more powerful informal practices" often reinforce gender-based differences (Liff \& Ward, 2001, p. 30). Lyness and Thompson (1997) found that 72 percent of the women they interviewed cited stereotypes about women's roles and abilities as a barrier to their career advancement. Others note that women are less likely to receive signals from the organization to expect a promotion (Cassirer \& Reskin, 2000). In addition, female managers may have difficulty getting the message of their career commitment across to superiors who assume that they are less ambitious than their male peers (Liff \& Ward, 2001).

It is also useful to look at the patterns of difference in objective career success (commonly operationalized as salary, total compensation, salary growth, promotions, or place in the hierarchy by researchers) between men and women. Numerous studies have shown that women do obtain less objective career success than men do, even when controlling for other explanatory factors. However, different studies have shown different patterns in rewards. Table 2-2, below, summarizes the findings from various studies and compares the findings for rewards in terms of pay and in terms of rank. Both the table below and several meta-analytical studies (Ng et al, 2005; Powell \& Mainiero, 1992; Chênevert and Tremblay, 2002) found that, overall, women do tend to gain fewer objective rewards than men, but the pattern of rewards found by researchers is not always the same.

Four articles showed comparisons between the pay rewards than men and women received. In three cases, women tended to receive less pay rewards that men did (Stroh, 
Brett, \& Reilly, 1992; Chênevert \& Tremblay, 2002; Ng et al, 2005). In one case, women actually received higher pay rewards, with committed female employees receiving greater salary increases, even though the same study found that men tended to earn higher salaries (Chênevert \& Tremblay, 2002). One study found that women's pay rewards were the same as men's (Lyness \& Thompson, 1997).

Seven articles compared the rewards in rank that men and women received. Four of these articles showed that women received lesser rewards in rank than men did (Cannings \& Montmarquette, 1991; Powell \& Mainiero, 1992; Lyness \& Thompson, 1997; Chênevert \& Tremblay, 2002). One article found that women tended to be promoted more quickly than men (Tsui \& Gutek, 1984) and another that women tended to hold higher hierarchical positions, even though the same study found that women were promoted more slowly and men more likely to be rewarded with promotions (Chênevert $\&$ Tremblay, 2002). Two articles found that men and women had similar promotion rates (Stroh, Brett, \& Reilly, 1992; Ng et al, 2005). 


\begin{tabular}{|c|c|c|c|}
\hline Summary & Finding & Group studied & Source \\
\hline Pay 4 & $\begin{array}{l}\text { women more likely to be rewarded } \\
\text { with salary increases }\end{array}$ & committed employees & $\begin{array}{l}\text { Chênevert \& Tremblay, } \\
2002\end{array}$ \\
\hline Pay $=$ & women's salaries were the same & senior managers & Lyness \& Thompson, 1997 \\
\hline Pay $\downarrow$ & $\begin{array}{l}\text { women had less salary } \\
\text { progression }\end{array}$ & $\begin{array}{l}\text { managers who had taken } \\
\text { job transfers }\end{array}$ & Stroh, Brett, \& Reilly, 1992 \\
\hline Pay $\downarrow$ & men tended to earn higher salaries & $\begin{array}{l}\text { successful public sector } \\
\text { managers }\end{array}$ & $\begin{array}{l}\text { Chênevert \& Tremblay, } \\
2002\end{array}$ \\
\hline Pay $\downarrow$ & $\begin{array}{l}\text { women tended to be rewarded } \\
\text { with lower salaries }\end{array}$ & meta-analysis & $\mathrm{Ng}$ et al, 2005 \\
\hline Rank 4 & $\begin{array}{l}\text { women were promoted faster than } \\
\text { men }\end{array}$ & managers & Tsui \& Gutek, 1984 \\
\hline Rank 4 & $\begin{array}{l}\text { women tended to hold higher } \\
\text { hierarchical positions }\end{array}$ & $\begin{array}{l}\text { successful public sector } \\
\text { managers }\end{array}$ & $\begin{array}{l}\text { Chênevert \& Tremblay, } \\
2002\end{array}$ \\
\hline Rank = & $\begin{array}{l}\text { women had similar promotion } \\
\text { rates }\end{array}$ & $\begin{array}{l}\text { managers who had taken } \\
\text { job transfers }\end{array}$ & Stroh, Brett, \& Reilly, 1992 \\
\hline Rank = & women promoted as often as men & meta-analysis & $\mathrm{Ng}$ et al, 2005 \\
\hline Rank $\downarrow$ & $\begin{array}{l}\text { women were promoted more } \\
\text { slowly }\end{array}$ & middle mangers & $\begin{array}{l}\text { Cannings \& Montmarquette, } \\
1991\end{array}$ \\
\hline Rank $\downarrow$ & $\begin{array}{l}\text { women's promotions were less } \\
\text { vital to their firms }\end{array}$ & meta-analysis & Powell \& Mainiero, 1992 \\
\hline Rank $\downarrow$ & $\begin{array}{l}\text { women had fewer subordinates } \\
\text { and less authority }\end{array}$ & senior managers & Lyness \& Thompson, 1997 \\
\hline Rank $\downarrow$ & $\begin{array}{l}\text { women were promoted more } \\
\text { slowly }\end{array}$ & managers & $\begin{array}{l}\text { Chênevert \& Tremblay, } \\
2002\end{array}$ \\
\hline Rank $\downarrow$ & $\begin{array}{l}\text { men more likely to be rewarded } \\
\text { with promotions }\end{array}$ & committed employees & $\begin{array}{l}\text { Chênevert \& Tremblay, } \\
2002\end{array}$ \\
\hline
\end{tabular}

In addition, the empirical data suggests that the situation is changing, perhaps due to equal pay efforts over the past several decades. Kirchmeyer (2002), for example, found that women appeared to be advancing more slowly before the mid 1990's, and that since then the situation has improved (although women were disadvantaged by starting from a lower benchmark in previous years). In their meta-analysis, $\mathrm{Ng}$ et al (2005) also 
found evidence that the gender-salary relationship has lessened over the past ten years, although the gender-promotion relationship has not.

In summary, there is sufficient evidence to say that there are gender differences in objective career success that cannot be explained purely by differences in situational factors. Gender-related pressures or biases do seem to play a role. At this point, we cannot, however, make specific predictions about how the measures of objective career success (such as pay or promotions) will vary with gender. The empirical research results in different findings, perhaps based on national or organizational cultures, specific differences in the methodology used, or the time period when the research was undertaken.

\subsubsection{Subjective career success}

Hughes originally distinguished between the objective and subjective careers in 1937. Hughes (1937, p. 409) sees the objective career as "a series of status and clearly defined offices" (in a rigidly structured society) or "typical sequences of position, achievement, responsibility, and even of adventure" (in a less rigid one). In contrast, Hughes sees the subjective career as "the moving perspective in which the person sees his life as a whole and interprets the meaning of his various attributes, actions, and the things which happen to him" (1937, p. 409-410). These definitions lay the groundwork for more modern definitions of the objective and subjective career.

Nevertheless, by the early 1990 s, little research had been done into the subjective definitions of career success held by managers (Herriot, Gibbons, Pemberton \& Jackson, 1994; Poole, Langan-Fox \& Omodei, 1993). Researchers did acknowledge, however, the 
need to examine both types of success, and recognized that individuals seek more than pay and promotion from their careers (Gattiker \& Larwood, 1988; Howard \& Bray, 1988; Judge et al, 1995; Sturges, 1999; Heslin, 2003). The rising interest in subjective career success may relate to the rise of the "protean career" with its increased focus on selffulfillment and internal criteria for success (Hall \& Moss, 1998).

Heslin (2005, p. 114) follows Hughes in defining subjective career success as "an individual's reactions to his or her unfolding career experiences." These reactions may reflect standard societal markers of career success as well as personal ones and may be related to both intrinsic and extrinsic aspects of career (Greenhaus, Parasuraman \& Wormley, 1990). It is experienced directly by the individual, is defined by the individual's reactions to or judgments about their career (Burke, 2001), and it is based on subjective criteria (Gattiker \& Larwood, 1986). Dyke \& Orser (2005, p. 36) point out, however, that "there is no accepted typology of success" and that few studies have examined the link between subjective success criteria and the individual's overall rating of their own success.

Subjective career success is often operationalized as career satisfaction (Heslin, 2005; Ng et al, 2005; Greenhaus et al, 1990; Judge et al, 1995). Career satisfaction is defined as an individual's "feelings of accomplishment and satisfaction with their careers" (Judge et al, 1995, p. 487). Career satisfaction has been operationalized with various established measures (Greenhaus, Parasuraman \& Wormley, 1990; Powell \& Mainiero, 1992). Subjective career success is also sometimes operationalized as job satisfaction, or as job and career satisfaction together (Heslin, 2005; Powell \& Mainiero, 1992; Ng et al, 2005; Judge et al, 1995). Job satisfaction is defined as how content an 
individual is with his or her job and has been operationalized using various measures (Scarpello \& Campbell, 1983; Judge et al, 1995).

\subsection{2.a Theoretical models of subjective career success}

Four articles have been selected as key to identifying the determinants of subjective career success: Judge et al (1995), Ng et al (2005), Heslin (2003) and Dyke and Orser (2005). Judge et al (1995) and $\mathrm{Ng}$ et al (2005), as in the objective career success section, have been selected for their broad and rigorous empirical approach. Heslin (2003) and Dyke and Orser (2005) have been selected for the unique perspectives they bring to the discussion, supported by good empirical foundations. A description of the methodology and groupings of variables used by Judge et al (1995) and Ng et al (2005) appears above in Section 2.3.1.a and will not be repeated here. The groupings of variables are the same for subjective career success, with a few exceptions. Judge et al (1995) included objective career success as a predictor of subjective career success, while Heslin (2003) included the relationship of self- and other-referent career success with subjective career success. Dyke and Orser (2005) used principle components analysis to identify the following variable groupings: organizational performance, rewarding work, balanced life, financial rewards, community impact, and personal well-being.

Judge et al (1995, p. 493) conceptualizes subjective career success "as consisting of two components: current job satisfaction and career satisfaction." Judge et al (1995, p. 497) defined job satisfaction according to Locke's (1976, p. 1300), definition as “a pleasurable or positive emotional state resulting from an appraisal of one's job or job experiences." It was operationalized using three different satisfaction measures: a Gallup 
Poll measure of job satisfaction (not referenced), a single item adaptation of the G. M. Faces Scale (Scarpello \& Campbell, 1983), and an adapted version of the Fordyce Percent Time Satisfied (Diener, 1984). Career satisfaction was defined as "the satisfaction individuals derive from intrinsic and extrinsic aspects of their careers, including pay, advancement, and developmental opportunities" (Judge et al, 1995, p 487) and measured using a scale developed by Greenhaus, Parasuraman, and Wormley (1990). Although Judge et al (1995) measured subjective career success using both job and career satisfaction, they reported the results separately for each, and they found that the variables that predicted job satisfaction tended to be different from those that predicted career satisfaction (Judge et al, 1995, p. 506).

$\mathrm{Ng}$ et al (2005) included in their meta-analysis only those articles that operationalized subjective career success as career satisfaction. They do not strictly define career satisfaction, but do refer to it as a measure of subjective career success that captures “individuals' subjective judgments about their career attainments" ( $\mathrm{Ng}$ et al, 2005, p. 368-9).

Heslin (2003, p. 271) measured overall subjective career success using a singleitem satisfaction Likert scale, in response to the question "Everything considered, how successful do you consider your career to date?" Heslin's study examined 71 Canadian part-time MBA students. Heslin does not present a visual model, but the relationships tested in his study are shown in Figure 2-3. 
Figure 2-3: Heslin's (2003) model of criteria affecting subjective career success

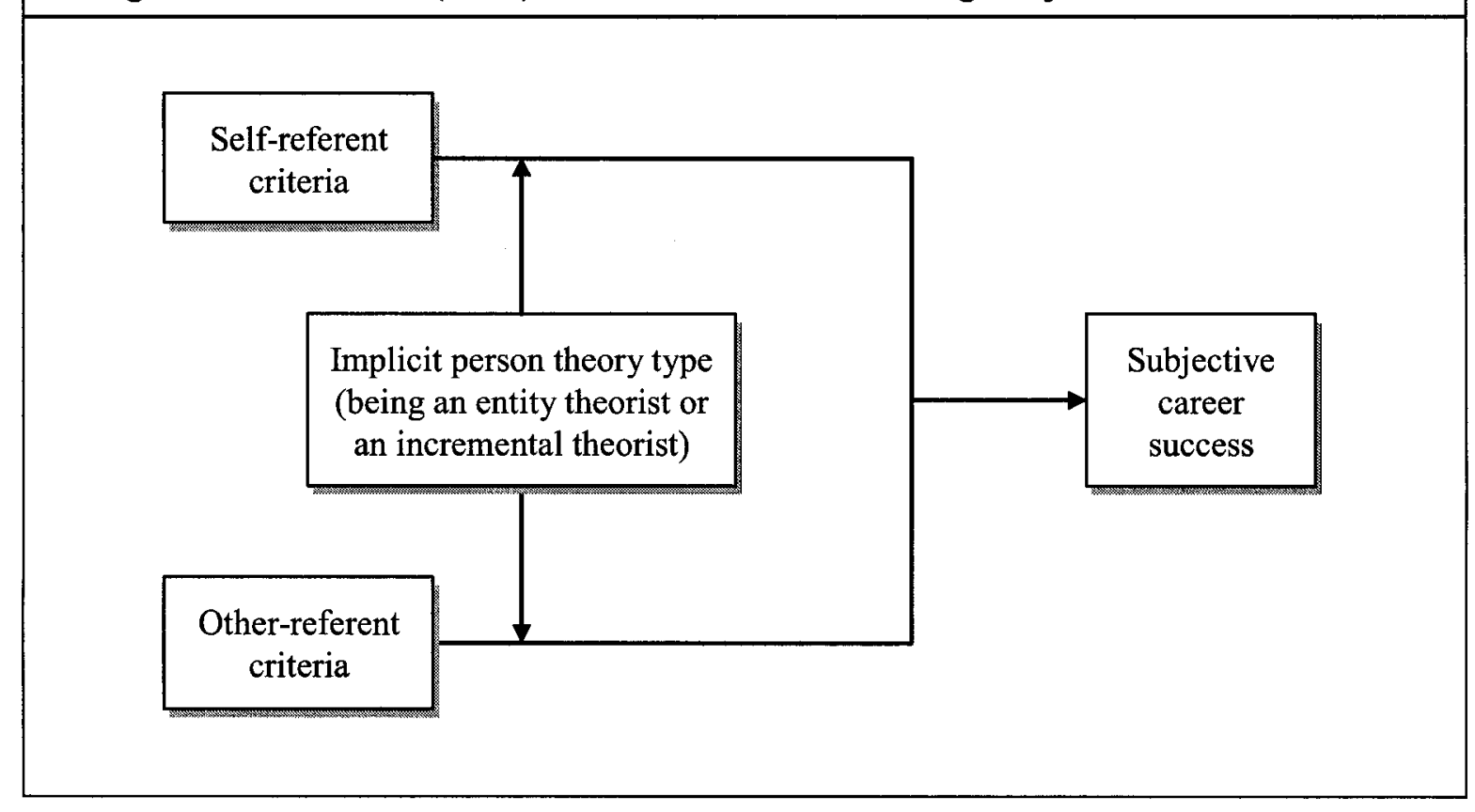

Dyke and Orser (2005) surveyed 545 middle and upper level managers in private and public organizations, augmented by 24 women from the list of Canada's Top 100 Most Powerful Women. They defined subjective career success as overall career success, measured using 5-item Likert scale questions asking respondents to rate their overall career success.

The models presented by Judge et al (1995) and Ng et al (2005) demonstrate the relationship between the predictors and subjective career success, as can be seen in Figure 2-1 and Figure 2-2 above. Although Heslin (2003) did not provide his diagram of the model, he predicts that both self-referent criteria (compared to the individual's own aspirations) and other-referent (compare to the perceived attainments and expectations of peers) will predict subjective career success. No hypotheses were made regarding the specific elements that might make up self- and other-referent criteria. 
Dyke and Orser (2005) do not identify a model up-front. Rather, they asked participants to rate 24 success criteria on (1) the importance of each criterion for evaluating their career success and (2) how successful they had been on each criterion. The 24 criteria were based on a proposed typology of career success developed by Dyke and Orser (2005), shown below in Figure 2-4. A principal components analysis then resulted in the 24 criteria being combined into 6 groupings. This 6 -factor solution (organizational performance, rewarding work, balanced life, financial rewards, community impact, and personal well-being) explained 57 percent of the variance in scores.

\section{Figure 2-4: A Typology of Success Criteria (Dyke \& Orser, 2005)}

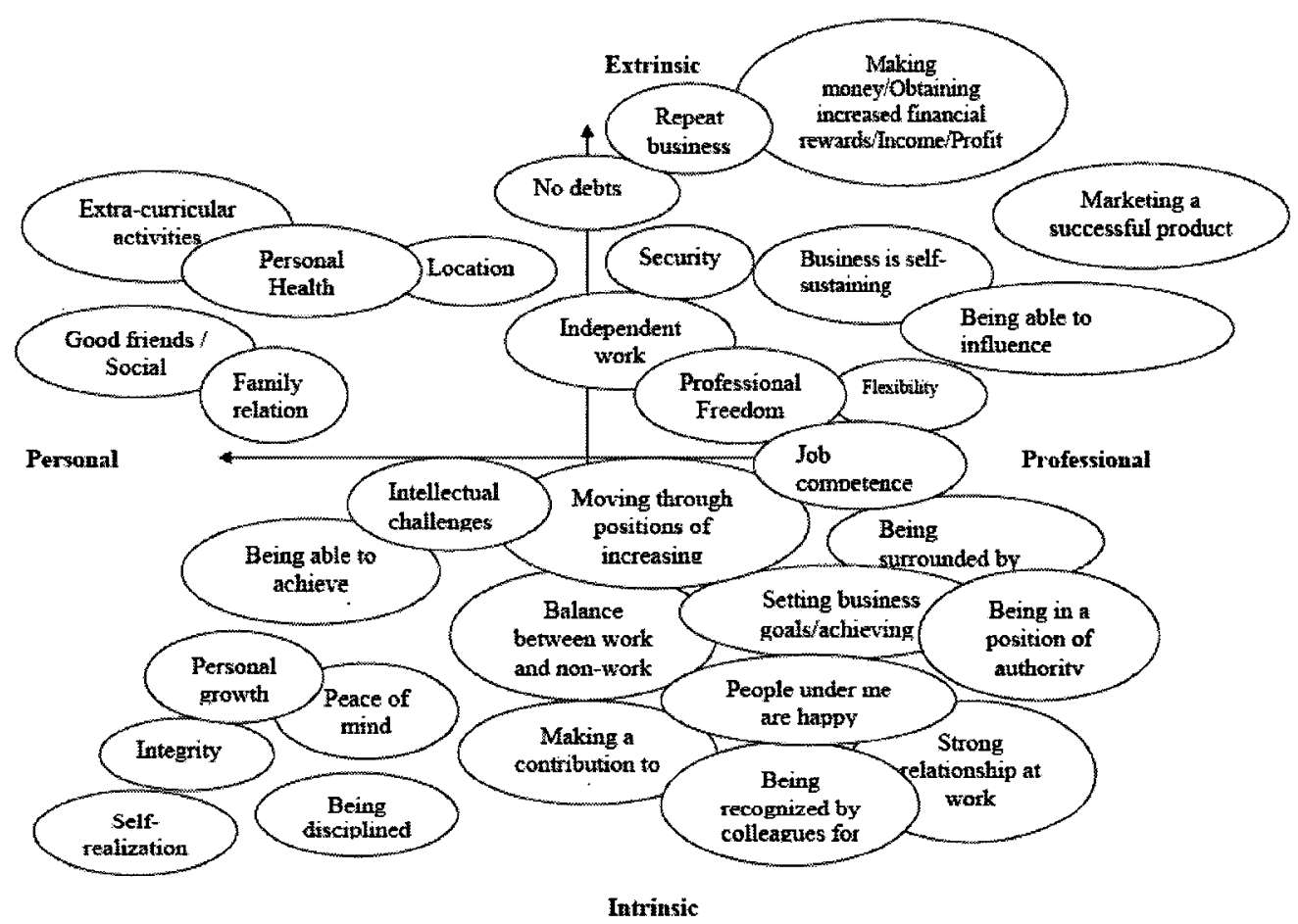




\subsection{2.b Determinants of subjective career success}

As described above, the researcher's findings are reorganized into Personality, Demographic, Human capital, and Organizational/industrial/regional groupings in this discussion. Objective career success and Frame of reference groupings are also included in this section to reflect the additional determinants of subjective career success examined by Judge et al (1995) and Heslin (2003). Dyke and Orser's (2005) 6 factors can also be folded into the existing groups, with the exception of two new groupings: job variables and work-life balance variables.

\section{Objective career success variables}

Objective career success was posited by Judge et al (1995) as one of the key elements of subjective career success, and was measured as described above (i.e. as total annual cash compensation and number of upward changes in job levels). Although Judge et al (1995) measured objective career success using both pay and promotions; they reported the results separately for each measure. The hypothesis that objective career success would positively predict subjective success was only partially supported by the data. While both pay and promotions were found to positively influence career satisfaction, they were not associated with job satisfaction.

$\mathrm{Ng}$ et al (2005) operationalized objective career success as total compensation and promotions. They predicted that objective and subjective career success would be positively related but still distinct constructs. This prediction was supported by the data. 
Dyke and Orser's (2005) analysis led to financial rewards (including income, employee benefits, and stability of income) being created as a factor. Financial rewards had the highest correlation with the respondent's self-evaluations of their overall success.

\section{Frames of reference variables}

In this context, frames of reference (Judge et al, 1995) describe the standards or context by which individuals measure their career success. Individuals may use these frames to measure their success against either their internal standards, or the success of others.

Judge et al (1995) suggested that "frames of reference," comparing either to the self or to others, should influence subjective career success. In the analysis, Judge et al (1995, p. 494) suggest that demographic, human capital, and motivational variables "influence the internal standards by which career success is judged" and that they act as the frames of reference individuals use to evaluate their subjective career success. This idea-that specific variables act as frames of reference by which individuals compare themselves to their peers-is not actually tested in their data analysis. Rather, it is part of the reasoning for considering the impact of variables such as age, education, industry, or job experience on subjective career success. The hypotheses and results for these variables are discussed in the relevant sections.

Heslin (2003) measured self- and other-referent career success using several different tests, including: 1) an open-ended question where comments were coded as either self- or other-referent, 2) twelve Likert-scale items measuring success compared to self or to peers, 3) a measure estimating career success under six hypothetical scenarios 
relative to peers and 4) two additional Likert-type scales measuring attention paid to the success of peers and measuring success compared to peers. The study found that when the participants evaluated their career success, $89 \%$ used self-referent criteria and $68 \%$ used other-referent criteria (Heslin, 2003). Self-referent success accounted for $30 \%$ of the variance in overall career success, while other-referent success accounted for an additional $12 \%$ of the variance.

\section{Personality variables}

$\mathrm{Ng}$ et al (2005) included what they called stable individual differences variables in their model. They operationalized this using the Big Five personality factors (neuroticism, conscientiousness, extroversion, agreeableness, and openness to experience), proactivity, locus of control, and cognitive ability, as defined and measured in Section 2.3.1.b. These variables were predicted to be more strongly related to subjective than objective career success. This hypothesis was supported by the data. Neuroticism was negatively related to career satisfaction, while conscientiousness, extroversion, agreeableness, proactivity, locus of control, and openness to experience were positively related to career satisfaction.

\section{Demographic variables}

Judge et al (1995) predicted that the following demographic variables would predict subjective career success: age, marital status, employment status of spouse, time devoted to dependent responsibilities, gender, and minority status (see Section 2.3.1.b). Age was predicted to be negatively associated with subjective career success, while being 
female or non-white was expected to be positively associated. Predictions were not made for the other variables. As predicted, being older or white was negatively associated with career satisfaction, as were higher levels of dependent care time (Judge et al, 1995).

$\mathrm{Ng}$ et al (2005) included the following socio-demographic variables in their model: gender, race, marital status, and age (see Section 2.3.1.b). These variables were predicted to be less strongly related to subjective than objective career success. This was found to be true when the comparison was between salary and career satisfaction. Fewer significant differences were found when promotions were compared to career satisfaction. Race and marital status showed a weak relationship with career satisfaction.

\section{Human capital variables}

Level of education, type of degree obtained (business, law, engineering, or other), university quality (including whether the university was Ivy League), job tenure, occupational tenure, international experience, accomplishment ratings, and service on an external board of directors were the human capital variables included by Judge et al (1995). These measures are defined in Section 2.3.1.b above. Higher job experience, occupational experience, education quality, attendance at an Ivy League university, and executive accomplishment ratings were all expected to be negatively related to subjective career satisfaction. The logic behind this prediction is that, for two executives earning similar salaries (i.e. having the same level of objective career success), the executive with a more prestigious educational or career background will be less satisfied with their level of objective career success. Support for these hypotheses was somewhat mixed. Judge et al (1995) found that university quality positively predicted job satisfaction, while 
engineering degrees, university quality, and accomplishment ratings were partially associated with career satisfaction. Occupational tenure was negatively associated with the measure of subjective career success.

Motivational variables considered by Judge et al (1995) included job importance, hours worked, evenings worked, desired work hours, and ambition. Again the measures used were defined as described earlier in this thesis (see Section 2.3.1.b). Ambition was predicted to be negatively associated with subjective career success. This was found to be true, as ambition negatively predicted both job and career satisfaction. Evenings worked per month and hours of work desired were positively associated with job satisfaction.

As noted in Section 2.3.1.b, $\mathrm{Ng}$ et al (2005) operationalized human capital using number of hours worked, job involvement, job tenure, organization tenure, work experience, willingness to transfer, international work experience, education level, career planning, political knowledge and skills, and social capital variables. These variables were predicted to be positively related to subjective career success, but the association was expected to be weaker than with objective career success. There was only partial support for this hypothesis. Number of hours worked, work centrality, education level, career planning, and social capital were all positively associated with career satisfaction (Ng et al, 2005). Salary, work centrality and social capital were more strongly associated with career satisfaction than with objective measures of career success, but this was not the case for the other variables. 
Job-related variables

Dyke and Orser (2005) found two job-related variables: rewarding work and community impact. Community impact included environmental impact, professional recognition, and creating employment, while rewarding work included supportive work culture, reputation of organization, competent colleagues, professional autonomy, and employment flexibility. Rewarding work was the second highest correlation with respondent's self-evaluations of overall success, but community impact had a median level of correlation.

\section{Work-life balance variables}

Two of Dyke and Orser's (2005) factors (balanced life and personal well-being) can be categorized here as work-life balance related variables. Balanced life included personal relationships, managing work/life demands, intellectual activities, dependent care/parenting, and spiritual well-being, while personal well-being included personal health and being active in the community. Out of the six factors identified by Dyke and Orser (2005) in their study, the balanced life and personal well-being factors had the two lowest correlations with the respondent's overall subjective evaluations of their career success.

\section{Organizational, industrial, and regional variables}

Judge et al (1995) examined organization size, success, being a publicly traded company, region, and industry. These variables were defined and measured as described above in Section 2.3.1.b. While none of these variables was predicted to influence 
subjective career success, organization success was found to be positively associated with job satisfaction and career satisfaction. In addition, one industry sector (consumer durable goods) had higher levels of career satisfaction than the others did. Since this was the only significant result, it may be spurious.

As noted earlier (in Section 2.3.1.b) $\mathrm{Ng}$ et al (2005) also examined the following organizational sponsorship variables in their model: career sponsorship, supervisor support, training and skill development opportunities, and organizational resources variables. These variables were predicted to be more strongly related to subjective than objective career success. The data supported this hypothesis. Career sponsorship, supervisor support, training, and skill development opportunities were all positively and strongly related to career satisfaction.

Dyke and Orser's (2005) organizational performance factor can be included here. It included the variables employee relations, customer relations and image, product or service quality, employee productivity, organizational profitability, and investor relations. This factor had a median level of correlation with the respondent's self-evaluations of their career success.

\subsection{2.c Gender-based differences in subjective career success}

As with gender differences in objective career success, it is useful to start by demonstrating that the difference exists. This section will first present some evidence from the literature regarding gender differences in men's and women's subjective career success. Then it will present two different theories that have been proposed to explain those differences: 1) the idea that men have a different and more objective model of 
career success than the "subjective" female model; and 2) that women have lower expectations of career success because of their lower possibilities for objective career success.

There is significant support in the literature for the idea that men and women do tend to define career success differently. In her study of managers' personal definitions of career success, Sturges $(1999$, p. 248) found that men tended to see life success as "driven by career success." They tended to measure their success by their position in the hierarchy and value pay for the status it conferred (Sturges, 1999). Women, on the other hand, seemed to be much more concerned with issues of balance and with achieving success in their lives as a whole rather than in objective success criteria such as salary and promotions (Powell \& Mainiero, 1992; Sturges, 1999).

In a similar vein, a number of researchers have found that women tend to define career success differently from the "male" pay and promotions model (O'Connor \& Wolfe, 1987; Powell \& Mainiero, 1992; Sturges, 1999; Russo, Kelly \& Deacon, 1991) and focus more on subjective internal career success. Women may be more likely to define their career success as "how they are feeling about their careers, rather than what their careers actually look like" (Powell \& Mainiero, 1992, p. 220, emphasis original) and these feelings appear to be more complex than only a sense of achievement (Hardesty and Jacobs, 1986). Sturges' (1999) study of managers' definitions of success, for example, found that women were more likely to define success by intangible criteria such as accomplishment, achievement and personal recognition; to desire advancement in order to obtain influence, recognition, or more interesting work; and to value pay for its utility, 
not for its status (Sturges, 1999). Women may put more emphasis on personal fulfillment and security (Parker and Chusmir, 1992).

Dyke and Murphy (2006) found more support for a gender-based difference in definitions of career success in their study of a snowballed sample of individuals with notable work-related achievements. Women tended to focus on balance and relationships, as $50 \%$ of the women mentioned something related to the theme of balance. Men focused more on material success (45\%), although they did address other elements as well, in particular relationships (30\%), making a contribution, and having freedom. Financial rewards were an important component of success for almost $50 \%$ of the men interviewed.

On the other hand, in their comparison of men's and women's self-evaluations of their overall career success, Dyke and Orser (2005, p. 40) found "no significant gender differences in the importance of organizational performance, community impact, personal well-being or financial rewards." They did, however, find that women found rewarding work and a balanced life to be more important to their career success than men did. This finding gives some additional support to the idea that when defining career success, women place more emphasis on intrinsic criteria (as opposed to extrinsic criteria) than men do. Interestingly, their study also found that women had higher ratings of their overall feeling of success.

There are two main themes in researchers' explanations for gender differences in subjective career success. Some researchers have suggested the divergence is due to socialized or innate differences in men and women's concepts of a successful career, with men tending to emphasize more objective criteria. For example, the objective definition 
of career success is sometimes described as a "male" concept of career success (Powell \& Mainiero, 1992), and some researchers have suggested that women's lower promotion rates are due to a lack of interest in advancement (Hoffman \& Reed, 1981; Schultz, 1990). Although there is some support for this hypothesis, researchers in this area need to take care that they do not fall into the trap of stereotypes about the "subjective feminine" and the "objective masculine".

Another interpretation of men and women's differences in subjective career success hypothesizes that these differences are caused by women's lowered expectations due to the influences of national and organizational cultures. According to this school of thought, women's definitions of career success are influenced by their socialization (Gallos, 1989; Gilligan, 1982) as well as by the structural barriers they experience in organizations (Davidson \& Cooper, 1992; Poole et al, 1993; Sturges, 1999). In other words, women may adjust their definitions of career success to accommodate the limitations on their options (structural barriers) or what they or others believe to be their limitations (socialization barriers). This interpretation of the data also receives some support from the empirical literature. Compared to their male counterparts, women appear to have lower expectations for pay and promotions (Greenberg \& McCarty, 1990) lower expectations about career opportunities and attainments (Judge et al, 1995; Ng et al, 2005) and appear to be "more satisfied with the same" (Kirchmeyer, 2002, p. 20).

\subsection{Decision to seek a promotion}

The decision to seek a promotion in general has not been much studied, perhaps because researchers have assumed that any employee (i.e. any male employee) will seek 
a promotion if it is available, or because in most organizations promotion-seeking processes are informal and thus difficult to study. In general, the literature on careerrelated decision-making appears to concentrate more on women's career choices, or on contrasting men's and women's career choices (often in an effort to understand how these career choices may affect women's lowered objective career success) than it does on the theory of career-related decision-making in general. Because it is so difficult to separate these bodies of literature, the impact of gender on career-related decision-making will be discussed concurrently with decision-making in general. This approach will also highlight the gap in information about men's career-related decision-making (as opposed to women's). This section of the review will examine what is known about the decision to seek a promotion. It begins with a definition of career-related decision-making in general. Next, the scope will be narrowed specifically to the decision to seek a job promotion, examining theoretical and operational definitions and the variables that researchers have theorized or demonstrated that individuals take into account when deciding whether to seek a promotion. It should be noted that this study will focus on the decision to seek a promotion to management, not only the decision to seek a promotion. It is important to make the distinction because of the unique attributes and requirements of the management job.

Finally, gaps in the existing literature are addressed by undertaking a review of other studies regarding decisions to leave the workforce or to work less, from which we can infer information about career-related decisions in general, such as the decision to seek a promotion. 


\subsubsection{What is career-related decision-making?}

Hastie and Dawes (2001) define a decision as a response to a situation that includes more than one possible course of action, where the decision-maker has expectations concerning both the outcomes and consequences from each course of action. Thus, decision-making is the process of making this decision. Researchers generally treat decision-making as a rational process, based on the concept of prospective rationality, or the idea that decisions are "based on a search for and use of information that allows the decision maker to form rational expectations about how good or bad the alternatives are likely to be" (O'Reilly \& Caldwell, 1981, p. 598).

For the purposes of this review, career-related decision-making is defined as the act of making decisions that are related to an individual's career. Understanding the process of making a career-related decision can allow us to improve the quality of decisions or to influence them in a particular direction. For instance, if an employer wishes to encourage their employees to seek management jobs, then understanding the process by which employees decide whether to pursue management can help the employer to make conditions conducive to the outcome they desire.

Decision-making is more difficult to define operationally. Since the actual decision-making process takes place inside a person's thoughts and may "leave no concrete trace of the exact moment of its passing" (Langley, 1999, p. 693) researchers must rely either on observable behaviors or on an individual's description of their thought processes in order to "measure" the cognitive decision. 


\subsubsection{Theoretical models of decisions to seek a promotion}

Theories of decision-making, such as expectancy theory (Vroom, 1964), rely on the idea that career decisions and behaviors are guided by the individual's desired outcomes and expectation of attaining those outcomes through the decision (London, 1983). Thus, if a decision seems to be irrational or poor, it is assumed to be caused by "inferior information, misperceptions, or inaccurate interpretation of information" (London, 1983, p. 625). Much of decision theory research focuses on understanding how to optimize decision-making or on identifying difficulties that would prevent individuals or groups from making optimal decisions.

There are a variety of decision-making models that attempt to describe how individuals identify the need for a decision; identify the possible decision options; gather information on which to base the decision, including possible outcomes; and select strategies by which to enact the decision. However, on a simplified level, London's (1983) model of career motivation, shown in Figure 2-5, provides a good basis for understanding the type of decisions considered in this thesis.

Figure 2-5: An Interactive Model of Career Motivation Components (London, 1983)

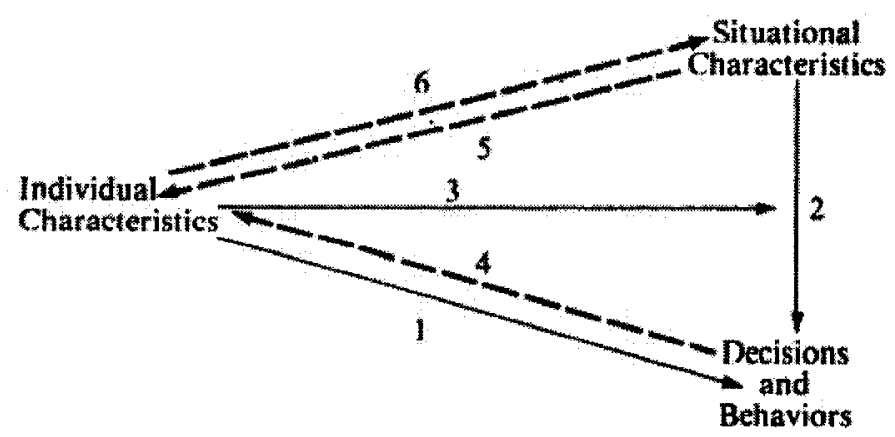

Prospective rationality processes

- Retrospective rationality processes 
London's model presents proposed relationships among the individual and situational characteristics and the decisions and behaviors. The solid-line relationships noted as 1, 2, and 3 all represent prospective rationality processes (i.e. evaluations based on rational expectations about the potential outcomes). The dashed-line relationships noted as 4,5 , and 6 represent retrospective rationality processes (i.e. evaluations based on other's evaluations, characteristics of the organization's environment, and/or outcomes or consistency with the individual's past behaviour). Individual characteristics are expected to directly influence decisions and behaviours, and may also interact with situational characteristics to affect them. For example, the correspondence between the individual and the situation may affect an individual's decision. In addition, individual characteristics can influence the individual's interpretation of the situation. Situational characteristics are expected to directly affect—by restricting or determining—an individual's decisions and behaviours. Situational characteristics can also influence current individual characteristics, as the individual has feelings in reaction to the environment. Past decisions and behaviours are expected to influence an individual's characteristics, in particular because an individual may strive to maintain consistency between past behaviours and current attitudes.

As shown in Figure 2-6 below, the elements of London's (1983) model can be shifted to place the emphasis on the outcome (the decision) and on an expectancy approach to decision-making. Figure 2-6 shows only the paths of interest to this study. The model shown in Figure 2-6 will form the basis of the proposed model of the decision to seek a promotion, to be tested by this thesis (in Section 3.1). The rest of this review of the decision-making literature will compare researchers' models to this proposed model. 
Figure 2-6 : Proposed Model of a Rational Decision-making Process

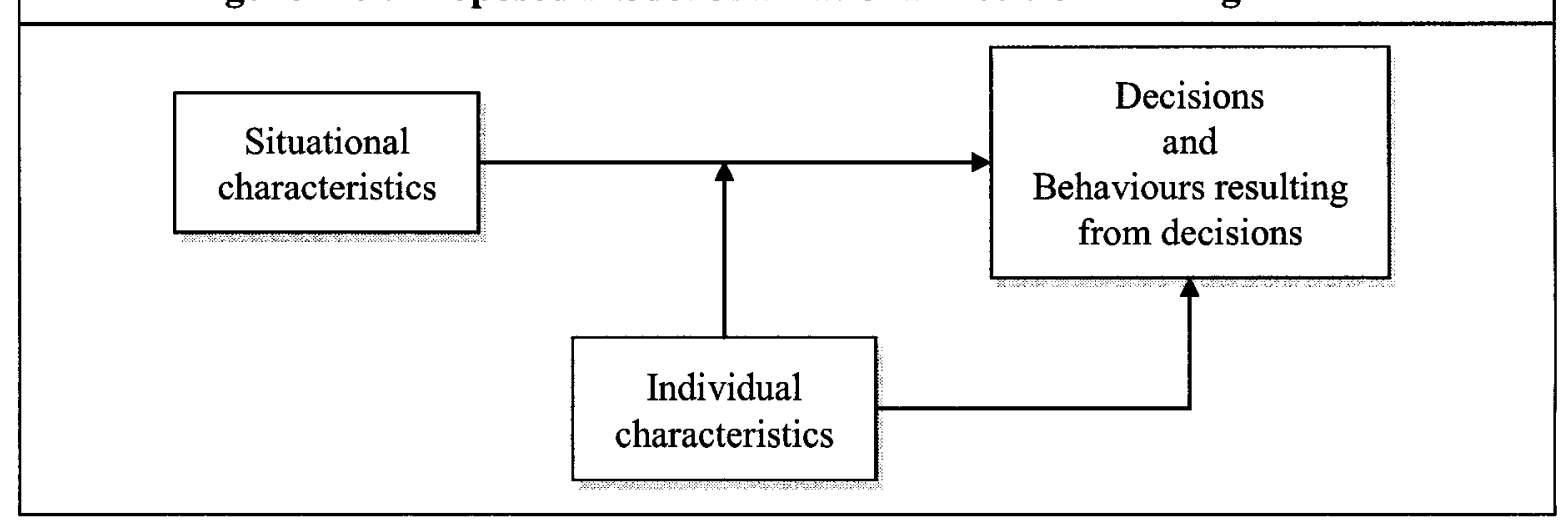

Other models of career-related decision-making, such as that proposed by Mihal, Sorce and Comte (1984) are far more complex (see Figure 2-7 below). This model takes into account "influencing variables, decision process behavior and situations, and the process of decision implementation" (Mihal, Sorce \& Comte, 1984, p. 96). It also integrates the idea of a cognitive map, the "internal model of the world and self," and the idea that the career assessment process is ongoing and cyclical (Mihal, Sorce, \& Comte, 1984, p. 96). Mihal, Sorce, and Comte (1984) suggest that career decisions are prompted by a career role discrepancy, which they define as a perceived gap between the current state and the ideal state. It is useful to note that the model includes not only the internal cognitive process of the decision, but also the actions taken by an individual based on that decision. 
Figure 2-7: Process Model of Individual Career Decision Making (Mihal, Sorce \& Comte, 1984)

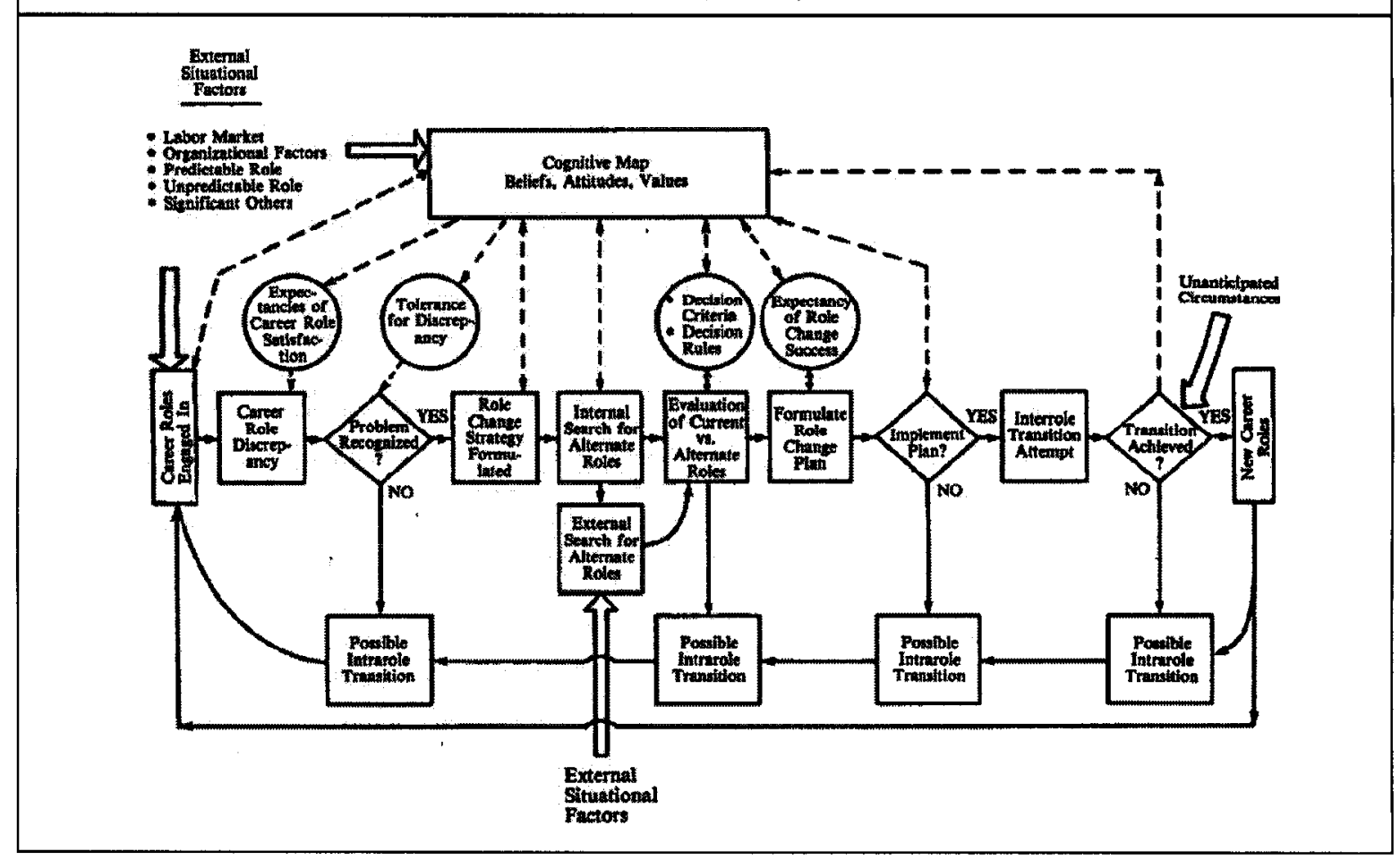

As shown in Figure 2-8, this more complex model can also be simplified to the same three factors shown previously in Figure 2-6 (i.e. individual characteristics, situational characteristics, and the resulting decision and related behaviours) by removing the paths describing the cognitive decision process and the post-decision processes and simplifying the remaining paths. In this case, the primary difference is that the situational characteristics are shown as a moderator of the effect of the individual characteristics, instead of the reverse as shown in Figure 2-6. 


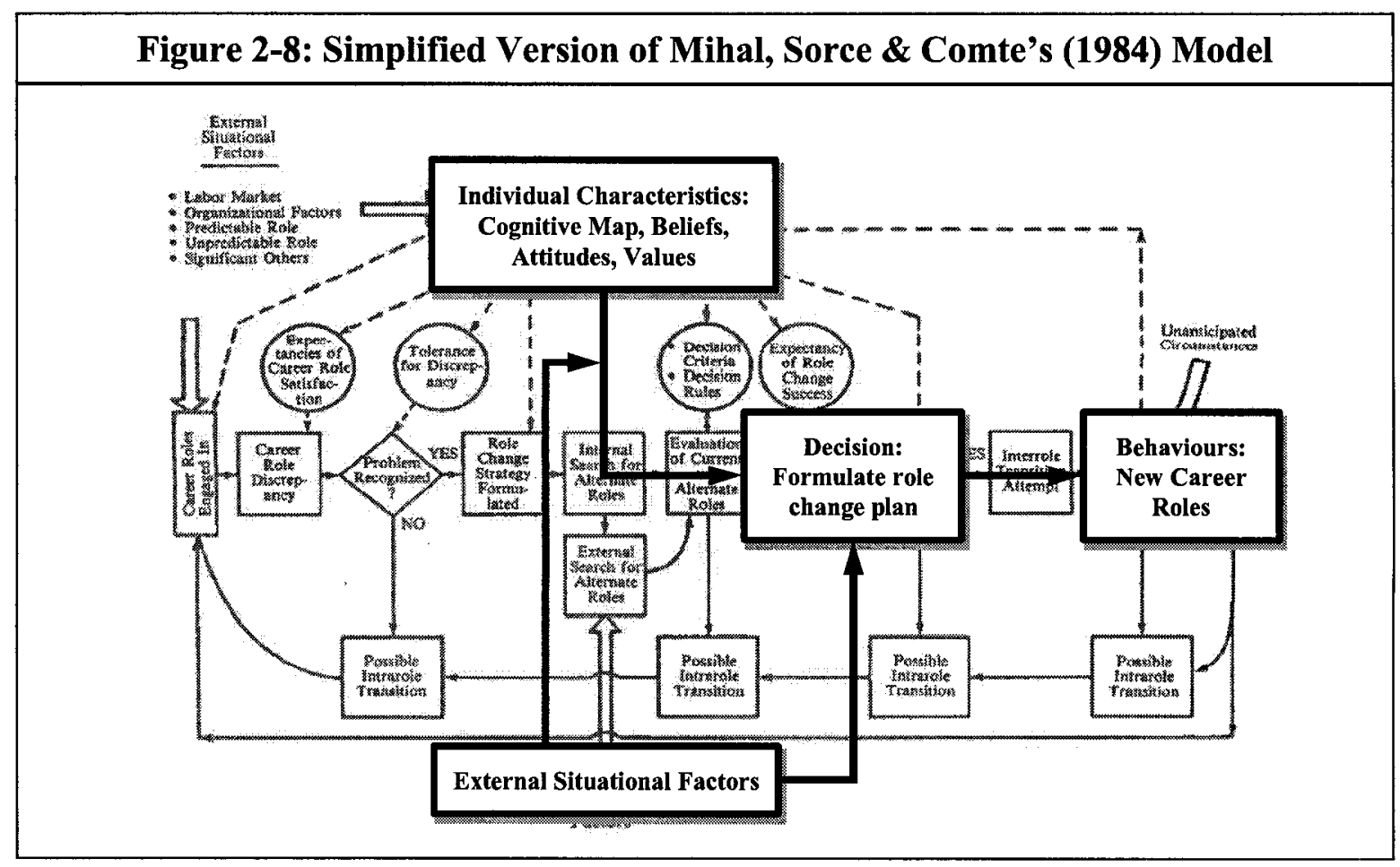

Two more decision-making models will be presented before moving on to a review of the variables that may influence the decision to seek a promotion: Cassirer and Reskin (2000) and Powell and Mainiero (1992). These models are drawn from the review of the decision to seek a promotion literature that will be examined in Section 2.4.3.

Although Cassirer and Reskin (2000) do not present a diagrammatic model, the descriptions in the text can be presented visually as shown in Figure 2-9. It is interesting to note that this model, again, is very similar to the proposed model presented above in Figure 2-6. Cassirer and Reskin's (2000) model shows organizational structures (one aspect of situational characteristics) influencing the individual's promotion aspiration (related to the actual decision to seek a promotion). This relationship is moderated by 
demographic characteristics (an element of individual characteristics), which also influence the level of promotion aspiration.

Figure 2-9: Cassirer and Reskin's (2000) Model of Influences on Promotion Aspiration

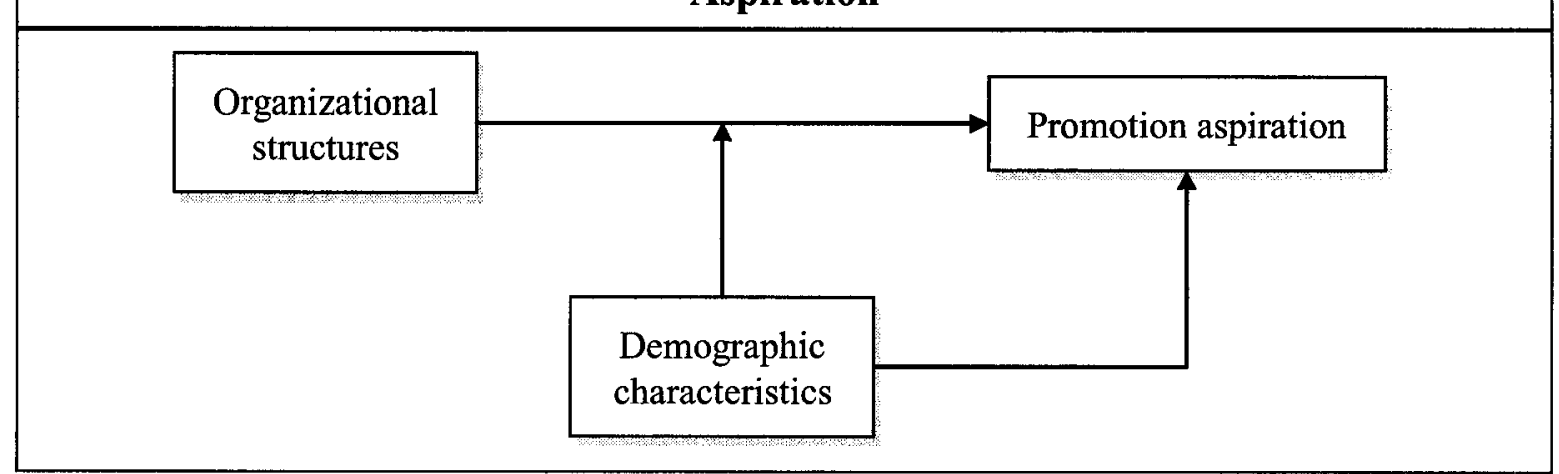

Powell and Mainiero (1992) present a literature review of the evidence about variables that influence women's career development. Figure $2-10$, below, is a visual interpretation of the model they present. According to these authors, personal factors and organizational factors are expected to influence career decisions. ${ }^{3}$

Figure 2-10: Powell and Mainiero's (1992) Model of Factors Influencing Women's Careers

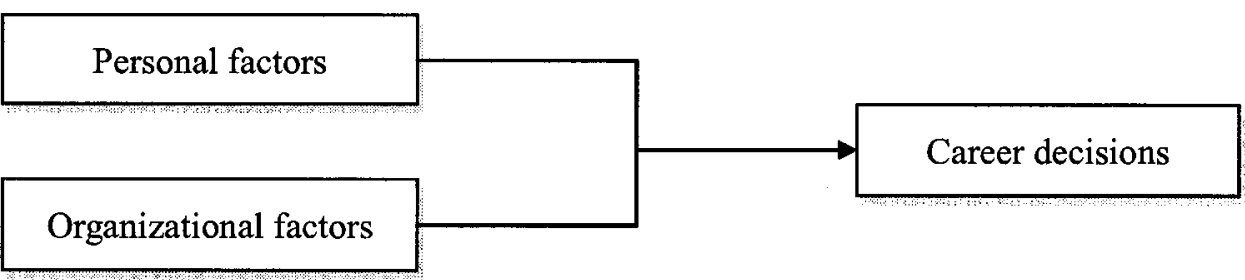

${ }^{3}$ The authors also discuss how societal factors influence opportunities for career success, but do not extrapolate how these opportunities might influence career-related decision-making. 
This review of key articles has shown that the model of a rational decisionmaking process proposed in Figure 2-6 is representative of the models in the literature presented by various authors.

\subsection{2.a Gender-based differences in career-related decision-making}

This section will first discuss gender-based differences in career-related decision making in general. Research specifically dealing with how gender may moderate the effect of other variables on career-related decision-making will be discussed in Sections 2.4.3 and 2.4.4. The findings about these gender-related differences appear to fall into three categories. The first two of these are similar to the literature on gender differences in subjective career success: 1) the idea of a male model focusing on more independent criteria and female model focusing on more holistic criteria, while another, and 2) the idea that women have lowered ambition because of social or organizational factors. The third finding is 3 ) that women appear to plan their careers differently from the way men do, in order to take into account time to care for children.

The independent male vs. holistic female model

Research in this area suggests that women and men may use different decisionmaking criteria and strategies when making career-related decisions. In Stone and Lovejoy's (2004) assessment of reasons to leave the workforce, they found that women considered the work environment itself, their children, and their husbands. Similarly, Mainiero and Sullivan (2005, p. 111-13) found that women evaluate each career action based on "the impact such decisions may have on her relationships with others" including children, spouses, elders, friends, coworkers, and clients, and also "whether their choices 
were true to who they are, their vision for work/non-work balance, and their need for challenging work" in an attempt to find a best fit between relationships and work. In contrast, they found that men "tended to examine career decisions from the perspective of goal orientation and independent action" and for the benefit of their career (Mainiero \& Sullivan, 2005, p. 111). In general, these studies focused more on the perspective of women. Less focus was given to identifying the perspective of men.

It is interesting to note that in their study of 40 successful participants, $35 \%$ of the men evidenced regret, related either to career opportunities or to relationships (Dyke \& Murphy, 2006). This regret about the choices and tradeoffs they had made was rare in the women's interviews.

\section{Lowered ambition}

Fels (2004) argues that ambition requires both mastery and recognition. As Hewlett \& Luce (2005, p. 48) put it, “a vicious cycle emerges: As women's ambitions stall, they are perceived as less committed, they no longer get the best assignments, and this lowers their ambitions further." The recent media focus on women's "opting out" (i.e. choosing to leave the workforce) has also suggested that women are less committed or less ambitious. However, Hewlett and Luce (2005) found that $17 \%$ of the women they surveyed took an off-ramp from their jobs because they did not find their jobs sufficiently satisfying or meaningful. This was the third most common response, after child-care or elder-care responsibilities (44\%) and seeking more training (23\%).

It has also been suggested that women become disillusioned by corporate politics at higher levels (Rosin \& Korabik, 1989) or that blocked opportunities reduce promotion 
aspirations (Kanter, 1977). Astin (1984) proposes that women's different socialization affects their career aspirations, and that in addition these experiences combined with different (lesser) opportunities constrains their expectations for their work, which then leads to different career choices. Some studies have borne out this hypothesis, finding that women have different occupational aspirations, attach less importance to promotions and tend to have lower promotion aspirations (Cassirer \& Reskin, 2000).

\section{Career planning}

It also appears that women's key concerns in their career decisions may differ at different times in their careers. Mainiero and Sullivan (2005) found that women were most interested in challenge at the early career stage. By mid-career, they were most interested in balance and at late career in authenticity (Mainiero \& Sullivan, 2005). While this finding might indicate why older cohort women are less ambitious than younger ones, it may also reflect the fact that women from earlier generations were less ambitious.

Other studies support the idea that women who do seek management jobs plan their careers differently from the way men do. Bailyn (1980) found that women might well end up at the same level as men in their careers, but that it took them longer to reach that level due to their family and personal commitments. Cardozo (1986) suggested that many women use a sequencing strategy of switching focus between career and children which involves taking a break from their career to care for children full time. Consistent with this idea is the fact that women in top management positions were more likely to have delayed marriage and children (White \& Cooper, 1995). 


\subsubsection{What we know about the variables influencing decisions to seek a promotion}

Two articles have been selected in order to identify the variables that influence the decision whether to seek a promotion: Cassirer and Reskin (2000) and Liff and Ward (2001). Only two articles are discussed here because the field of articles looking at this issue from a broad perspective is very small.

Cassirer and Reskin's (2000) study focussed on promotion aspirations (i.e. the desire to gain a promotion). The sample consisted of 733 respondents to the 1991 General Social Survey (Davis \& Smith, 1991), who were employed (not self-employed) and answered the career aspiration item discussed earlier. They did not define the term promotion aspirations but operationalized it using an item that asked respondents how important being promoted was to them, coded on a 0 to 3 scale.

The second article discussed in this section was done by Liff and Ward (2001). The authors interviewed 38 junior and middle level managers and 14 senior managers in a British high street bank about their expectations of "the demands and rewards that would come with promotion" and their understanding of the promotion process (Liff \& Ward, 2001, p. 22). The participants were selected by the organization as being individuals likely to achieve promotion or likely to be interested in participating in the study. Liff and Ward (2000) do not present a model. This was an exploratory research study, so no predictions or measures were included. In addition, because of the format of the research, they did not specifically measure levels of ambition, so direct relationships cannot be reported here. It can, however, be an important paper for this thesis, as it provides a comprehensive exploration of the factors that individuals take into account 
when considering whether to seek a promotion. As such, it provides some structure for the model to be proposed in this study.

This discussion will roughly follow the categories used in the career success section and will include the following groupings: demographic, human capital, jobrelated, work-life balance, and organizational structures (i.e. the existence of structures facilitating promotional opportunities) variables. Some additional variables suggested by other authors will also be discussed.

\section{Demographic variables}

Cassirer and Reskin (2000) included marital status and having children under age twelve, as well as gender, in their model. Predictions were not made for the relationship between marital status and/or the age of children and promotion aspirations. With one exception, (single men) marital status and parenthood did not moderate the association between the variables with promotion aspirations. Promotion aspirations of single men were more positively associated with being in a female-dominated occupation than for married men. A higher percentage of men than women felt that being promoted was important (i.e. a high level of promotion aspiration), although being promoted was important to the majority of both male and female respondents. When the organizational measures were added to the model it was found that men and women in comparable organizational locations have similar promotion aspirations. 
Work-life balance variables

As part of their study, Liff and Ward (2001) looked at whether work-life balance issues were of concern to respondents who were considering promotion to senior positions. Respondents indicated that a number of work-life balance related factors concerned them: a lack of visible women with children in senior positions, a lack of information about flexible work options, a perception that motherhood was equated with a lack of ambition, negative stereotypes about the ambition of women, and negative stereotypes about women in management. Liff and Ward (2001) also found that informal practices reinforced these aspects of the organizational culture, despite formal equality statements intended to give the opposite message.

\section{Human capital variables}

Hours worked and education were included by Cassirer and Reskin (2000) as control variables. Nevertheless, they did report some findings for the relationships of these variables with promotion aspirations, thus they will be discussed here in the human capital section. Number of hours worked was measured by the respondents' estimated hours of employment per week. Number of hours worked and years of education were predicted to be positively associated with promotion aspirations; however, only hours worked per week were found to be positively related to promotion aspirations.

\section{Job-related variables}

Liff and Ward (2001) found that limited knowledge of what the job entailed, perceptions that there were certain specific routes to promotions, and perceptions of long 
work hours and high commitment being required for the job were all considered by respondents in their decisions about seeking a future promotion. In particular, there was a perception that long hours were seen as an indicator of commitment. Despite some respondents' limited knowledge of senior jobs, others said that they felt "able to handle the technical or skill requirements of such jobs" (Liff \& Ward, 2001, p. 24).

\section{Organizational structures variables}

Cassirer and Reskin (2000) included a number of organizational structure variables in their model, including job ladders, formalized evaluation processes, occupational sex composition, and past treatment by the employer. Job ladders were defined as "sets of rules that link jobs vertically, thereby regularizing the paths of advancement in organizations" (Cassirer \& Reskin, 2000, p. 442). Job ladders were measured with questions asking whether there were regular procedures for promoting individuals at the respondents' job level, whether the respondent had a supervisor, and whether their supervisor had a supervisor. Formalized evaluation processes were measured by asking respondents whether respondents were regularly evaluated. The sex composition of the occupation was measured using Census data. Past treatment by the employer was measured by asking about past promotions by the current employer and years in the current job.

The presence of job ladders and being in a female-domination occupation were both expected to be positively associated with promotion aspirations in general. Formalized evaluation processes were expected to have a positive relationship with women's promotion aspirations but have mixed or negative relationships for white men. 
The two measures of past treatment by the employer were expected to have different results, with a positive association for past promotions and a negative association for tenure.

The association of job ladders with promotion aspirations was mixed, as the results were different for the two measures: regular promotion procedures (positive) and supervisors above them (negative for women, no association for men). As expected, formalized evaluations were positively related to women's aspirations but not to men's. Working in a female dominated occupation had a mixed result, as it raised men's promotion aspirations but did not affect women's. The results for past employer treatment were as expected for both men and women. Past promotions by the current employer were strongly and positively associated with promotion aspirations, while job tenure was negatively associated.

Liff and Ward (2001) presented a similar set of variables under the heading "perceptions of the promotion process." Respondents reported that the promotion process was opaque and that it depended on whom you knew, being in the right place at the right time, and having the right types of experiences and personal characteristics, such as ambition and keenness. Formal evaluation and training programs were not seen as useful to the promotion process.

\section{Additional variables from other authors}

Very few additional sources were found that discussed the impact of factors on the decision to seek a promotion. It is evident that there is very little literature on this topic, especially on the impact of individual characteristics, with a few exceptions. 
Cutler and Jackson (2002) found that in their study of 229 members of the sales force of a major financial institution, the respondent's partner's career was a consideration in the decision to seek a promotion, but influenced the advancement plans of women more than men. In a theory-building article, Acker (1990) suggested that organizational processes are gendered and thus affect men and women's promotion-seeking decisions differently. Kanter (1977) also famously presented the idea that gender differences in organizational contexts are due to structural effects in the organization, not innate differences between men and women.

\subsubsection{What we can infer about the decision to seek a promotion from other career- related decision-making models}

There is a relatively small pool of articles examining career-related decisions other than the decision to seek a promotion. These articles, in general, are focused on women's decisions to interrupt their careers (examined here) or on both men's and women's decisions to accept a transfer (not examined in this discussion). ${ }^{4}$

The following three articles that examine other types of career-related decisions were identified as having relevance to this review: Powell and Mainerio (1992), Stone and Lovejoy (2004), and Hewlett and Luce (2005). Powell and Mainerio (1992) examine women's career decisions in general. They present a review of the literature on women's careers, which is important to include here due to its comprehensiveness and frequency of being cited. As with Liff and Ward (2001), above in Section 2.4.3, this review points

\footnotetext{
${ }^{4}$ Literature on the decision to accept a job transfer has not been included here, because it is felt that the impact of moving on the spouse's career and the family as a whole makes such decisions materially different from the decision to seek a promotion or the decision to off-ramp.
} 
more towards a general overview of factors that should be considered, rather than precise findings of relationships between variables. They aim to present an integrative approach to understanding the "influence of key personal, organizational, and societal factors that limit or constrain women's career decisions" (Powell \& Mainiero, 1992, p. 215), and thus touch directly on the topic of interest to the current review.

The other two articles examine women's decisions to interrupt their careers. This topic has been of increased interest lately due to media coverage regarding professional women's decisions to "off ramp" or "opt out" from the workforce. This issue has been popularized in the press by articles such as Belkin's (2003) “The opt-out revolution” article in The New York Times. Scholarly research has also addressed this issue. Stone and Lovejoy (2004) interviewed 43 professional and managerial married women with children about their decisions to interrupt their careers. Hewlett and Luce's (2005) study used a national survey of 2,443 highly qualified women, and also looked at why these women had decided to interrupt their careers.

\section{Demographic variables}

Stone \& Lovejoy (2004, p. 78 ) found that about $25 \%$ of the women they surveyed whose husband played a role in their decision to leave work said that their husbands "communicated to them, either explicitly or implicitly, that they expected their wife to be the one to sacrifice or modify her career to accommodate family responsibilities." 
Work-life balance related variables

Almost one third of the women interviewed by Stone and Lovejoy (2004) said that workplace inflexibility regarding part-time work was a significant factor in their decision to quit. Many (an exact figure was not given) of those who were able to arrange part time work reported that "the nature of their jobs and the culture of their workplaces meant that they worked part-time in name only" or became "mommy tracked" into limited opportunities for promotion and less interesting work (Stone \& Lovejoy, 2004, p. 69).

Hewlett and Luce (2005, p. 48) found that $38 \%$ of the women they studied had "deliberately chosen a position with fewer responsibilities and lower compensation than they were qualified for, in order to fulfill responsibilities at home." Thirty-six percent had used part time work as a strategy to balance their work and personal lives, and $35 \%$ reported that aspects of their organizations' cultures penalized people who took advantage of work-life balance policies (Hewlett \& Luce, 2005).

\section{Human capital variables}

Powell and Mainiero (1992) define human capital variables as personal factors; however, they relate closely to the human capital category from the objective success section. The researchers present two categories of variables in this group: 1) career interruptions, dual-career demands, and parenting demands and 2) work motivation and career choices. They go on to suggest that personal factors may influence the amount of emphasis that women place on their careers and how quickly they progress in their careers. They note that women's career progression decisions may be slowed by career 
interruptions, the influence of their spouse in deciding how to divide work/family responsibilities, and parenthood. They also suggest that men do not tend to see parenthood as a constraint on their career emphasis or career success, but that women do. The authors also present some evidence that women have different definitions of what career means, with more of an emphasis on work-life balance, which thus influences them to make different career decisions.

\section{Organizational variables}

In their article, Powell and Mainiero (1992) discussed four categories of organizational variables. Only one, however, alternative work arrangements, was discussed in terms of its effect on career decisions. The researchers observed that alternative work arrangements and assistance with childcare arrangements help women to balance family responsibilities so that they can pursue career success through their career decisions.

\subsection{Linking subjective career success definitions and seeking a promotion}

A rational model approach to decision-making hypothesizes that when deciding whether or not to seek a promotion, an individual will compare the potential outcomes of that decision to their desired results or goals. Then, they will choose based on how well the decision may meet those desired results. The rational decision-making model, therefore, supports the idea that an individual's decisions about their career ought to be in line with how they define a successful career. Judge et al (1995) and $\mathrm{Ng}$ et al (2005), as presented above in Section 2.3.2.b demonstrated that an individual's subjective career 
success can be positively associated with their objective career success (in other words, with promotions or pay). Thus, there is some support for the idea that an individual may measure their subjective career success by the hierarchical level they have attained. In addition, other studies have found that an individual's career-related decisions are influenced by their feelings about their career success, namely their aspirations and the importance attached to promotions (Cassirer \& Reskin, 2000), feelings of personal achievement, (Powell \& Mainiero, 1992), and job satisfaction (Hewlett \& Luce, 2005). In a similar vein, Dyke and Murphy (2006) found that both the men (65\%) and women $(60 \%)$ studied felt that their definitions of career success had limited their career progress. Women felt their careers had been slowed by choices based on balance, values, and interests, while men felt their career had been slowed by their desire for independence and recreational pursuits.

Although these articles have not examined the question in detail, this evidence supports the idea that individual definitions of career success may influence the actual decisions that individuals take about seeking a promotion.

\subsection{Critique of the literature}

This section will critique the career success literature, the decision-making literature, and the related gender issues literature. The main problem with the literature as whole is that this is an under-researched area, in particular where the decision-making and career success literature overlaps. For both the career-related decision-making and subjective career success literature, there is a need for more meta-level analysis, to attempt to synthesize what different researchers have discovered. 


\subsubsection{Problems with the career success literature}

Some researchers have criticized the research with respect to objective career success. It has been argued for example that objective success is not truly objective: but rather depends on who is doing the judging (Jaskolka, Beyer \& Trice, 1985) and the career concept being used (Heslin, 2005). In addition, it appears that the various operational measures of objective career success, such as salary and promotion, may be different constructs ( $\mathrm{Ng}$ et al, 2005). This may also be true for subjective career success as Judge et al (1995) found that the variables that predicted career satisfaction were different from those that predicted job satisfaction. Furthermore Judge et al (1995) suggested that job satisfaction might be more process oriented, while career satisfaction may be more outcome oriented In addition, some researchers have found that objective and subjective success were positively but only moderately related (Bray \& Howard, 1980; Judge \& Bretz, 1994), or that they were influenced by different variables (Cox \& Harquail, 1991; Judge \& Bretz, 1994). There is also a lack of exploratory studies examining how individuals define career success for themselves. This would suggest career and job satisfaction alone may not be adequate constructs for measuring subjective career success.

\subsubsection{Problems with the career decision-making literature}

Little research has been done into the decision about whether to seek a promotion. As discussed in Section 2.4 there appears to be an underlying assumption that individuals will always seek or accept any promotion that is available—unless they are women choosing to interrupt their careers for family responsibilities. Much of the research into 
career-related decision-making has been done for decisions other than whether to seek a promotion. While these studies into other career-related decisions allow us to infer some things about the decision to seek a promotion, there is no way to check the accuracy of our inferences. There has been some examination of how individual characteristics, such as the individual's career goals or definition of career success, influence career decisions. Unfortunately, this literature is of necessity based on reporting or recall of the decision process, as it is impossible to observe the cognitive process undertaken by the individual. As such, it is subject to reporting bias. In addition to the above problems, there has been little examination of the relationship of the promotion environment with career decisions. Many organizations manage promotions through informal processes, whereas others have formal application processes. There is little investigation into how these promotion environments may affect individual's decisions.

These criticisms indicate that there is a need for testable models of the career decision process in general that could be applied to specific types of career decisions. Such a model would allow us to examine decisions with respect to whether or not to apply for a promotion in organizations that have formal application contexts as well as those that rely on unofficial channels.

\subsubsection{Problems with the gender issues literature}

Much of the literature that has been found on career decision-making and subjective career success is tied up with gender issues. In some cases, this has lead to studies where the results for women are reported in far more detail than for men. The premise seems to be that men are a well-researched norm, so that it is more useful to 
detail the results for women. However, some evidence shows that, for example, there has been an observable narrowing of the gender wage gap in recent years ( $\mathrm{Ng}$ et al, 2005). Other results and attitudes may be changing for both men and women, so it would be more useful to examine both in equal detail. Moreover, there is a lack of research that examines both genders equally, instead of focusing only on either men or women. It is important to identify both areas of similarity and of difference, in order to fully understand topics of career-related research.

Finally, such research should also pay attention to how age differences may affect these areas of similarity and difference, as younger men and women may not be the same as their older peers.

Next, Section 3 presents the model to be developed and tested in this thesis, and outlines how this model addresses many of the issues noted in this critique. 


\section{THEORETICAL FRAMEWORK}

This section will present a preliminary model of the relationship between 1) subjective career success definitions and 2) the decision about whether to seek a promotion, including 3 ) the moderating effect of gender. The preliminary model was developed by the researcher based on the literature review in the previous section. During the study, this model was tested and refined using a grounded-theory analysis of the related interview data.

\subsection{Researcher's proposed model}

Previously, Section 2.4.2 presented a simplified model of the career-related decision-making process (see Figure 2-1). Figure 3-1 below shows this model, altered to show a decision about whether to seek a promotion and to highlight the path of interest. In this case, the individual's definition of career success and gender are included as individual characteristics, and are hypothesized to have a moderating influence on the relationship between situational characteristics and the decision to seek a promotion. These individual characteristics, including the definition of career success and gender, are also hypothesized to have a direct relationship on this decision. In the decision-making step, the individual is posited to go through a cognitive process of comparing how well the potential outcomes of each behaviour (i.e. seeking or not seeking a promotion) relate to their definition of career success. The final decision results in a behavioural outcome, where the individual either takes action to seek the promotion or decides not to seek the promotion and does nothing. 
Figure 3-1: Proposed Model of a Rational Decision-making Process for PromotionSeeking Decision

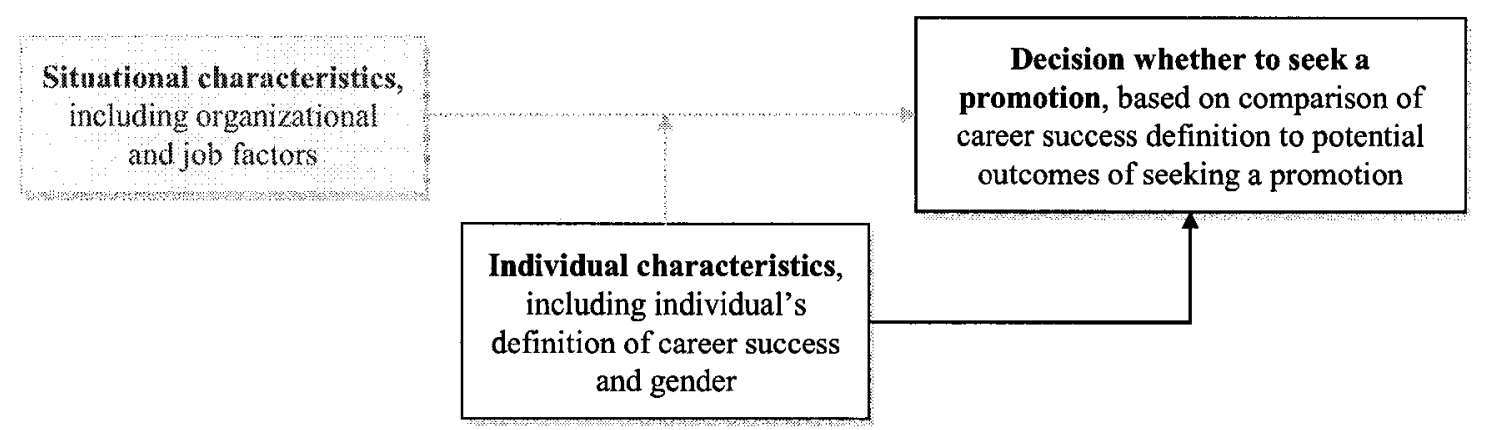

Note: The path of interest to the research question is shown in black and white. Paths not of interest are shown in grey.

\subsection{Theoretical and operational definitions}

The model includes two main constructs: subjective career success and the decision to seek a promotion. Subjective career success was defined theoretically as how individuals personally define career success. It was operationalized as a list of the factors that individuals referred to when describing their individual definition of career success. The decision to seek a promotion was defined as the cognitive process involved in choosing between seeking a promotion and not seeking one. Since this cannot be measured directly, the decision to seek a promotion was operationalized by examining what respondents reported as having taken place during this cognitive process. In other words, by having the participants describe the factors they considered when deciding on whether or not to seek a promotion. This resulted in a list of factors that were compared to the list of factors extracted from the participant's definition of career success. 


\subsection{Factors in the model}

This model is a mock-up proposed by the researcher that was refined and developed during the execution of the thesis. Potential factors in the model were identified in the literature review and used as a starting point for the research.

The reader will note that in Figure 3-1 above, the individual compares their definition of career success to the potential outcomes of seeking a promotion. Based on the literature, we might expect to find that that an individual will consider demographic, human capital, objective career success, frame of reference (self- and other-referent), and organizational/industrial/regional factors when generating their definition of career success. Their personality may also affect how they define career success, although it is not expected that they will list personality factors when describing their definition of career success. Since the research was done in a single institution in a single city, it was expected that the organizational, industrial, and regional variables would not be relevant, since no comparison is possible. However, they were included in the model since individuals with work experience in other locations might make comparisons to their past experiences. Additionally, the literature suggests that when individuals make work related decisions they consider demographic, spouse, work-life balance perceptions, human capital, job perceptions, and organizational structures variables. These were also included in the model.

The reader will note that the literature search generated a list of factors that might influence subjective career success that is somewhat different from the list of factors that might influence career-related decision-making (see Table 3-1). As noted earlier, however, the area of career related decision-making is under-researched. The model, 
therefore, hypothesizes that the factors that potentially influence subjective career success will be the same as those that potentially influence career-related decision-making. The list of factors that were included in our initial model, therefore, is shown in Table 3-1.

Table 3-1: Comparison of factors in the proposed model with those found in the literature

\begin{tabular}{|c|c|c|}
\hline $\begin{array}{c}\text { Factors in the } \\
\text { proposed model }\end{array}$ & $\begin{array}{c}\text { Subjective career success } \\
\text { factors from the literature }\end{array}$ & $\begin{array}{c}\text { Career-related decision-making } \\
\text { factors from the literature }\end{array}$ \\
\hline Demographic & Personality & $\begin{array}{c}\text { Demographic } \\
\text { Spouse }\end{array}$ \\
\hline Human capital & Human capital & Human capital \\
\hline Objective career success & Objective career success & \\
\hline Self-referent & Self-referent & \\
\hline Other-referent & Other-referent & Job related \\
\hline Job related & Job related & Work-life balance \\
\hline Work-life balance & Work-life balance & Organizational \\
\hline Organizational/regional/industrial & Organizational/regional/industrial & \\
\hline
\end{tabular}

Figure 3-2, below, shows the role of these factors in the model. This figure shows the paths of interest extracted from Figure 3-2, with the list of factors that are hypothesized to be considered in the decision-making process. Note that gender is also included as one of the individual characteristics that may affect the relationship. 
Figure 3-2: Role of Factors in the Proposed Model of a Rational Decision-making Process

Individual characteristics, including individual's definition of career success and gender
Decision whether to seek a promotion, based on comparison of the factors in the career success definition to the factors considered in deciding on whether or not to seek a promotion

Factors compared:

- Demographic

- Human capital

- Objective career success

- Self-referent

- Other-referent

- Job perceptions

- Work-life balance

- Organizational / regional / industrial

\subsection{Research questions}

The primary objective of this study was to develop a theoretical model describing the relationship between subjective career success definitions and career-related decisionmaking. To this end, a number of research questions were posed to guide the research. The primary research question was "What is the relationship between definition of career success and the decision to seek a promotion?" The following secondary research questions were also posed:

- How do public servants define career success?

- What factors do public servants report taking into account when making the decision on whether or not to seek a promotion? 
- Is there a relationship between a public servant's definition of career success and the factors they describe taking into account when deciding whether to seek a promotion?

- To what extent does data bear out the model proposed by the researcher?

- To what extent does the relationship between definitions of career success and the decision to seek a promotion depend on gender or on level?

The answers to these secondary research questions will lay the groundwork for answering the primary research question.

Next, Section 4 presents the research design and methodology that was used in this thesis. 


\section{RESEARCH DESIGN AND METHODOLOGY}

This section will summarize the research methodology used to test the model presented in Figure 3-1. This section is divided into four sections. The overall research approach is given first, followed by a description of the sample and the methods of data collection. The last section details the methods of data analysis, including a general overview of the methodologies used, the steps followed in the methodology, and how each research question was answered.

\subsection{Overall research approach}

The overall approach was exploratory and qualitative, using a mixed-methods approach to grounded theory. The study made use of semi-structured interviews-which were recorded as part of a prior study - to develop a model of the factors that influence an individual's decision to seek a promotion. This data was studied using the case study method, where each individual can be considered a case, in an attempt to understand the dynamics involved in this situation (Eisenhardt, 1989). A mixed-methods approach to grounded theory was used to study the participants' responses and develop a model of the processes that were occurring. Further details of these elements are given below.

\subsection{Sample}

The sample for this study came from a study of 88 managers in mid- to latecareer, at the middle and executive management levels in a Canadian federal government 
department. ${ }^{5}$ These individuals participated in a prior study on career satisfaction and the decision to seek a promotion. The participants were either at the EX minus 1 level (a feeder group for the executive cadre) or the EX 1 to 3 levels (executive cadre managers). The response rate for the original study was $75 \%$.

The sample for the current study — namely, the respondents from the first studyis shown in Table 4-1. The organization under study is unique in some ways, but it is expected that the results of this study can be extended from the reference population of managers within this single department, to suggest implications for the wider group of similar managers in other Canadian Public Service organizations.

\begin{tabular}{|l|c|c|c|}
\hline \multicolumn{4}{|c|}{ Table 4-1: Original Sample by Level and Gender } \\
\hline & Total & Female & Male \\
\hline Total & 88 & 45 & 43 \\
\hline EX - Minus 1 & 44 & 22 & 22 \\
\hline EX & 44 & 23 & 21 \\
\hline
\end{tabular}

Of the 88 managers originally studied (shown in Table 4-1), 52 agreed to participate in this thesis. Of these, 40 interviews were conducted in English and of sufficiently audible quality for this study. ${ }^{6}$ Table 4-2 shows the ultimate distribution of the interviews used. Note that the proportions of each group in the $2 \times 2$ matrix are roughly the same as those in the original sample population (i.e. roughly $1 / 4$ of the group). All of the participants in this sample have already sought and obtained the promotion

\footnotetext{
${ }^{5}$ The name of the department studied has been redacted to protect the anonymity of the participants in this study.

${ }^{6}$ French language interviews were ultimately excluded due to the researcher's lack of access to translations adequate for the grounded theory analysis.
} 
being studied here (the promotion that they decided to seek as a result of the decision studied in this thesis).

\begin{tabular}{|l|c|c|c|}
\hline \multicolumn{4}{|c|}{ Table 4-2: Final Sample by Level and Gender } \\
\hline & Total & Female & Male \\
\hline Total & 40 & 19 & 21 \\
\hline EX-Minus 1 & 17 & 9 & 8 \\
\hline EX & 23 & 10 & 13 \\
\hline
\end{tabular}

\subsection{Data collection}

The original study involved the collection of both qualitative (interview) and quantitative (survey) data. No additional participation or time commitment was required from respondents with respect to their participation in this study. Their permission to use their data in this thesis was required, however.

\section{Interview}

The managers from the prior study participated in semi-structured interviews that lasted between 30 and 90 minutes. The current study used only selected questions from the interviews in this analysis. These questions are presented below. While the interviews for participants at the EX level were different from those given to the EXminus-1 level, the questions selected to be used in this thesis were the same for both groups. The interviews were taped and coded for the initial study. For this thesis, the questions of relevance were transcribed and then re-coded by the researcher using grounded theory methodology. 
Survey

The participants also filled out a 29-item questionnaire. The only two pieces of demographic information required for this thesis, the gender of the participants $(\mathrm{M} / \mathrm{F})$ and whether they were at the EX level (Yes/No), were also captured in the reference number given to participants and recorded on the tape. Thus, no demographic information from the surveys was used in this thesis.

\subsubsection{Selected questions used for this study}

This thesis relied on the responses to selected questions from the original study. A range of questions were selected because the interviews were semi-structured; therefore, content relevant to this analysis was sometimes included in the response to another related question. The following questions from the original study were transcribed for this thesis, but only the content relevant to this study was coded and analyzed:

A. How would you define "career success"? What does having successful career mean to you?

B. How would you define "life success"? What does having a successful life mean to you?

C. How does having a successful life differ from having a successful career - or does it?

D. How has your definition of career success and life success affected your career at [Department]? 
E. In the ideal world (i.e. if everything goes according to plan, things go your way) where would you like your career to go in the next two years? Ultimately? Why do you say this?

F. What factors (if any) have influenced your decision to compete for the promotion to your current level [M1 or EX] at [Department]? (encouraged or discouraged)

\subsection{Data analysis}

This section will first examine the reasons for using the selected approaches (explanatory research, case study, and mixed-methods grounded theory methodologies). Next, the methodological steps that will be used to process the data and develop the model will be explained. Finally, an explanation of how each research question was answered will be presented.

\subsubsection{Support for the selected approaches}

This section will explain the reasons for using an exploratory approach, case study methodology, and mixed-methods grounded theory methodology in this thesis. The strengths and weaknesses of each methodology will also be discussed.

\section{Exploratory approach}

As established earlier, there is a significant gap in the research on understanding the factors that individuals take into account when deciding whether to seek a promotion. This area, therefore, can benefit from an exploratory approach.

According to Hartwig and Dearing $(1979$, p. 9), "the underlying assumption of the exploratory approach is that the more one knows about the data, the more effectively data 
can be used to develop, test, and refine theory." An exploratory approach can be used to flesh out a topic in a qualitative, or even narrative, way. The results of the exploratory study can then be used to develop questions for confirmatory analysis studies. The exploratory approach is appropriate for qualitative work, since it often focuses on "the building or development of new theory" as opposed to the "theory testing" model of most positivist research (Goulding, 2002, p. 20).

\section{Case study approach}

Case study methodology, which was used in this thesis, is well suited to producing inductive results. This methodology is generally used for exploratory research and for "understanding the dynamics present within single settings" (Eisenhardt, 1989, p. 534). In particular, case study methodology is best used in cases where the focus is "in process rather than outcomes, in context rather than a specific variable, in discovery rather than confirmation" (Merriam, 1997, p. 19). Eisenhardt (1989) points out that the case study methodology has several strengths: it is likely to generate fresh theory, produce theory that is testable with easily measured constructs, and be empirically valid. On the negative side, case study methodology can tend to produce theory that is either overly complex and "tries to capture everything" or that is narrow and idiosyncratic (Eisenhardt, 1989, p. 547). It is hoped that by comparing the exploratory results to the results from a review of the literature, as Eisenhardt (1989) recommends, this thesis has avoided these pitfalls. In this study, the individual cases were the participants in the study, each individual representing a case. 


\section{Grounded theory methodology}

Grounded theory is a qualitative methodology that aims to help researchers develop new theory that is "grounded in data which are systematically gathered and analysed" (Goulding, 2002, p. 42). The basic procedure of the methodology is to fracture the source documents into codes to allow for "microscopic examination" (Locke, 2001, p. 66), and then to use constant comparison between cases and "interplay between analysis and data collection" (Goulding, 2002, p. 42) to develop a substantive theory. This methodology helps the researcher to "conceptualize [the data] in a way that transcends the particular interview or situation in which they were embedded" (Locke, 2001, p. 66). The goal is "to sort, synthesize, and organize large amounts of data and reassemble them in new ways... bringing data back together again in a coherent whole" (Charmaz, 2006, p. 60).

There are two broad strains of grounded theory methodology, one school following Barney Glaser and the other following Anselm Strauss and Juliet Corbin (Goulding, 2002). Both the Glaser and the Strauss and Corbin methods involve the same basic steps: open coding (where many codes are generated based on the data), selective coding (where codes are refined) and development of the model. The Strauss and Corbin method (Corbin \& Strauss, 1998) also includes axial coding before selective coding, where the relationships between codes are fleshed out using a coding paradigm. These four stages are discussed in more detail below.

The open coding stage is sometimes called generative coding, as this phase of the methodology focuses on generating new codes with an open mind. The researcher fractures the source documents by "taking the data apart and examining the discrete parts 
for differences and similarities... The aim of this stage of analysis is to identify discrete concepts, which are the basic units of analysis in grounded theory" (Priest et al, 2002, p. 33) and to "give the analyst new insights by breaking through standard ways of thinking" (Corbin \& Strauss, 1990, p. 12). Goulding (2002, p. 77) recommends that "every line of the transcribed interview is searched for key words or phrases which give some insight into the behaviour under study. These are then highlighted and abstracted from the interview." Charmaz (2006, p. 49) recommends coding in the form of a gerund ${ }^{7}$ to help the researcher "detect processes and stick to the data." During open coding, the codes may be clustered into groups or a more abstract category (Goulding, 2002; Miles \& Huberman, 1994).

In the Strauss and Corbin model, the next stage is axial coding, which focuses on the idea of building "a dense texture of relationships around the "axis" of a category" (Strauss, 1987, p. 64). They provide a detailed coding paradigm to help researchers think through the relationships found in their data. The coding paradigm includes the following categories: causal conditions, phenomenon, context, intervening conditions, action/interaction strategies, and consequences (Charmaz, 2006). Charmaz (2006, p. 61) notes that this paradigm "provides a frame for researchers to apply," but it can "extend or limit your vision."

The next stage is selective coding, where the categories identified in the analysis are unified into a theory. This phase develops a more abstract understanding of the data, collapsing "more empirically grounded categories into higher order conceptual

\footnotetext{
${ }^{7}$ A gerund is "a verb form which functions as a noun," ending in "-ing" in English (The Concise Oxford English Dictionary, 2006).
} 
constructs" and "specifying relationships and delineating a core category or construct around which the other concepts revolve" (Goulding, 2002, p. 77-78). In the Glaser paradigm, this phase is fluid, relying on intuitive relationship with the data. Strauss and Corbin, on the other hand, encourage use of a prescriptive coding matrix to understand the linkages between macro- and micro-level influences on the phenomenon (Corbin \& Strauss, 1998).

The general end result of a grounded theory methodology is a model of some kind that seeks to put forward a theory. In particular, the methodology is well suited to exploratory research "to generate theory where little is already known" (Goulding, 2002, p. 42). As the theory is developed, the researcher may also use earlier theories about an area "to create a dense integrated theory of greater scope" (Goulding, 2002, p. 56). Turning to the existing literature is an important step, as established theory provides "a context in which a researcher's model links the new findings with established knowledge. Ultimately, the goal is to be able to place the results in the context of established knowledge and to claim new contributions (Morse, 1994).

Researchers disagree, however, about whether theories resulting from grounded theory are generalizable or not. Glaser argues that the theories developed from grounded theory methodology should only explain the phenomenon under study (Goulding, 2002). Similarly, other researchers recommend that grounded theory be used to develop substantive theories that "can be used to explain similar situations" (Bringer, Johnston \& Brackenridge, 2004, p. 251) or in cases where the analysis can zero in on exploring "the interpretations and emotions of different individuals or groups living through the same processes" (Langley (1999, p. 700). Strauss and Corbin, on the other hand, suggest that 
researchers use their coding matrix to facilitate being able to "conceptualise beyond the immediate field of study" (Goulding, 2002. p. 45).

The literature also points out a number of cautions for researchers using grounded theory. Goulding (2002) notes that one of the benefits of using the methodology with secondary data is that it allows the research to devote more energy to analysis and interpretation, but that it can also cause problems in that it may not be possible to conduct theoretical sampling beyond the existing data set. Researchers should therefore ensure that the dataset used is large enough to allow for the constant comparison process so that they can truly claim saturation (Goulding, 2002). This will be taken into account in this thesis.

This study employed a mixed-methods approach to grounded theory, incorporating some elements of content analysis. Thus, the methodology followed Mintzberg's (1979) recommendation that researchers employ both systematic methods and inductive detective work. A systematic, inductive approach (grounded theory) was used to understand the processes at work and codify them into testable categories. Then, a more quantitative approach (content analysis) was employed to answer the research questions. Although this mixed-methods approach is not classical grounded theory methodology, there is still considerable debate in the literature surrounding how best to report the findings that result from grounded theory research. It was felt that in this case, reporting some quantitative results would provide the most helpful tool for assessing the results of the analysis and for guiding future research.

Strauss and Corbin's version of grounded theory methodology was selected for this thesis. Glaser has rejected the Strauss and Corbin method as being too prescriptive; 
however, it is also the method most commonly used in the management literature (Goulding, 2002). An effort was made to address the concerns with this method. This thesis also relied heavily on Goulding (2002) and Charmaz (2006) for guidance in execution of the grounded theory method.

\subsubsection{Steps in the methodology}

This study used grounded theory methodology to code the interview data and develop a substantive theory about the relationship between subjective career success and career-related decision-making. This study primarily follows the methodologies described be Goulding (2002) and Charmaz (2006), but is also influenced by the methods described by Lillis (1999) and Loxley (2001). It should be noted here that memos were developed throughout this methodology to guide the analysis.

The first step in the methodology was preparing the data and importing it into NVivo. The interviews were recorded in audio cassette format. These were transcribed by the researcher into RTF (rich text format) using MS Word, such that each interview constituted one file. These documents were formatted for input to NVivo using MS Word's Heading Styles functionality to flag question sections and participant responses in order to facilitate coding. The files were imported into NVivo such that each document was coded as a "case node," where this node was the same as the participant's reference number. This terminology also reflects the case study methodology, as each participant constituted a case. A table of attribute data was prepared in MS Excel, indicating the gender of participants $(\mathrm{M} / \mathrm{F})$ and whether they were at the EX level 
(Yes/No) based on reference number. This data was applied to each case node in NVivo by importing the table.

In preparation for detailed analysis, the second step was classifying the interview content on a per-sentence basis as either one of the research categories ("Subjective definition of career success" and "Factors considered in decision to seek a promotion") or "Other." In some cases, sentences could fall into more than one code.

Third, open coding was performed for the "Subjective definition of career success" and the "Factors considered in decision to seek a promotion" research categories. All data within the code for a given participant was reviewed and broken down into provisional, "in vivo" codes as close to the participant's own words as possible. As suggested by Charmaz (2006), the focus was on reducing these codes to gerunds, in order to focus on the action or state, and to make codes similar enough for comparison. Constant comparison between cases was used to refine codes by developing conceptual labels for and grouping together the phenomena observed (Corbin \& Strauss, 1990). As part of this process, various classifications were expected to emerge that related similar provisional codes. These classifications are called sub-themes in the discussion section of this thesis.

Fourth, axial coding was performed for the "Subjective definition of career success" and the "Factors considered in decision to seek a promotion" research categories. At this point, Strauss and Corbin's (1998) coding paradigm was used as a tool to relate the sub-themes to broader themes and to understand the relationships between various provisional codes found in the data (Corbin \& Strauss, 1990). The researcher returned to the original source as needed, to see if the codes really belonged 
together or not. Initial process models of the two research areas (subjective career success and career-related decision-making) were developed to facilitate understanding of the relationship between phenomena.

The fifth step was selective coding, in order to identify and understand the core category or "central phenomenon" of the study around which all themes could be unified (Corbin \& Strauss, 1990). The themes and sub-themes, as well as the initial process models, were developed for each of the research categories and compared in order to understand the core category and build an aggregate model linking the areas together and answering the research question. The literature was used to extend and refine the model.

In addition to these steps, some quantitative tests common to content analysis methodology were used, to supplement the grounded theory analysis in developing the final model and drawing conclusions from the findings. Fisher's Exact Probability Test was used, which is a significance test for $2 \times 2$ or $2 \times 3$ contingency tables (Cramer, 2004). It is an alternative to the chi-square test "in circumstances in which the assumptions of chi-square such as minimal numbers of expected frequencies are not met" (Cramer, 2004, p. 65).

Due to the relatively small sample size in this study, in a number of cases the expected frequencies for a given test were less than 5 . Since the data being tested was produced from a qualitative analysis not normally intended for statistical testing, the significance level was be set at 0.1 . Because of this, and the risk of a fairly high familywise error rate (due to multiple tests on the same data), the results should be interpreted with some caution. These quantitative tests were not intended as a definitive test of 
statistical significance. Rather, findings at a significance level less than 0.1 were taken as indicative of a possible trend in the data (Cramer, 2004).

The tests were conducted by using matrix queries in NVivo to produce a set of dummy variables for each participant, indicating whether or not they were coded for a particular node. These results were then used to report frequency data, which was exported to Minitab 15 where Fisher's Exact Probability Test was performed for significance tests.

\subsubsection{How the research questions were answered}

The primary research question, (What is the relationship between the definition of career success and the decision to seek a promotion?), was answered by building on the findings for each of the secondary research questions, as described below.

How do public servants define career success? This question was answered by calculating the frequency at which the participants in the sample were coded at each of the themes and sub-themes related to subjective career success. The data will be presented in the next section as a histogram, and will provide some evidence as to how public servants tend to define career success. Additional findings from the grounded theory analysis will also be presented, for a more nuanced understanding of how participants experience and think about career success.

What factors do public servants report taking into account when making the decision on whether or not to seek a promotion? The answer to this question will be presented as a histogram showing the number of participants in the sample that were coded at each of the themes and sub-themes related to the decision to seek a promotion. 
Presenting these findings will provide some evidence as to what public servants consider when they decide to seek a promotion. In order to provide a more nuanced understanding of how participants experience and think about the decision to seek a promotion, some additional findings from the grounded theory analysis will also be presented.

Is there a relationship between a public servant's definition of career success and the factors they describe taking into account when deciding whether to seek a promotion? The relationship was examined by comparing the themes and sub-themes identified in each of the research categories to identify if any appeared in both the individual's subjective definition of career success and the factors they considered when deciding to seek a promotion. A matrix query in NVivo was then used to identify whether individuals were coded for these themes and sub-themes in both research categories, or in only one. Figure 4-1 shows an example, where an individual mentioned a spouse theme in relation to both their definition of career success and the decision to seek a promotion, but other themes appeared in only one category. The existence of a relationship was decided based on the grounded theory analysis and the frequency of theme matches. The methodology for this will be discussed in more detail in Section 5.3, as it will build on the results of the findings for the first two research questions. 
Figure 4-1: Comparison of Coded Factors with Hypothetical Examples

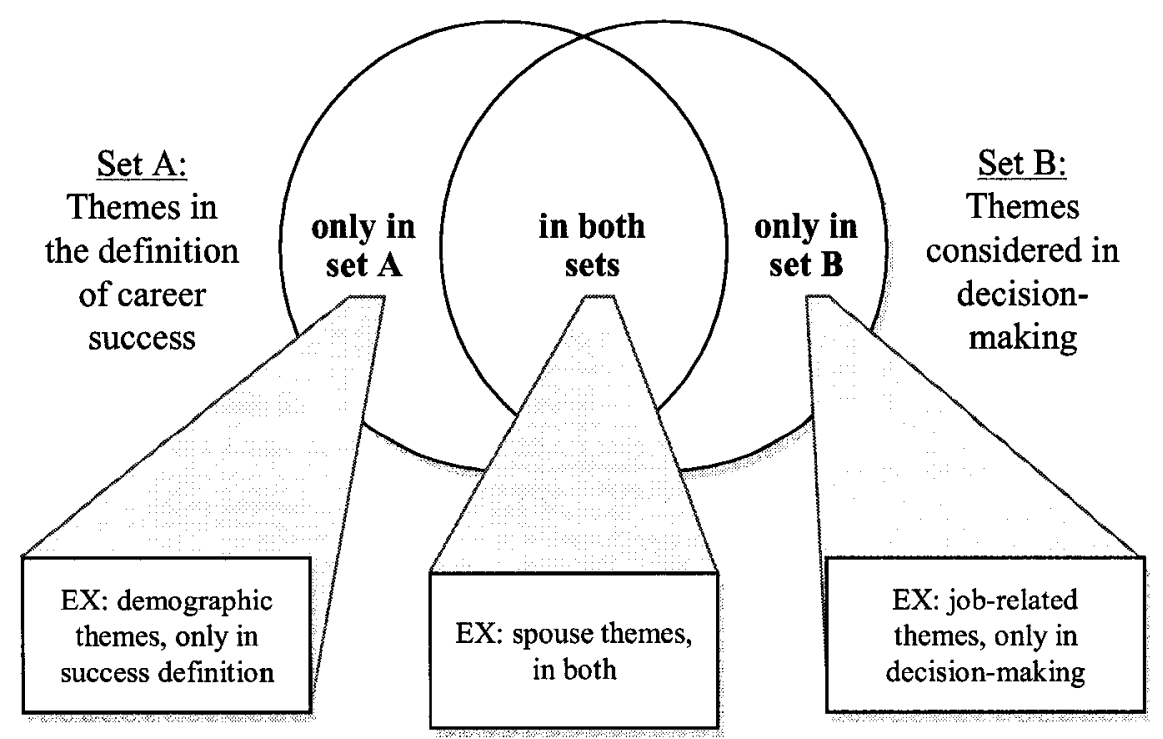

To what extent do the data bear out the model proposed by the researcher in the previous section, based on the literature? Since the answer to the previous question was "Yes, there is a relationship," a model was developed to show that relationship. The model was based on the findings from the grounded theory analysis and the content analysis.

To what extent does the relationship between definitions of career success and the decision to seek a promotion depend on gender or on level? Gender and level may have an influence that should be reflected in the model; however, the influence of gender and level on the matches between the two research categories could not be tested due to the small sample size. Instead, the researcher looked at the results of the gender and level analysis that was done separately for each of the research categories. Fisher's Exact Probability Test was used to identify trends in the influence of gender or level 
(independently) on the frequency of the themes and sub-themes in career success definitions or on the decision to seek a promotion. This analysis indicated whether gender and/or level influenced either the individual's subjective definition of career success or the factors they considered when deciding to seek a promotion. These results provided some indication as to whether gender and level influence the relationship between these two constructs. The answer to this research question was also influenced by the results of the grounded theory analysis.

What is the relationship between the definition of career success and the decision to seek a promotion? Since a relationship was found between subjective career success and the decision to seek a promotion, the primary research question will be answered in Section 6.1 .3 , by providing a model of that relationship.

The next section will present the findings of this thesis in detail. 


\section{DISCUSSION OF FINDINGS}

This section will present the findings from this study by examining the answers to each of the research questions as was described in Section 4.4.3. There will be five sections. Each will address one of the secondary research questions: how public servants define career success, what factors they report taking into account when deciding whether to seek a promotion, whether there is a relationship between these two factors, to what extent the findings bear out the proposed model based on the literature, and whether gender and level have a significant influence on the constructs in the model. Relevant quotations from the data will be presented in order to illuminate the findings. ${ }^{8}$ The primary research question will be answered in Section 6.1.4, where a final model of the relationship between the definition of career success and the decision to seek a promotion will be presented.

\subsection{How do public servants define career success?}

During the open coding stage of the grounded theory analysis, 67 provisional codes were identified in relation to how participants defined career success. These were eventually narrowed to five broad themes (shown in Figure 5-1), categorizing seventeen sub-themes (shown in Figure 5-2). These broad themes were Experiences While Working, Benchmarking, Outcomes of the Work, Work Roles, and Having Fit. There were also 23 codes reflecting how participants contextualized their definitions; these are discussed in

\footnotetext{
${ }^{8}$ Please note that in some cases these quotations have been edited to protect the anonymity of the participants. Such edits are marked with ellipses (...) or square brackets ( [ ] ).
} 
Section 5.1.1. Table 5-1 shows the average number of these codes that were mentioned per participant in his or her definition of career success: a mean of 2.7 themes and 3.75 sub-themes per participant. One important finding from this analysis is that there is a range in the frequency of the various themes and sub-themes. This indicates that some aspects or approaches to defining career success are more common than others.

This section will present these themes and sub-themes in detail, with examples drawn from the transcripts of the interviews. In addition, 12 codes were identified that relate to how participants contextualized their definitions of career success, which will be discussed further in Section 5.1.1.

Table 5-1: Frequency of Occurrence of Subjective Career Success Themes and Subthemes

\begin{tabular}{|l|c|c|}
\hline & Themes & Sub-themes \\
\hline $\begin{array}{l}\text { Total number identified in } \\
\text { grounded theory analysis }\end{array}$ & 5 & 17 \\
\hline $\begin{array}{l}\text { Mean number mentioned per } \\
\text { participant }\end{array}$ & 2.7 & 3.75 \\
\hline
\end{tabular}


Figure 5-1: Frequency of Occurrences of Subjective Career Success Themes Number of participants coded per theme

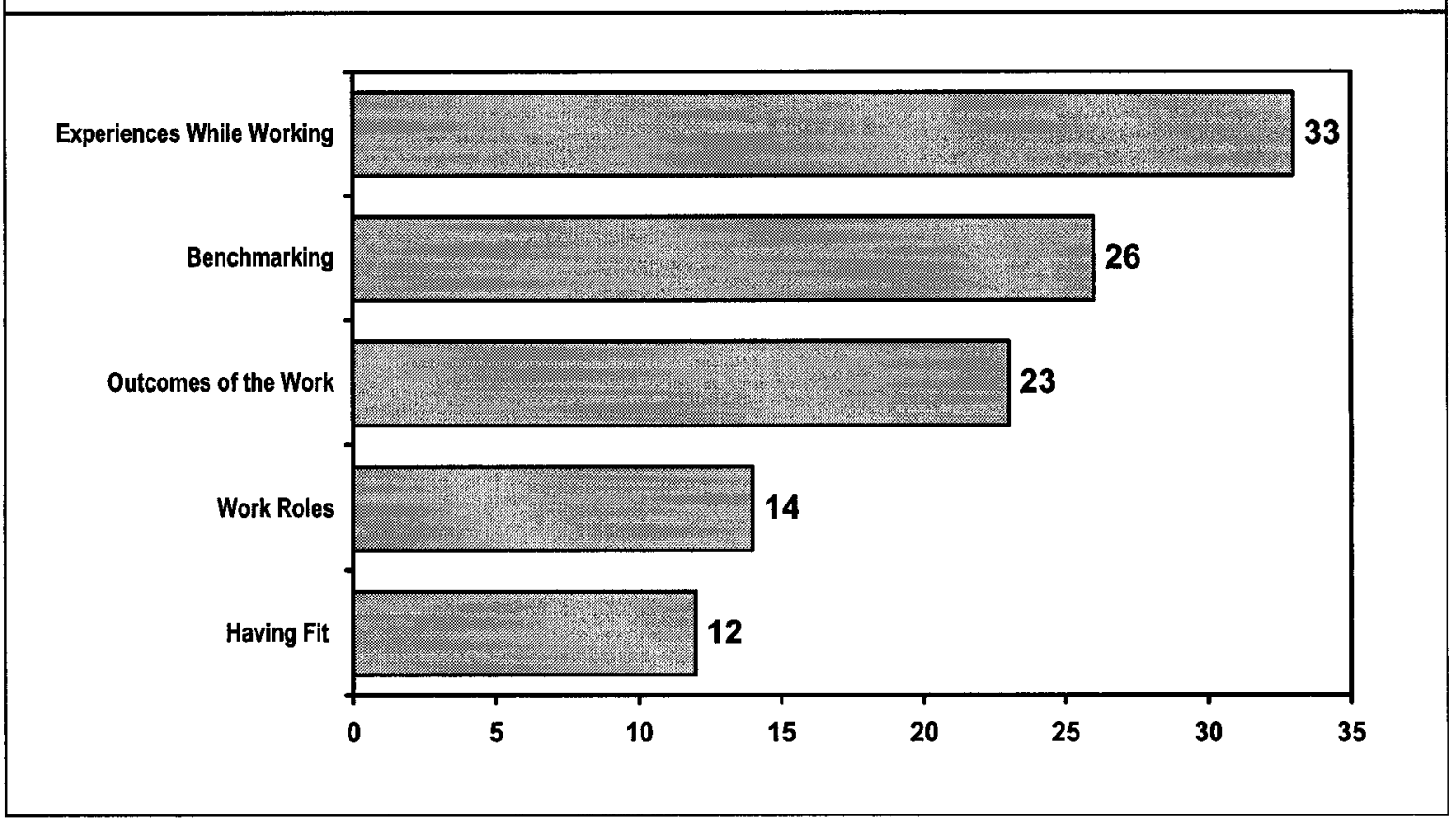


Figure 5-2: Frequency of Occurrences of Subjective Career Success Sub-themes

Number of participants coded per sub-theme, grouped by theme

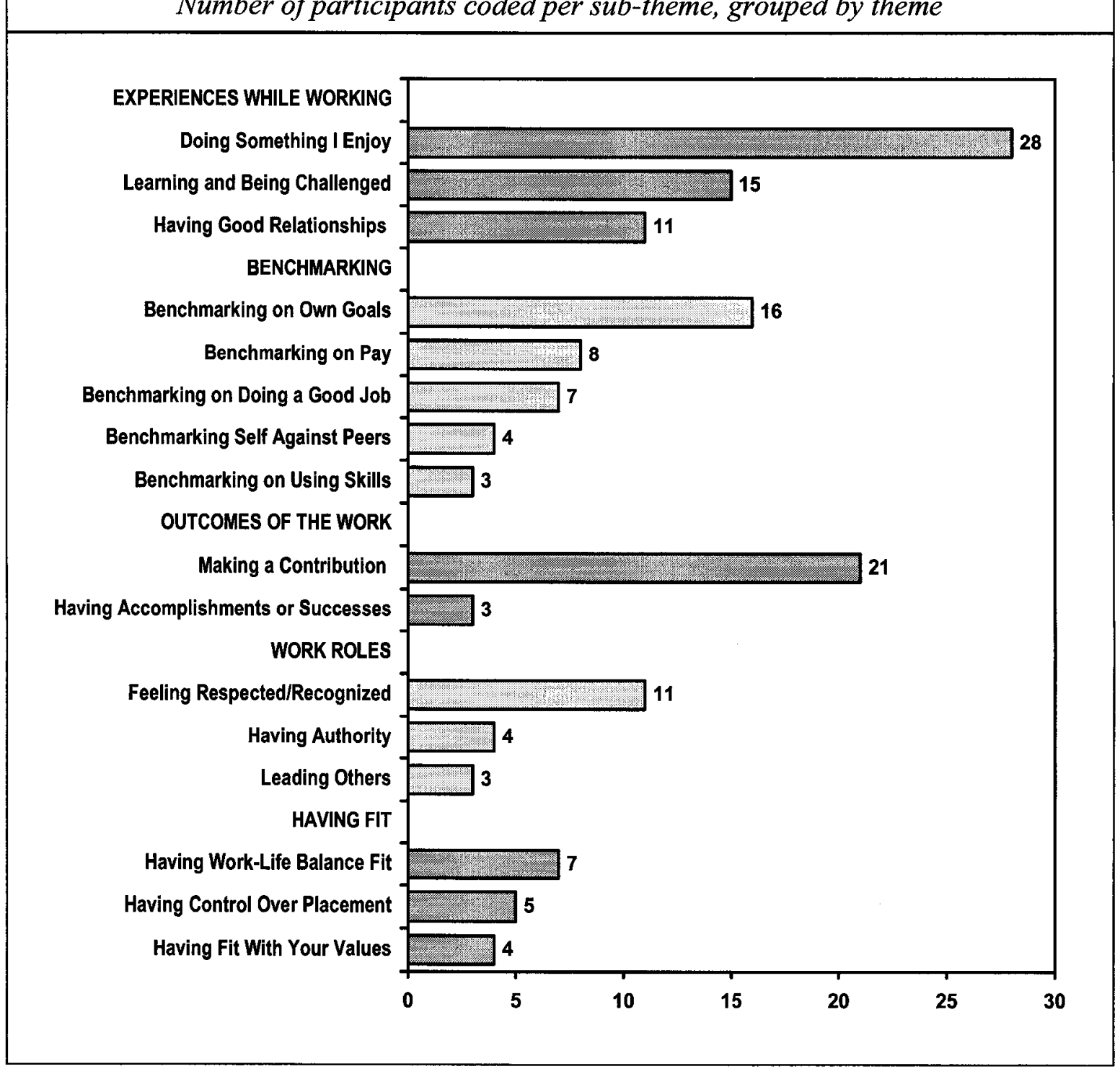

\section{Experiences While Working}

Thirty-three of the participants, or $82.5 \%$ of the sample, defined success with a theme of Experiences While Working. This denotes descriptions of career success that involve what the participant experiences during his or her work. This definition focuses on an idea of career success that is intrinsic and in-the-moment, not goal-oriented. The 
three sub-themes within this theme are Doing Something I Enjoy, Learning and Being Challenged, and Having Good Relationships.

Twenty-eight of the participants described career success as involving enjoyable or interesting work (the Doing Something I Enjoy sub-theme). This was the most commonly stated aspect of career success, with $70 \%$ of the participants mentioning it, in statements such as the following:

For me, successful career is a career first of all in which you've enjoyed working.

I think career success is being somewhere where you enjoy what you do.

I guess it means doing what I like.

It means to me... interest in what l'm doing.

I think the most important thing for me is enjoying coming to work every day, a job that I'm really interested in.

Fifteen participants described success in terms of the sub-them Learning and Being Challenged. This was the fourth most common definition aspect of career success, mentioned by $35 \%$ of participants in statements such as

So l'm not bored which would mean the job is too easy.

I'm feeling challenged.

The first thing would be that I have done a job that's challenged me, that's pushed me to my limits to some extent, at each stage of my career.

Having that opportunity to learn.

I'd like a sustained self development and growth. To be a bit more specific for me that means that over time I can take on and successfully manage more complex, more expansive projects.

Eleven participants (27.5\%) talked about career success as Having Good Relationships in the organization: 
I enjoy the people l'm working with.

Having a solid group of people no matter what area in the organization you go to that are more than willing to work for you and accept you into the structure.

I have a lot of support from colleagues, I have staff that like to work with me.

It means to me, working with people that I want to be working with, that I enjoy working with, working with a boss, an immediate supervisor that I enjoy working with.

Feeling that I have respect for both the people I work with and the people I work for.

\section{Benchmarking}

Twenty-six of the participants, or $65 \%$ of the sample, do some kind of benchmarking when defining career success. These participants benchmark by comparing their current state to an internal rubric of some kind. Five sub-themes were identified within this theme: Benchmarking on Own Goals, Benchmarking on Pay, Benchmarking on Doing a Good Job, Benchmarking Self Against Peers, and Benchmarking on Using Skills. One sub-theme, Benchmarking on Own Goals, is the third most common sub-theme found.

Sixteen of the participants, or $40 \%$ of the sample, defined career success in terms of how well they had met their own goals (Benchmarking on Own Goals). In some cases this goal related to a specific level in the hierarchy; in other cases there were other goals. It is important to note that many of these references to goals related to what the participants expect of themselves, not to the expectations of others. Participants who talked about goals said

I guess achieving the level that you want to achieve, or that you had set out to achieve.

l've always wanted to continue up the ladder and seek the promotions. 
I think l'm doing pretty good in terms of trying to achieve what my vision of myself is, in terms of my career success, anyway. Obviously my goal is to reach the EX level.

To me a successful career is somebody obtaining their goal of what they wanted to do as a career, whatever level that is.... Well I guess I had a certain wanting to be successful and to arrive at a certain level and I guess at some point I had said that if I could get to the chief level that to me I could feel quite comfortable that l'd achieved my goal and I could be quite comfortable and say I did a good job and I had a job that I enjoyed and that. I guess l've been more successful than I expected.

Being in a situation ... where the types of things that I wanted in life I have.

I guess sort of on a subconscious level I had set some objectives for myself, and that was to become a director at [Department]. And I am one, so at some level l'm comfortable with where I am in my career.

I think it's achieving your goals, and goals can be different for different people... For me I would go with level.

I guess it means achieving the sort of level that you expect you're capable of.

In contrast, 10 participants ( 6 females and 4 males) contextualized that achieving a certain level was not necessary to their idea of career success, and two females noted that career success was not simply accomplishing goals.

Eight participants (20\%) talked about the sub-theme Benchmarking on Pay, reaching a desired or "fair" level of pay. Those who considered pay, talked about I feel l'm being fairly and justly paid.

Doing something ... where I feel that I'm getting adequately compensated for it. Being able to move into the kind of work that ...you feel that there's appropriate remuneration. It's always good to get a good paycheck.

In contrast, two participants (one male and one female) specifically stated that money was not a theme in their definition of career success. 
Seven participants, or $17.2 \%$ of participants, talked about career success as doing a good job or being able to do the job. This sub-theme, Benchmarking on Doing a Good Job, was seen in examples such as:

I could be quite comfortable and say I did a good job.

That if I look back I could say that I did good work.

In my mind it's pretty clear. I'm in a job that I like and I can perform.

Four of the participants measured their career success by the sub-theme Benchmarking Self Against Peers, comparing themselves to peers across the organization or in their school cohort. This represented $10 \%$ of the participants.

I think in career success you more often compare yourself to other people around you than you do in life success.

Another point is peer equivalency... when I look across the organization... the level I see my self-defined peers, people that $I$ judge to be equivalent in their competencies to myself, and if they're above or below me.

Finally, three participants (7.5\%) mentioned the sub-theme Benchmarking on Using Skills, wanting to make use of their skills and training in their jobs.

My definitions of career success include... having a job involving appropriate use of my education training and skills.

A successful career for me is basically you're able to obtain the full level where you'd be able to express your potential, both your intellectual potential, basically what you learn how can you apply it to your day to day work, and also in your interpersonal relationships with your colleagues.

\section{Outcomes of the Work}

Over half of the participants, 23 or $58 \%$ of the sample, talked about the theme Outcomes of the Work in their definitions of career success. This theme focussed on 
elements that participants saw as resulting from their work, not on a specific goal or benchmark. The two sub-themes within this theme were Making a Contribution and Having Accomplishments or Successes.

Making a Contribution was the second most common career success sub-theme, mentioned by 21 participants, or $53 \%$ of the sample. Five of these participants directly mentioned a desire to contribute to Canadian society. Participants who mentioned this theme mentioned things such as

Career success is making differences more on organizations or the operations, or how we do things.

For me it means having a job ... that I feel l'm contributing to... where I feel l'm making a difference.

Feeling good about contributing to the health of Canadian society through public service efforts.

I think for me, [a] successful career is a career first of all in which you've enjoyed working, and enjoyment to me is having a sense that you've contributed something, it doesn't have to be big, but that the work that you do here 8 hours a day is towards something.

To me having a successful career is doing something that you enjoy, something that you feel value in, that you're able to get up in the morning and be happy and go into work and come home at the end of the day feeling like you made a difference.

A successful career is making a contribution that's important to you.

Three participants (7.5\%) talked about the sub-theme Having Accomplishments or Successes as key to their definition of career success.

If I'm looking at my work success I'm looking at the accomplishments I earned here. I would say success has a lot to do with not just goals, but the things l've managed to accomplish in my career, obviously. I've had [a number of] really challenging jobs... And I feel that I have succeeded in those jobs. 


\section{Work Roles}

Fourteen (35\%) of the participants talked about the theme of Work Roles in their definitions of career success. This theme included the sub-themes Feeling Respected/Recognized, Having Authority, and Leading Others.

Over a quarter (27.5\%) of the participants (11 individuals) discussed career success in terms the sub-theme Feeling Respected/Recognized. Sometimes this theme took the form of having a good reputation.

For me it's not only being the smart one, or the smart person leading a group, but this is another aspect, being able to exercise leadership with your group and also being able to be respected by your peers, your employees, your colleagues, your superiors, for me that's a successful career.

I feel that I have succeeded in those jobs and have been recognized for the work that I did in those areas. So I guess I have a good reputation at [Department] in terms of being able to do things

I guess it means making a reasonable contribution and being recognized for it.

I think everybody likes to feel that they're important, contributing and that people recognize their good work.

Building a solid enough reputation that you'll have a solid group of people no matter what area in the organization you go to that are more than willing to work for you and accept you into the structure.

Four participants (10\%) also discussed the sub-theme Having Authority (such as a decision-making role) as important in career success, as in the statements below:

The ability to influence some decisions.

I like a position where I have authority, and some control in terms of making decisions and things like that.

For me, well it would mean ... a reasonable range of authority so that I can make decisions and take actions to do good things. 
Finally, $7.5 \%$ of participants ( 3 individuals) specifically mentioned having a leadership role, the Leading Others sub-theme. Examples include:

Feeling that you're accomplishing through others something that's very meaningful. Another point would be that I have.... staff to supervise and develop.

\section{Having Fit}

Twelve of the participants discussed criteria for career success that involved the idea of fit. The Having Fit theme represented $30 \%$ of participants, and included four subthemes: Having Work-Life Balance Fit, Having Control Over Placement, and Having Fit With Your Values.

Seven participants considered the sub-theme Having Work-Life Balance Fit and criteria that related to balance work and life demands (17.5\%). Such as

My successful career and life they start to kind of cross over. I have to have a good mix. So for me career success had been following what I think is the right thing to do at the right time for the right reasons, that basically fit within my own life successfully. I'm trying to achieve success in the public sector but trying also to have a certain balance with my personal life.

Career success as I define it is a good balance between personal and business.

Five participants (12.5\%) were concerned with the sub-theme Having Control Over Placement, in other words having control over where they would be placed in the organization and the fit they would have with their job.

Being able to move into the kind of work that you enjoy doing.

I guess having a successful career to me is doing something that I enjoy doing, and I guess as much as we can be, be in control of moving to the next level that we want to move to. 
For me a successful career is not necessarily related to the level or how high you go, it's really being able to move to a job where you can really fulfill your potential.

Finally, ten percent of participants ( 4 individuals) mentioned the sub-theme Having Fit With Your Values. Two of these individuals also mentioned a concept of "right timing" in conjunction with their comments about fit with values.

So for me career success had been following what I think is the right thing to do at the right time for the right reasons, that basically fit within my own life successfully.

I like working for Canadians and not for a corporation.

Right place, right time, right fit in a way that you can make a contribution that is important to your values.

You feel you're doing the decent thing in all aspects.

Feeling good about all the people you interact with, you're not pulling the rug out from under their feet, you're not letting them down, that type of thing.

\subsubsection{Other interesting findings about career success}

During the axial coding stage of the grounded theory analysis, Strauss and Corbin's (1998) coding paradigm was used to structure and make sense of the themes emerging from the data. The interim process model developed as part of this stage is shown in Appendix B to show the researcher's analytical process. Analysis of the way participants contextualized their definitions of career success brought out several interesting results that can help us to better understand how the participants think about career success or point to areas that bear more scrutiny.

A number of these themes relate to the individual characteristics found in the decision-making literature, which were not included in the proposed model. For example, thirteen participants $(32.5 \%)$ had trouble answering the question when asked 
how they would define career success. This may indicate that some individuals have not previously articulated a definition of career success for themselves. Five individuals noted that their definitions had changed over time (12.5\%), while three other participants admitted that their definitions had not changed ( 3 participants, 7.5\%). Also, some individuals $(13$, or $32.5 \%)$ expressed a hierarchy among the sub-themes they listed, seeing some sub-themes as more important than others. These findings may relate to personality factors, or to past experiences that causes them to examine or change their definitions of career success.

In addition, the participants used a variety of perspectives to measure their career success. Twenty participants spoke about reaching a certain measurable goal or end state $(50 \%)$, five talked about their day to day feelings and experiences $(12.5 \%)$, and three talked about looking back over their career (7.5\%). It was also noted during the analysis that some participants looked at their career success from an action perspective (using words such as doing, making) and other participants some from a state perspective (using words such as having, being, or feeling) perspective. This use of action or state perspective did not appear to be linked to which sub-theme the participant was discussing; rather, it may be indicative of how personality affects subjective career success in that personality may affect the perspective individuals are most likely to take.

Other themes related to situational characteristics, which were included in the proposed model. For example, some participants perceived norms about the definitions of career success. Two participants (5\%) qualified their definitions by saying that it contrasted with norms, while others explicitly stated that they did not measure success by a specific criteria such as level (10 participants, $25 \%$ ) or pay (2 participants, $5 \%$ ). 
Finally, some themes related to the form of the subjective career success construct itself. Many participants appeared to recognize the subjectivity of their career success definitions. This was shown by four participants who noted that definitions vary by individual (10\%). Also, twenty-nine individuals also contextualized their answers as being their personal definition of career success ${ }^{9}(72.5 \%)$.

These findings provide some useful insight into how the participants understand career success, and could form useful directions for future research. They support the inclusion of situational characteristics in the proposed model. The presence of individual characteristics in these findings may indicate that this construct should be included in the proposed model.

\subsection{What factors do public servants report taking into account when making the} decision on whether or not to seek a promotion?

One hundred and eighteen provisional codes were identified during the open coding stage for how participants made the decision to seek a promotion. These provisional codes were eventually narrowed to nine broad themes (shown in Figure 5-3) and 25 sub-themes (shown in Figure 5-4). These broad themes were Benchmarking, Experiences While Working, Expected Fit, Expected Work Roles, Expectation of Getting the Job, Input From Others, Strategic Decision-Making, Expected Outcomes of the Work, and Importance to Self of Applying.

\footnotetext{
${ }^{9}$ This may have been partially affected by the wording of the question, since participants were specifically asked for their own definition in the question wording: "How would you define career success? What does having a successful career mean to you?"
} 
As shown below in Table 5-2, the participants gave a mean number of 4.45 themes and 6.0 sub-themes in their description of the factors they considered in the decision to seek a promotion. This section will present these themes and sub-themes in detail, with examples drawn from the transcripts of the interviews.

In the interviews used in this study, participants were asked to describe which factors encouraged and discouraged their decision to seek a promotion. Among the various sub-themes mentioned, some appeared in both a negative (discouraging) and positive (encouraging) form, while others appeared in only one form. Appendix A notes how many individuals found each theme or sub-theme to be encouraging or discouraging.

In addition, during the grounded theory analysis, 15 codes were identified that reflected how participants contextualized their decision to seek a promotion, and 8 codes related to decision-making behaviours. These will be discussed further in Section 5.2.1 below.

Table 5-2: Frequency of Occurrences of Career Decision-making Themes and Subthemes

\begin{tabular}{|l|c|c|}
\hline & Themes & Sub-themes \\
\hline $\begin{array}{l}\text { Total number identified in } \\
\text { grounded theory analysis }\end{array}$ & 9 & 25 \\
\hline $\begin{array}{l}\text { Mean number mentioned per } \\
\text { participant }\end{array}$ & 4.45 & 6.0 \\
\hline
\end{tabular}


Figure 5-3: Frequency of Occurrences of the Decision to Seek a Promotion Themes Number of participants coded per theme

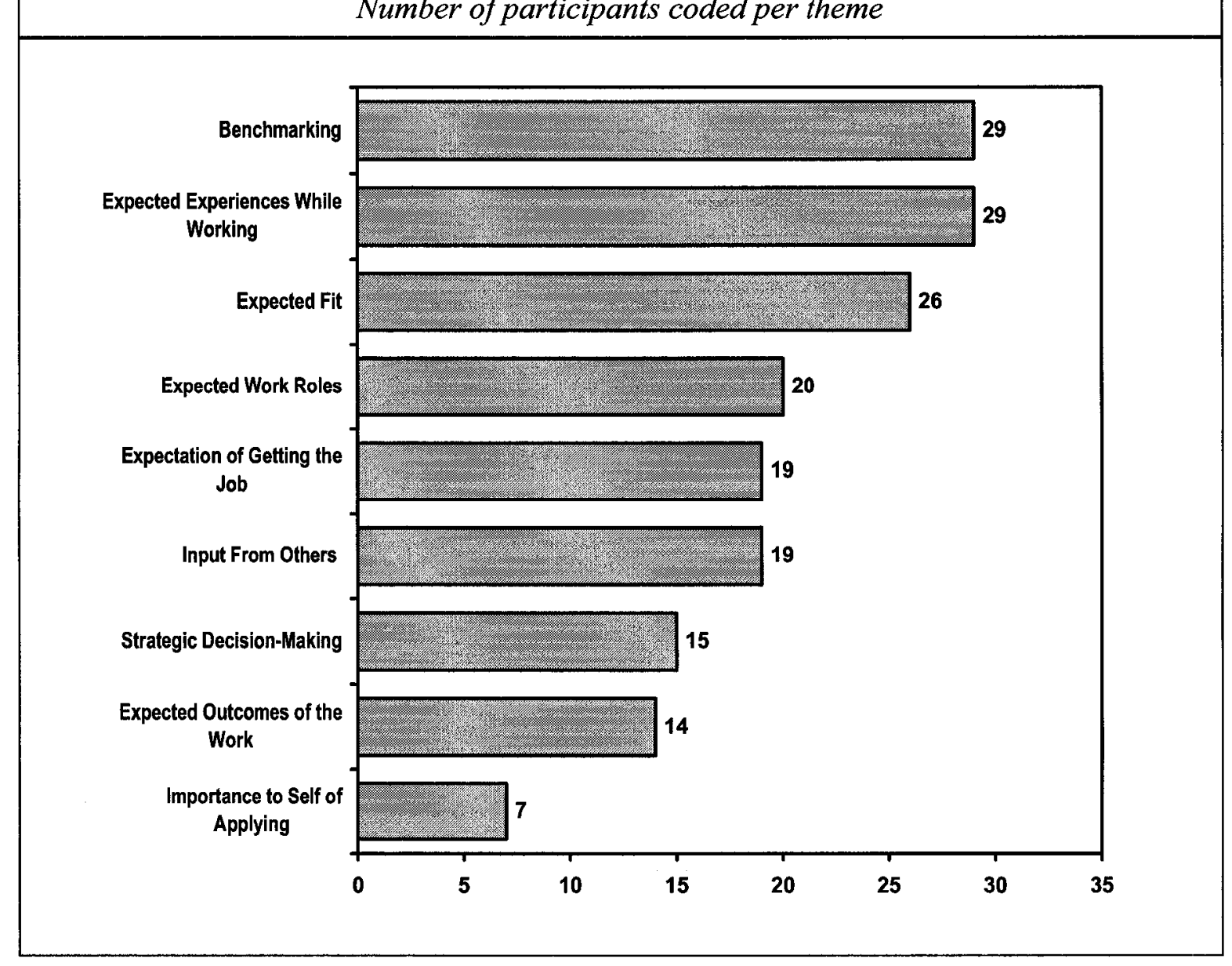


Figure 5-4: Frequency of Occurrences of Decision to Seek a Promotion Sub-themes Number of participants coded per sub-theme

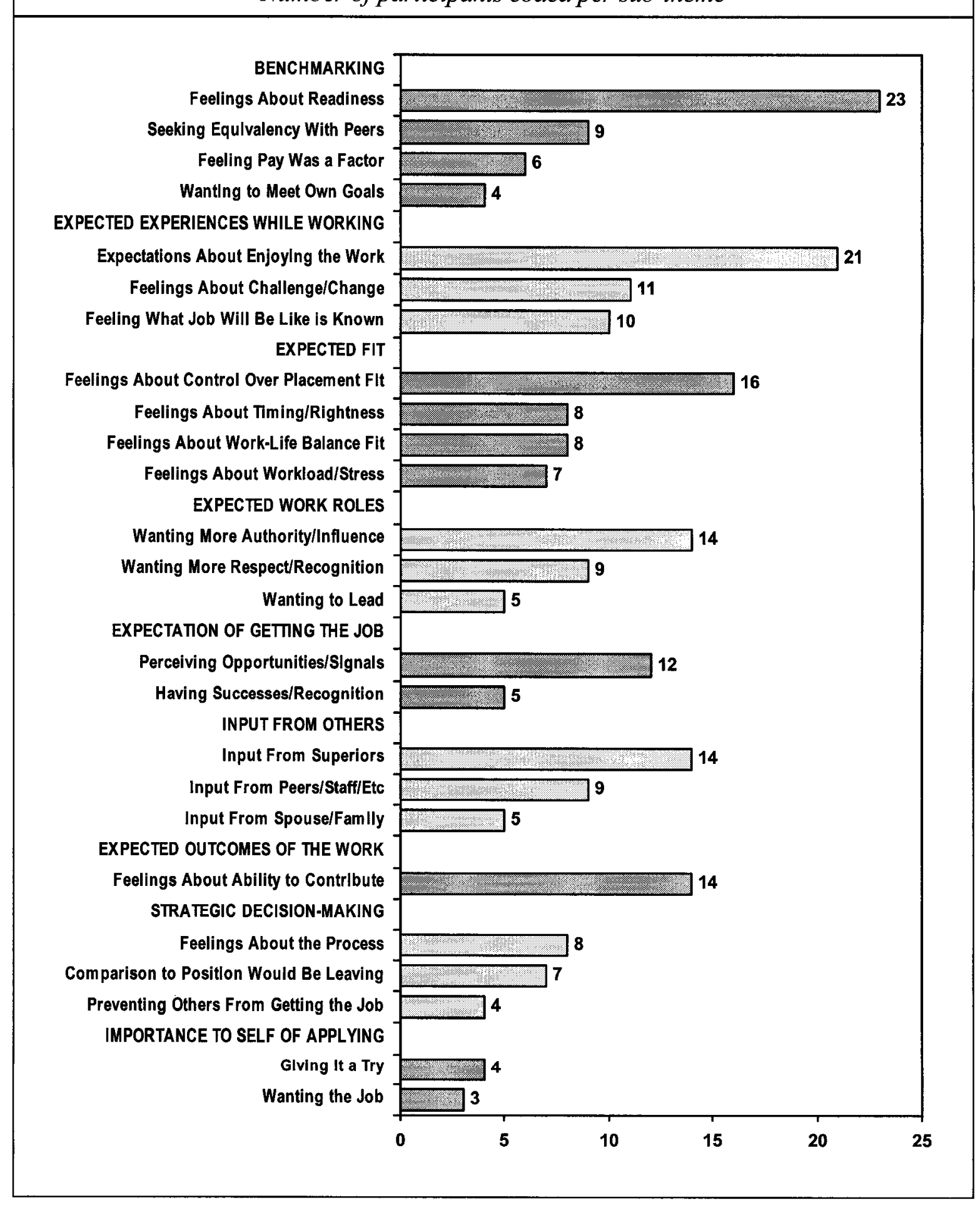




\section{Benchmarking}

Twenty-nine of the participants ( $75 \%$ of the sample) mentioned the Benchmarking theme, comparing their new position to various criteria in their decision to seek a promotion. These participants benchmarked by comparing the potential job to an internal rubric of some kind. Four sub-themes were identified within this theme: Feelings About Readiness, Seeking Equivalency With Peers, Feeling Pay Was a Factor, and Wanting to Meet Own Goals.

The most common sub-theme was Feelings About Readiness, an assessment of whether they were ready, able, and qualified to do the new job, which was mentioned by 23 participants (58\% of the sample). Almost all (20 out of 23 ) of these individuals reported feeling that they were ready for the job and were encouraged by this.

I knew that when I took on the challenges that go along with that job, that I would have the capacity and the skills to be able to meet them.

I thought I had the knowledge to be able to do it.

I knew I was very competent in my job and that I could take on those duties.

I just felt that I would be able to do a good job.

Comparing to other individuals too I did feel that I was very much qualified and at the right level of experience, I felt ready in that sense.

Nine of the 23 individuals who benchmarked on Feelings About Readiness questioned their own ability to do the new job. It should be noted that despite the results of their personal benchmarking, all 23 of these individuals went on to apply for the promotion, and all were successful in obtaining the promotion. Some examples include: Well, normal hesitation, can I do this job, that kind of stuff. But on the whole I think that I felt pretty ready, I had a lot of experience. 
Not knowing if I had the skills required, if I was ready for that, chances are I would be moved to a completely new area and so would $I$ be able to adapt to that.

I hadn't been that long in the position I had occupied previously... And I always thought this organization had a culture that you need to walk before you run.

Nine $(23 \%)$ of the participants benchmarked against their peers, mentioning the sub-theme Seeking Equivalency With Peers in their decision to seek a promotion. For all nine this process encouraged them to seek the promotion.

I've seen other people that I've worked with move up, there's always this... how do I measure up, that's a natural thing to do I think, is to see how you measure up with your peers but also with your age group... But you watch kind of your peer group, the peer group you had as a young adult and there's a certain amount of well, if he can do that, I can do that.

I knew that people at my level were applying too, and if they could do it I could do it sort of thing.

l'd probably be really pissed off if somebody else got the job, let's put it that way.

The people I was coming up with through the ranks were also achieving those levels and it was important to be seen to be achieving the same levels that they were.

When you start to look at the people who are moving up then you see yourself in relation to them and say well wait a second, I think I've got a lot that I can contribute.

Six of the participants ( $15 \%$ of the sample) considered the sub-theme Feeling Pay Was a Factor and benchmarked on pay in the new job. Again, this process appeared to encourage them to seek the promotion. It is also interesting to note that an additional six individuals ( 3 males and 3 females) specifically mentioned that money was not a theme in their decision to seek a promotion.

The money is always an encouraging factor. I mean it is, just that economic security and that.

Well part of it's financial of course. The fact that it's a fairly well-paid level. 
Ten percent of the participants ( 4 individuals) were encouraged by the sub-theme Wanting to Meet Own Goals.

Just my own particular goals and to prove to myself, yes I could get here, I believe I would be a good director, I would never have rested until I was a director.

For me it's mostly about the self-satisfaction. Not in a vain way, just in a, what should you expect out of yourself kind of thing.

\section{Expected Experiences While Working}

Almost three-quarters (73\%) of the participants considered the experiences they expected to have while working in the new job as part of their decision-making process for seeking to seek a promotion. These 29 participants mentioned three sub-themes, which were Expectations About Enjoying the Work, Feelings About Challenge/Change, and Feeling What Job Will Be Like is Known/Unknown.

Twenty-one of the participants - over half $(53 \%)$ - talked about considering whether they would have positive feelings about the work in the new position. This subtheme, Expectations About Enjoying the Work, was described in terms of enjoying the work, being made happy by the work, or deriving satisfaction from it. Such expectations encouraged the decision to seek a promotion.

I want a position that I know is interesting and challenging and something I want to do, so basically until this position opened up I didn't consider it.

I thought I was a bit more likely to be placed somewhere where I would interested and useful

So those are things that give me great pleasure and typically are found at the Director level.

I think it was a job I was really interested in doing, it's a subject matter l'm interested in. 
Eleven (28\%) of the participants reported the sub-theme Feelings About Challenge/Change, as they considered a desire for change or challenge in their decision to seek a promotion. Again, such expectations encouraged the decision to seek a promotion.

I believe I had gone through all the different jobs, job aspects in my area of expertise and I was ready for that new level of challenge, I was ready to feel a bit - I had plateaued, and the challenge wasn't there as much anymore, and I felt like I was ready to get to the next stage.

It was time for a change, and I felt that the work at the same level, just in a different division would probably be too much the same, so the next step was the next step up.

I think the biggest motivator for me tends to be challenge.

For the challenge. I like the challenge. I need to be stimulated and motivated and something new.

I was ready for a change.

One quarter of the participants (10 individuals) considered the sub-theme Feeling What Job Will Be Like is Known/Unknown. Having done similar work before and thus knowing what the job would be like was an encouraging theme for seven people. I was reasonably aware of what the demands of that job would be. I guess what really encouraged me was the support that I had from my director at the time, who not only encouraged me to go that path but kept trying to give me opportunities to do that type of work...So I guess having a flavor for that type of managerial work I really enjoyed it.

I effectively was the director of that division for [a period of time].

Fearing the unknown in the new job discouraged the decision to seek a promotion for three people. For example: 
There's always a little bit of what does this mean, what ladder am I climbing onto now and where is it going to lead? A little bit of that unknown.

\section{Expected Fit}

Twenty-six participants, or $65 \%$ of the sample, considered issues of fit with the potential promotion when deciding on whether or not to seek the promotion. This theme, Expected Fit, included four sub-themes: Feelings About Control Over Placement Fit, Feelings About Timing/Rightness, Feelings About Work-Life Balance Fit, and Feelings About Workload/Stress.

The most common of these sub-themes, Feelings About Control Over Placement Fit sub-theme relates to the amount control that participants felt would have over where they would be placed (and thus control over the fit they had with their job). This subtheme included participants who considered whether a specific job or areas was available when they applied for the promotion. Sixteen (40\%) of the participants considered this sub-theme in their decision to seek a promotion. Twelve were encouraged by feeling that they had some input, or felt likely to be placed a specific area or position.

I thought I was a bit more likely to be placed somewhere where I would interested and useful .... Because they had changed the process a bit and because I knew that there were some openings in some places that I guess I thought that I had a good chance at ... When I applied there was a list of potential opportunities, so you look at the list and you say okay, there is more than one that l'd like to get. Because of a particular position that I was interested in. That was basically the only factor.

They said they were staffing the following positions, so I said l'm here because I'm interested in that one, you're allowed to leave that out on the table. 
I thought I would be able to continue in the [specialty] I'm doing right now so I took a chance.

Until this position opened up I didn't consider it.

The job in the area that I was most interested in was up for grabs.

Losing this control over placement fit discouraged promotion for eight participants.

The biggest I guess discouragement to this is the fact that you really have no say as to where you're put.

Well, I think everybody that applies for it in one of those generic director competitions has some kind of fear of where they're going to end up.

Chances are I would be moved to a completely new area and so would I be able to adapt to that?

Also something that discouraged me from seeking this particular promotion was the fact that at this the AD level it's the generic pool. Not that it's a generic competition, that never discouraged me, but the fact that once you're in this pool you can be moved wherever senior management decides that you should go. You don't have as much choice in where you would go.

The lack of any control or at least the perception that you didn't have much influence in terms of what subject matter you were going to go to. Turns out you have some voice but it's still pretty clear you don't have much influence on that. You get a chance to say an opinion but not much more than that, and it's not clear that that opinion has much weight in the final decision-making.

Eight participants considered the Feelings About Work-Life Balance Fit subtheme in their decision on whether to seek promotion ( $20 \%$ of the sample). Five people were discouraged by how the promotion might affect their work-life balance.

I was put where I was needed. And it makes it much harder to then balance the home responsibilities. You're doing what's good for the organization... in some ways there is more responsibility but in other ways there is greater flexibility. 
I guess what discouraged me...I think it would affect my life success, my life balance because I think in this organization you have to put in a lot of time. I think these jobs come at a price.

I was a bit worried about work life balance.

Family goals and personal goals, it just wasn't right. I wasn't ready to do that.

The other three felt that at that particular time in their life they would be able to handle it. For example:

It's easier to have little children and a management job than it is to have little children and be stuck in the middle reporting to people who are telling you what to do.

Eight participants, $20 \%$ of the sample, talked Feelings About Timing/Rightness being an encouraging sub-theme in their decision-making process. For seven of these, the timing encouraged them to seek a promotion.

This was what I was doing and the world unfolded wonderfully when I was now going to have this opportunity.

It was good timing.

That was the next logical step.

One of the eight, however, reported being unsure whether it was the right time or not for a promotion.

I wasn't sure whether it was my time or not.

Seven $(18 \%)$ of the participants considered whether they would have increased workload or stress at the higher level, the Feelings About Workload/Stress sub-theme. Five of these seven individuals were discouraged by concerns about increased workload and stress.

I knew it was more hours, it was even more time.

Well it comes down to workload too as you move up, it's more of an issue. 
The other two felt that they knew what the requirements would be and would not be bothered by them.

I feel I was reasonably aware of what the demands of that job would be and I was pretty confident ... that I could succeed at that level.

I mean with any promotion, not just the most recent, but with any, you always ask yourself, will I have a lot more headaches, a lot more stress, a lot more responsibilities. So you do always think about that, and you hesitate maybe a little bit, but so far l've always said, yah but l'm ready for it, l'm ready to handle those things.

\section{Expected Work Roles}

The theme Expected Work Roles was also important, as half of the sample (twenty individuals) considered issues such as their desire for authority, leadership, or respect/recognition, to be important factors in their decision to seek a promotion. The Expected Work Roles theme included the sub-themes Wanting More Authority/Influence, Wanting More Respect/Recognition, and Wanting to Lead.

Fourteen of the participants (35\% of the sample) cited the sub-theme Wanting More Authority/Influence, expressing a desire for increased authority as something that encouraged them to seek a promotion.

I liked that I would have the responsibility, the control, the opportunity to make decisions.

Originally, why I competed for it, I think was higher level of responsibility, ability to participate in the decision making process and to play a larger role in the policy making.

And the higher the level, the more kind of influential you can be.

The things that motivated me to move into management ... it was mainly a desire for more opportunity to influence.

What encouraged me was certainly the opportunity to provide direction to the programs... That was by far the driving factor. 
Being able to make an impact at a level where you really have some responsibility, some authority to get things done.

I wanted to have the extra responsibilities and be a bit more in control of situations. And be able to make my contribution to the department, because I thought I had the knowledge to be able to do it.

I felt as an EX that you would be more in charge and in control and you would have a few levers in your hands.

As you move up you have more say over how things are done and what's done.

Nine participants cited the sub-theme Wanting More Respect/Recognition, for example wanting to join the respected management group, as something that encouraged them to seek a promotion. This represented $23 \%$ of the sample.

I needed the pat on the back to say, I needed the recognition that I was an EX. I guess I didn't even realize perhaps how exciting and important that is to be able to say you've achieved EX status. You don't sort of realize how successful you are until you get it. Peer recognition, a sense of achievement.

Well I guess it's basically encouraged me, is l'm very committed to [Department]... I have a lot of respect for senior managers ... and I like to be involved in some of those decisions and some of those things. So that I guess has encouraged me to seek promotions. I knew that when I took on the challenges that go along with that job that ...I'd have the support of my peers and the respect in that sense and also the support and guidance of my superiors.

Five (13\%) of the participants talked about the sub-theme Wanting to Lead as something that encouraged their decision to seek a promotion.

It's managing a fairly large group of employees, supervising between 50 and 60 depending. So I really enjoyed working with a group of people, looking at what our objectives are, setting objectives, working together to try to achieve those and hopefully doing so successfully.

I enjoy supervising people. I enjoy motivating and getting teams to work together. 
I have probably some natural aspirations as a leader.

Expectation of Getting the Job

Almost half of the participants $(48 \%, 19$ individuals) considered the theme Expectation of Getting the Job, evaluating their likelihood of receiving the promotion. These considerations were in the form of two sub-themes: Perceiving Opportunities/Signals or Having Successes/Recognition (and therefore feeling confident that they had the reputation to receive the job).

Twelve participants ( $30 \%$ of the sample) said they were encouraged to seek a promotion because they perceived signals from the environment or opportunities being available (the Perceiving Opportunities/Signals sub-theme). It should be noted that two of these participants described waiting for the signals before applying.

Well I guess I was encouraged by senior managers that it was time and that I had a good chance at succeeding, and this position came open.

The opportunity was there. If the opportunity hadn't come I don't know that I would have necessarily been looking at other departments to get it. The door opened and I took it but I wasn't out there looking specifically.

So the lights were all kind of green in terms of the signal.

I thought that the opportunities were there and open and there's no issue with seeking a promotion.

I think that there was a window of opportunity.

I was waiting I guess for the signal of recognition and okay if you think I'm good for the job I'll apply and we'll see.

Five participants mentioned the sub-theme Having Successes/Recognition, feeling encouraged that they had met the requirements for promotion (13\% of the sample). 
I knew that I was more prominent, more sort of recognized because of what this project was accomplishing.

I had gotten extremely good evaluations on the work that was being done and some of the ideas l'd brought in.

I've also had the self confidence to say yes I could do a good job.

I thought I had a pretty solid track record

\section{Receiving Input From Others}

Nineteen (48\%) of the participants talked about input received or perceived from others as being either an encouraging or discouraging theme in their decision to seek a promotion. This Receiving Input From Others theme included the sub-themes Input From Superiors, Input From Spouse/Family and Input From Peers/Staff/Etc.

Fourteen individuals talked about the Input From Superiors sub-theme. Twelve of these 14 participants received only positive input.

Well I guess I was encouraged by senior managers that it was time and that I had a good chance at succeeding.

What has encouraged me to seek a promotion? l've had the support of my ...managers who have said you should try to seek a promotion because you'll do well.

And my director at the time came over and really pointedly asked me if I was going to apply for the competition, and I expressed my uncertainties and my concerns ... and I think he just very bluntly said, the time is now. Just do it. And he said, he encouraged me, you have a very good track record and you have a very good reputation... I was leaning quite strongly to applying anyways, but I think that's what pushed me over the edge. There was a lot of encouragement from my senior managers saying, you know I think you're ready, you should try. 
I guess what really encouraged me was the support that I had from my director at the time... having someone that was behind me all the time encouraging me and bugging me all the time.

I felt that I had the support and in a number of areas, and ... that was a big. If I didn't feel that I had the support I wouldn't have gone.

A little bit of encouragement and some positive signals from my supervisors in giving me the green light and saying that you are ready. I think that would be the single most influencing factor.

Two individuals received discouraging negative input from some superiors, but also encouraging positive input from others.

He said flatly, you will never be a Director at [Department], don't bother... then I went to talk to other people, other mentors and they encouraged me.

Other bosses ... championed me and had told me many times personally that I could do it. So that to me was critical, not only to know that I can do it, but other people out there actually agreed with that.

The Input From Peers/Staff/Etc sub-theme was mentioned by nine participants, who discussed receiving support from peers, staff, external contacts, general support in the environment, or did not specify who they received input from. All nine (23\%) of the participants mentioned only encouraging input.

You also feel you have to do it because everyone around you tells you should do it, you'll get it, you're good, you should try. So you feel a bit of that pressure.

People who I respect also encouraged me to go for it. They told me... if you're ready, you should try it and hope for the best.

I had all kinds of encouragement and support from colleagues and staff and family. I had the support of colleagues 360 , all around.

If you hear enough times people saying you should do this, you would make a good director someday, go to the next step, then it starts to sink in. 
There was a feeling and a consensus around that I was ready for it and that I had a lot to contribute.

Five participants (13\% of the sample) were encouraged by input from their spouse or family.
A lot of family support. My wife was very, very supportive and my parents as well.
It does come down to the spouse, family, friends, relatives, everybody, I think you're expected to achieve certain things and l'm sort of just fulfilling what I think is their expectations of me.

In two cases, the spouse had (discouraging) concerns about the participant seeking a promotion, but then was later supportive. For example:

My husband was more, why don't you stay where you are, we have a good balanced life, why do you want to get all that stress?

\section{Strategic Decision-making}

Fifteen of the participants mentioned a theme of Strategic Decision-Making, considering strategic comparisons between the outcomes of applying and not applying in their decision to seek a promotion. This represented $38 \%$ of the sample. The comparisons fell into three sub-themes: Feelings About the Process (deciding whether it is worth going through the promotion process), Comparison to Position Would Be Leaving (comparing the characteristics of the current job to the new one) and Preventing Others From Getting the Job (comparing who else might receive the promotion if the participant did not apply).

Eight (20\%) of the participants considered the sub-theme Feelings About the Process in their decision about whether to seek a promotion. Facing the promotion 
process was discouraging for seven participants. The process was encouraging for one participant because it had changed.

There's also a fear that a lot of people have that when you go to one of these boards, there's a whole bunch of important people sitting there, and if you really mess up then you've had it.

Well the process is gruesome.

It's a very, very stressful experience. I found it very stressful to go through the board... You're being evaluated by... your management that you very much respect and you're hoping that they'll support you and you don't know what they're thinking. The waiting period... it's long. You see those people and you know they know and they're not telling you.

Seven participants talked about the sub-theme Comparison to Position Would Be Leaving ( $18 \%$ of the sample). Four were encouraged to apply by the comparison (one had mixed feelings and thus falls into both groups).

But if you're an $A D$, or even a DG ... you don't have as much power. ... you had to do the management of it but you didn't really get to call the shots, your boss called the shots... So that was a motivator to get out of the $A D$ level.

One of the factors that has encouraged me is the fact that I think one of the most important things for me at work is who I work for. ... and I was in one of those situations at the time, where I didn't have a great deal of respect for the person who I was working for, ... and I decided to apply for the director's job ... because I wanted to be master of my own fate and change that.

So you had to look at the future and say are you ready to stay at this level for another 10 years. You're happy now but will you be.

Four participants were discouraged from seeking a promotion by the comparison. I was having a very, very good time where I was. 
Four (10\%) of the participants talked about being encouraged to apply for a promotion by the Preventing Others From Getting the Job sub-theme.

I didn't want to be managed by the people I thought were the alternatives.

I thought, you know, better for me to be in a position that I can influence than to let these other people call the- there's a few people that, do I want to work for this person, do I want this person to be my director?

I applied for this most recent job because I looked at the people who I could possibly end up working for and I thought I would rather work directly for the [skip level] than work for someone intervening who was going to cause me stress, so I applied for it. So it was self protection.

Expected outcomes of the new work

In their decisions to seek a promotion, fourteen participants considered the Expected Outcomes of the Work theme. This theme, which represented 35\% of the sample, included only one sub-theme: Feelings About Ability to Contribute. This was an encouraging theme for thirteen individuals, often in the form of wanting to be able to make a larger contribution by moving to a higher level.

I felt like I had something to contribute to the organization. I felt like that was a level I could work effectively at in terms of having impact, and having impact frankly is part of where the satisfaction lies... just generally being able to make an impact at a level where you really have some responsibility, some authority to get things done.

I thought I could make a contribution.

As much as anybody had power to make a division a success, the director has that power. And I wanted to try that.

I also thought that I had a lot to offer, I had ideas. 
I wanted to see if I could make a difference ... because of my vision of where the organization should go, in a position where I actually had the power to make that vision a reality.

So at one level you can influence 10 people, the next level you can influence 50 or 100 .

So what do you say has more impact.

Because I think I can change something. That's all. It's the only reason.

One individual voiced concerns about not being able to contribute in a given position or level.

I don't think that you can be very good everywhere.

Importance to Self of Applying

Seven participants, or $18 \%$ of the sample, weighed the importance of applying versus not applying when making their decision to apply for a promotion (the Importance to Self of Applying theme). In this theme, participants were communicating how much emotional importance they had placed on gaining the promotion, and how that affected their decision to seek a promotion. The Importance to Self of Applying theme included two sub-themes: Giving It a Try and Wanting the Job.

Four individuals $(10 \%$ of the sample) were encouraged to seek a promotion by the idea of Giving It a Try.

It just seemed like a good idea at the time.

I decided to try it.

I will at least try. If it doesn't work, I have nothing to lose.

Three participants were encouraged by their desire for the job (the Wanting the $J o b$ sub-theme). This represented $8 \%$ of the sample.

It was something I wanted to do. 
It's really do I want the job.

\subsubsection{Other interesting findings about the decision to seek a promotion}

Strauss and Corbin's (1998) coding paradigm was used to structure and make sense of the themes emerging from the data, leading to some interesting findings about how participants discussed their decision to seek a promotion, beyond the themes and sub-themes they considered in the decision. These findings can be used to better understand how the participants think about career-related decision-making. The interim process model developed as part of this stage is shown in Appendix C.

The participants showed evidence of some decision-making behaviours they had used while they were in the process of making the decision to seek a promotion. Fifteen of the forty participants (37.5\%) mentioned weighing the pros and cons, twelve (30\%) ranked some themes as more important than others, eight (20\%) enlisted the advice or help of others, six $(15 \%)$ identified a backup or escape plan in case they were unhappy with the outcome of their decision, and four $(10 \%)$ expressed putting thought into their decision. It is believed that this is a very important finding, and that the role of decisionmaking behaviours should be incorporated into the final model in this study as it shows a stage in the decision-making process not found in the proposed model.

The participants also clearly recognized the influence of various individual and situational characteristics on their decision-making. Individuals gave contextualizing information about individual characteristics such as personality (9 individuals, $22.5 \%$ ) and gender ( 2 individuals, $5 \%$ ). Others spoke about situational characteristics such as their colleagues, workplace or field (16 individuals, 40\%) or their families ( 3 individuals, 
7.5\%). Again, participants perceived norms in the themes of the decision to seek a promotion, and some specifically mentioned that money was not a theme in their decision (6 individuals, 15\%). These situational and individual characteristics correspond to the findings from the career-related decision-making literature. Situational characteristics are already included in the proposed model, but these findings argue for including individual characteristics as well.

Additionally, it was very common for the participants to make reference to or tell stories about past work-related experiences, as a way to expand on and explain the themes they used in their decision to seek a promotion. This tendency, done by twentyfive participants $(62.5 \%)$, may reflect the fact that individuals recognize the inscrutability or intuitive nature of this process, and attempt to "capture" the feeling of the decision process through story telling. Four participants $(10 \%)$ also noted how they felt about the outcome of their promotions. These findings provided some additional insight into how participants relate to the decision to seek a promotion construct and the decision-making process itself.

\subsection{Is there a relationship between a public servant's definition of career success and the factors they describe taking into account when deciding whether to seek a promotion?}

This section will first explain how the researcher tested for a relationship between subjective career success and the decision to seek a promotion by identifying matches between the themes and sub-themes. This explanation is followed by a description of the results of this matching process and an evaluation of whether or not these results support 
the assertion that there is a relationship between subjective career success and the decision to seek a promotion constructs.

\subsubsection{How the theme and sub-theme matches were identified}

The relationship between how respondents subjectively defined career success and factors they considered when deciding whether or not to seek a promotion was tested in two ways. The first approach uses the principles of grounded theory (i.e. inspection, constant comparison and continued abstraction) to identify which themes and sub-themes appeared to match. As described earlier, the grounded theory analysis identified five themes and 17 sub-themes for subjective career success (Section 5.1) and nine themes and 25 sub-themes for the decision to seek a promotion (Section 5.2). In order to test whether there was a relationship between subjective career success and the decision to seek a promotion, it was necessary for the researcher to identify:

- which of the 17 sub-themes in subjective career success described the same issues as the 25 sub-themes in the decision to seek a promotion, and

- which of the five career success themes described the same issues as the nine decision to seek a promotion themes.

The researcher first matched the sub-themes using constant comparison to see whether both the sub-theme construct and the source data were consistent between the participant's definition of subjective career success and the factors they considered when deciding to seek promotion. This process was repeated for each participant in the sample using the sub-theme data, and then for each participant using the theme data. In certain cases, when the source data for two matched sub-themes (or themes) were compared, 
some of the quotations appeared to deal with the same issues, but other quotations did not. In these cases the outlier quotations were re-coded into a new or different sub-theme (or theme). ${ }^{10}$

Figure 5-5 shows the results of the grounded theory based matching process. All five themes found in subjective career success were matched to a theme in the decision to seek a promotion. Four decision to seek a promotion themes that were not matched to subjective career success themes. These are not shown on the diagram.

The five subjective career success themes contained 17 sub-themes. The five matched themes in the decision to seek a promotion contained 15 sub-themes. All are shown on the diagram (although only 13 of these sub-themes are matched) because the statistical tests at the theme level included all of the participants coded at that theme (and thus coded at any sub-theme within that theme); they did not include only the participants coded at the matched sub-themes.

${ }^{10}$ For example, the decision-making sub-themes Feelings About Work-Life Balance Fit and Feelings About Workload/Stress were originally coded as the same sub-theme. During the matching process, however, it became clear that the comments in the Feelings About Work-Life Balance Fit sub-theme (of decision-making) matched with those in Having Work-Life Balance Fit sub-theme (of subjective career success), but the comments in the Feelings About Workload/Stress sub-theme did not. Therefore, they were separated into separate sub-themes. 


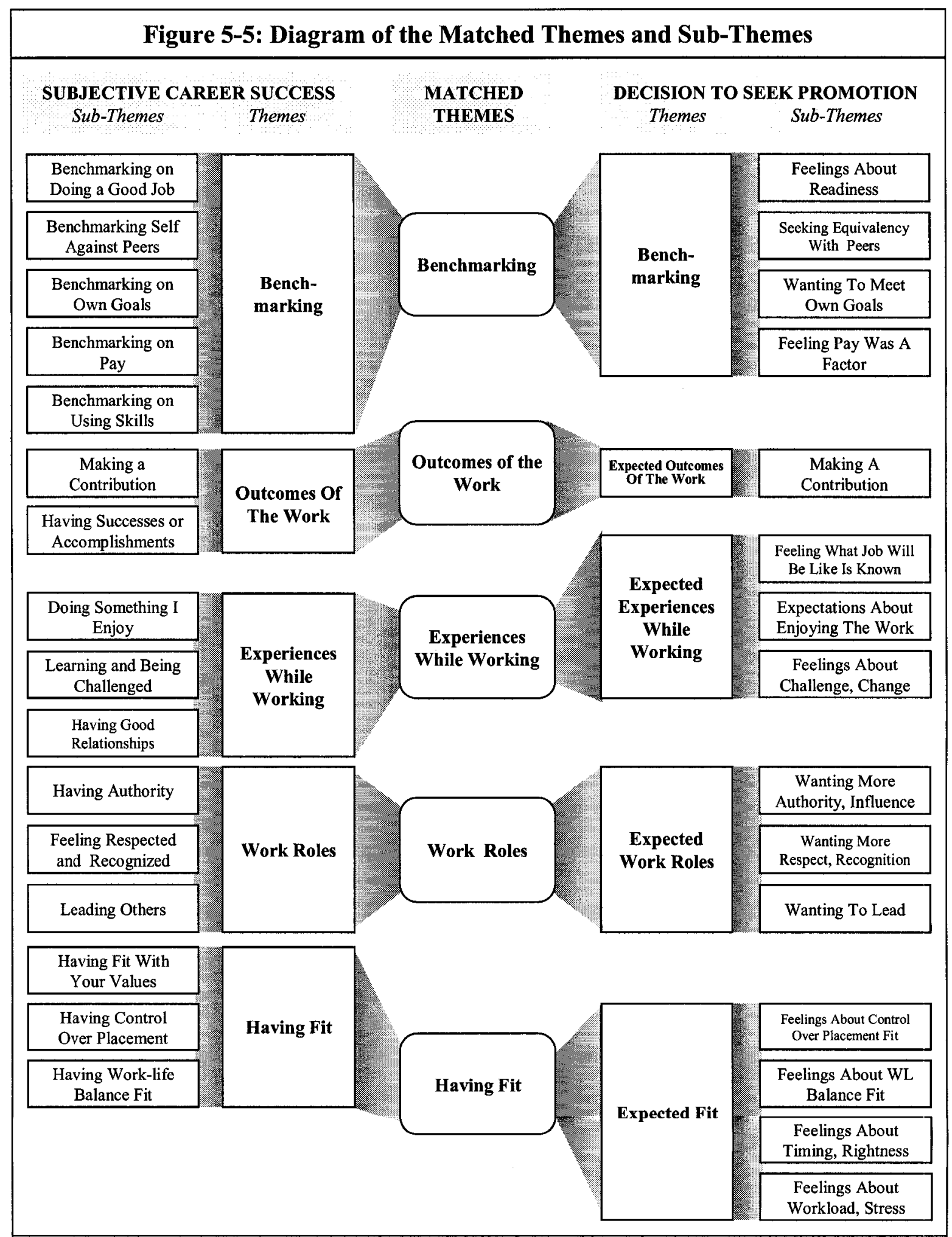


The second methodology used to test for matches was a simple quantitative analysis. The researcher calculated the percentage of individuals who mentioned a given theme (or sub-theme) in both their definition of career success and in their decision to seek a promotion, compared to the total number of individuals who mentioned that theme at all. As the example in Figure 5-6 shows, 29 individuals mentioned a theme of Benchmarking in their definition of career success, while 26 individuals mentioned this theme in their decision to seek a promotion. ${ }^{11}$ Examination of the data shows that the total number of participants who mentioned this theme in either category was 36 . Out of these 36 individuals, 19 people (53\% of the sample) mentioned this theme in both their definition of career success and in their decision to seek a promotion. These individuals can be considered to have a "match" for the theme of Benchmarking. On the other hand, seven of the individuals (47\%) who mentioned the Benchmarking theme in this study only mentioned it in their definition of career success or in their decision to seek a promotion, but not in both. These individuals were not, therefore, considered to have a match for the Benchmarking theme.

Although this quantitative analysis is not a statistical test, it can be used to give some indication of how often matches occurred in these semi-structured, open-ended interviews. This gives some indication as to whether a study with structured items might find a statistically significant number of matches.

${ }^{11}$ It should be noted that this analysis counted the number of individuals who mentioned a certain theme or sub-theme at all, not the number of references they made to this theme or sub-theme. Therefore, an individual who mentioned two sub-themes of the Benchmarking theme in their definition of career success (such as Benchmarking on Pay and Benchmarking Self Against Peers) was only counted as one instance of the Benchmarking theme in the subjective career success category. 
When interpreting the findings, higher matches were considered to be more compelling. While themes and sub-themes with $50 \%$ or higher matches are particularly convincing, themes with match rates of at least $30 \%$ were still considered to be indicative of a relationship between subjective career success and the decision to seek a promotion.

Figure 5-6: Example Showing the Proportion of Individuals with Theme Matches

40 participants

in total

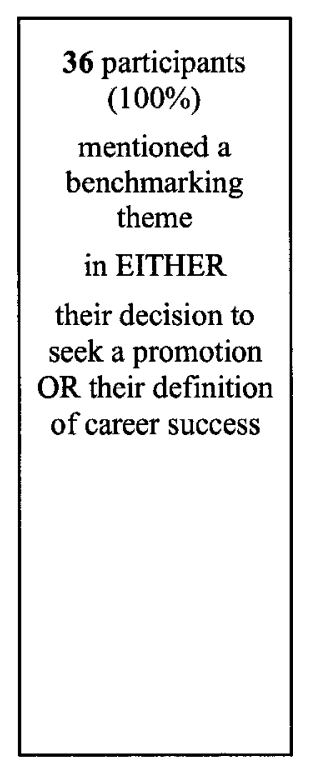

19 out of 36 participants $(53 \%)$

mentioned a benchmarking theme in BOTH their decision to seek a promotion AND their definition of career success

7 out of 36 participants $(47 \%)$ mentioned a benchmarking theme

in EITHER their decision to seek a promotion or their definition of career success BUT not in both

\subsubsection{Results of the matching process}

This section reports on the results of the matching process described above, including the percentage of matches found for each theme and sub-theme. Table 5-3 shows the number of matches found for the themes and sub-themes used in this analysis. The number of matches is " $\mathrm{n} / \mathrm{a}$ " in cases where a certain sub-theme existed only in the decision to seek a promotion or only in the subjective definition of career success. 
This section will also provide some examples of the statements made by participants who had matches between the themes they stated in their definition of career success and their description of factors influencing their decision to seek a promotion. Not only will sub-theme matches be presented, but also cases where an individual had a match at the theme level but not at the sub-theme level. This is intended to give the reader a richer sense of the theme and sub-theme matches. 
Table 5-3: Frequency of Occurrences of Theme and Sub-theme Matches

\begin{tabular}{|c|c|c|c|c|c|}
\hline & $\begin{array}{l}\text { Decision to } \\
\text { seek } \\
\text { promotion } \\
\text { Individuals who } \\
\text { mentioned theme in } \\
\text { this category }\end{array}$ & $\begin{array}{c}\text { Subjective } \\
\text { career success } \\
\text { Individuals who } \\
\text { mentioned theme in } \\
\text { this category }\end{array}$ & \begin{tabular}{|c|}
\multicolumn{1}{c|}{ Total } \\
Individuals who \\
mentioned theme \\
in either category
\end{tabular} & $\begin{array}{l}\text { Matches } \\
\text { Individuals who } \\
\text { mentioned theme } \\
\text { in both categories }\end{array}$ & $\begin{array}{l}\text { Percent matches } \\
\text { out of total } \\
\text { Individuals who mentioned } \\
\text { theme in both categories } \\
\text { compared to those who } \\
\text { mentioned it in either }\end{array}$ \\
\hline Benchmarking & 29 & 4.26 & 36 & 19 & $53 \%$ \\
\hline Goals & 4 & 16 & 17 & 3 & $18 \%$ \\
\hline Pay & 6 & 8 & 13 & 1 & $8 \%$ \\
\hline Ability to Do a Good Job & 24 & 7 & 26 & 4 & $15 \%$ \\
\hline Peer Equivalency & 9 & 4 & 11 & 2 & $18 \%$ \\
\hline $\begin{array}{l}\text { Appropriate Use of Your } \\
\text { Skills }\end{array}$ & no match & 3 & $n / a$ & $n / a$ & $n / a$ \\
\hline $\begin{array}{l}\text { Experiences While } \\
\text { Working }\end{array}$ & 29 & 33 & 37 & 25 & $68 \%$ \\
\hline Enjoyable Work & 21 & 26 & 31 & 16 & $52 \%$ \\
\hline Challenge & UYu 11 & 15 & 19 & 7 & $37 \%$ \\
\hline $\begin{array}{l}\text { Having Good } \\
\text { Relationships }\end{array}$ & no match & 11 & $n / a$ & $n / a$ & $n / a$ \\
\hline $\begin{array}{l}\text { Feeling What Job Will Be } \\
\text { Like is Known/Unknown }\end{array}$ & 10 & no match & $n / a$ & $n / a$ & $n / a$ \\
\hline Having Fit & 26 & 12 & 30 & 8 & $27 \%$ \\
\hline Work-Life Balance & 8 & 7 & 13 & 2 & $15 \%$ \\
\hline $\begin{array}{l}\text { Control Over Placement } \\
\text { Fit }\end{array}$ & 16 & 5 & 19 & 2 & $11 \%$ \\
\hline $\begin{array}{l}\text { Having Fit With Your } \\
\text { Values }\end{array}$ & no match & 4 & $n / a$ & $n / a$ & $n / a$ \\
\hline Right Timing & 8 & no match & $n / a$ & $n / a$ & $n / a$ \\
\hline $\begin{array}{l}\text { Feelings About } \\
\text { Workload/Stress }\end{array}$ & 5 & no match & $n / a$ & $n / a$ & $n / a$ \\
\hline Work Roles & 20 & 14 & 27 & 7 & $26 \%$ \\
\hline Recognition/Respect & 9 & 11 & 19 & 1 & $5 \%$ \\
\hline Authority & 14 & 4 & 16 & 2 & $13 \%$ \\
\hline Leading & 5 & 3 & 6 & 2 & $33 \%$ \\
\hline Outcomes of the Work & 14 & 21 & 28 & 9 & $32 \%$ \\
\hline Making a Contribution & 14 & 21 & 26 & 9 & $35 \%$ \\
\hline $\begin{array}{l}\text { Having Accomplishments } \\
\text { or Successes }\end{array}$ & no match & 3 & $n / a$ & $n / a$ & $n / a$ \\
\hline
\end{tabular}




\section{Benchmarking}

In the Benchmarking theme, 19 individuals matched at the theme level. Only the theme level had a high percentage of matches (53\%). Within the Benchmarking theme there were four sub-themes that matched in both research categories: Goals, Pay, Ability to Do a Good Job, and Peer Equivalency. In all cases, however, the sub-themes all had a relatively low percentage of matches (i.e. Goals and Peer Equivalency both matched in $18 \%$ of cases; Ability to Do a Good Job matched in $15 \%$ of cases, and Pay matched in only $8 \%$ of the cases). Finally, it is interesting to note that one sub-theme, Appropriate Use of Your Skills, was only mentioned in association with definitions of career success.

In some cases, the individual had matches at both the theme and sub-theme level. In the first example below, the response was coded for the Benchmarking theme, and also for the sub-theme Peer Equivalency:

Career success definition: My definitions of career success include... peer equivalency, and this is important in my lifestyle anyway, when I look across the organization, that I feel I'm being fairly and justly paid, I have the same prestige, I have the same travel, visibility opportunities, etc.

Decision to seek a promotion: The main factor that encourages me to seek promotion is where I see myself... I've also equated myself with my peers.

A second example of matches at both the theme and sub-theme level shows the data which represents a response which was coded for the Benchmarking theme and for the Goals sub-theme:

Career success definition: I think I'm doing pretty good in terms of trying to achieve what my vision of myself is in terms of my career success, anyway... my goal is to reach the EX level. 
Decision to seek a promotion: What motivated me? My ultimate goal is to be in the executive level, that has always been my goal.

In other cases, there was a theme match, but no sub-theme match. For example, one respondent mentioned the Benchmarking theme in both cases, but the benchmarking criteria when defining career success was not the same examined when deciding on whether or not to take a promotion. This individual defined career success in a sub-theme of Goals. The decision to seek a promotion, on the other hand, was based on the subtheme of Ability to Do a Good Job.

Career success definition: Well I guess sort of on a subconscious level I had set some objectives for myself, and that was to become a director.

Decision to seek a promotion: I knew I was very competent in my job and that I could take on those duties.

\section{Experiences While Working}

The Experiences While Working theme had 25 matches (68\% of possible matches) at the theme level. This was the highest match rate found in this thesis.

Within the Experiences While Working theme, there were only two matched subthemes: Enjoyable Work (with 52\% matches) and Challenge (with 37\% matches). Both of these matches appear to be substantive. The other two sub-themes, Having Good Relationships (a sub-theme of subjective career success) and Feeling What Job Will Be Like is Known/Unknown (a sub-theme of the decision to seek a promotion) did not have matching sub-themes.

As in the example below, some of the participants had matches at both the theme level (Experiences While Working) and the sub-theme level (Enjoyable Work): 
Career success definition: I guess it means doing what I like.

Decision to seek a promotion: Top one is the interest for the job.

In other cases, such as the example provided below, although respondents had subjective career success and decision to seek promotion responses that were both coded in the Experiences While Working theme, they described a different sub-theme when defining subjective career success (i.e. Challenge) than they were when making the decision to seek a promotion (i.e. Feeling What Job Will Be Like is Known/Unknown).

Career success definition: Well l'd like a sustained self development and growth. To be a bit more specific for me that means that over time I can take on and successfully manage more complex, more expansive projects

Decision to seek a promotion: There's always a little bit of what does this mean, what ladder am I climbing onto now and where is it going to lead? A little bit of that unknown.

\section{Having Fit}

Only eight $(27 \%)$ matches were observed at the theme level when considering the Having Fit theme. This is consistent with the fact that at the sub-theme level, only two matches were observed: Work-Life Balance (15\%), and Control Over Placement (11\%). In both cases, the percent matching was not substantive. For the remaining three subthemes within the Having Fit theme, individuals only mentioned the sub-theme in conjunction with subjective career success (Having Fit With Your Values) with respect to the decision to seek a promotion (Right Timing and Feelings About Workload/Stress).

The quotes below are provided to illustrate these patterns. The first example shows a match on the sub-theme Work-Life Balance: 
Career success definition: For me career success had been following what I think is the right thing to do at the right time for the right reasons, that basically fit within my own life successfully.

Decision to seek a promotion: The biggest I guess discouragement to this is the fact that you really have no say as to where you're put...and it makes it much harder to then balance the home responsibilities.

The second example shows a match at the Having Fit theme level but different sub-themes for the definition of career success (Work-Life Balance) and the decision to seek promotion (Feelings About Workload/Stress):

Career success definition: l'm trying to achieve success in the public sector but trying also to have a certain balance with my personal life.

Decision to seek a promotion: There was the fact that I knew it was more hours, it was even more time.

Work Roles

For the Work Roles theme, there were 7 theme level matches (i.e. 26\% matches). Within the Work Roles theme there were three sub-themes that matched: Leading (33\% matches), Recognition/Respect (5\% matches) and Authority, (13\% matches). Only the first of these, Leading, is substantive enough to note.

As in the example below, some of the participants had matches at both the theme level (Work Roles) and the sub-theme level (Leading):

Career success definition: For me it's not only being the smart one, or the smart person leading a group, but this is another aspect, being able to exercise leadership with your group and also being able to be respected by your peers, your employees, your colleagues, your superiors. 
Decision to seek a promotion: You participate in more strategic planning meetings, you supervise a team of professionals, you're more worried about the day to day operation of things.

In other cases, the participants had a match at the Work Roles theme level but had different sub-themes for the definition of career success (Recognition/Respect) and the decision to seek promotion (Authority):

Career success definition: I started out with the view that l'm going to become an expert in this area and that's how I define success.

Decision to seek a promotion: I also thought that I had a lot to offer, I had ideas, thought the program needed to budge this way or that way.

\section{Outcomes of the Work}

For the Outcomes of the Work theme there were nine matches at the theme level. In other words, one in three of the responses (or 32\%) given in terms of subjective career success matched to those given in terms of decision to seek a promotion. There were two sub-themes within the Outcomes of Work theme: Making a Contribution (35\% matches) and Having Accomplishments or Successes, which was only mentioned in conjunction with the decision to seek a promotion (i.e. no match).

An example of the responses given when a respondent matched at the Making a Contribution sub-theme is given below:

Career success definition: It's waking up every morning and being happy and enthusiastic about what you're doing and feeling that you're contributing.

Decision to seek a promotion: I thought I could actually make a contribution to the organization. 


\subsection{To what extent do the data bear out the model proposed by the researcher?}

This question will be answered by a review of how the research findings compare to the literature, and the model developed from the literature.

\subsubsection{Findings compared to the subjective career success literature}

This study provides support for most of the findings reported in the subjective career success literature. It also identifies a number of results not previously reported in the literature. Key areas of consistency as well as discrepancies are noted below.

There was support for the operational definitions of subjective career success used in the literature, although these reflected only a sub-set of the definitions given by participants. Judge et al (1995) defined subjective career success as being current job satisfaction and career satisfaction, based on Locke's definition "a pleasurable or positive emotional state resulting from an appraisal of one's job or job experiences" (1976, p. 1300). Although participants certainly appraised their job and job experiences, they did not focus much on the emotional outcome of this appraisal. The career satisfaction element of Judge et al's (1995) operational definition of subjective career success was found in this study, as participants did refer to "pay, advancement, and developmental opportunities" (Judge et al, 1995, p 487), when talking about career success. Ng et al's (2005) definition of career success was also supported, as individuals did mention their "subjective judgments about their career attainments" ( $\mathrm{Ng}$ et al, 2005, p. 368-9) when talking about how they defined career success.

While the findings from this study support the operational definitions of subjective career success used by researchers, this investigation suggests that researchers 
are simplifying this construct. This assertion is supported by comparing the richer and broader definitions of career success provided by employees in this sample to the definitions of subjective career success in the literature. The differences between the literature and the findings from this grounded theory study highlight the very different perspectives researchers and employees have when they think about subjective career success.

Figure 5-7 below, shows how the career success themes and sub-themes found in this study (shown on the right hand side and the centre of the diagram) compare to the factors suggested by the literature as influencing subjective career success (shown on the left hand side of the diagram). With three exceptions (personality, demographic, and organizational/regional/industrial variables), the factors mentioned in the literature as influencing definitions of career success (human capital, objective career success, selfreferent, other-referent, job-related, and work-life balance variables) were observed to varying degrees in this research. There were, however, differences in emphasis and richness that point to the different perspectives of researchers and participants when looking at this topic. These differences also point to the advantage of using a grounded theory approach to this issue. This section will review how each of the nine factors identified in the literature compares to the themes and sub-themes found in this study. 
Figure 5-7: Comparison of Career Success Factors Found In the Literature To Themes And Sub-Themes Found In This Study

\begin{tabular}{|c|c|c|}
\hline $\begin{array}{l}\text { FROM THE } \\
\text { LITERATURE }\end{array}$ & SUB-THEMES & \multirow[t]{4}{*}{ THEMES } \\
\hline Personality & Not tested & \\
\hline Demographic & Gender will be examined in Section 5.5. & \\
\hline \multirow{2}{*}{ Human capital } & Level will be examined in Section 5.s. & \\
\hline & Benchmarking on Using Skills & \multirow{5}{*}{ Benchmarking } \\
\hline \multirow{2}{*}{$\begin{array}{c}\text { Objective career } \\
\text { success }\end{array}$} & Benchmarking on Pay & \\
\hline & Benchmarking on Goals & \\
\hline Self-referent & Benchmarking on Doing a Good Job & \\
\hline Other-referent & Benchmarking Self Against Peers & \\
\hline \multirow{9}{*}{ Job-related } & $\frac{\text { Making a Contribution }}{\text { Having Accomplishments or Successes }}$ & $\begin{array}{l}\text { Outcomes of the } \\
\text { Work }\end{array}$ \\
\hline & Doing Something I Enjoy & \multirow{3}{*}{$\begin{array}{c}\text { Experiences While } \\
\text { Working }\end{array}$} \\
\hline & Learning and Being Challenged & \\
\hline & Having Good Relationships & \\
\hline & Feeling Respected/Recognized & \\
\hline & Having Authority & Work Roles \\
\hline & Leading Others & \\
\hline & Having Control Over Placement & \\
\hline & Having Fit With Your Values & Having Fit \\
\hline Work-life balance & Having Work-life Balance Fit & \\
\hline $\begin{array}{c}\text { Organizational / regional / } \\
\text { industrial }\end{array}$ & Not tested & \\
\hline
\end{tabular}


Personality and demographic factors

In this study, the personality and demographic variables described by researchers were not readily apparent in the form of themes, although they were hinted at by some of the participants' contextualizing statements that were discussed in Section 5.1.1. This finding is not particularly surprising since it is likely that participants are not consciously aware of how their personality affects their definition of career success. One of the demographic variables, gender, was expected to influence the definition of career success, based on the literature. This was only partially supported, as will be discussed further in Section 5.5.1.

\section{Human capital factors}

Human capital factors were only seen in the desire of some participants to do work in line with their education. The other human capital factors found in the literature, such as level of education or ambition (Judge et al, 1995), were not seen here. Based on the literature, it would be expected that level should have an influence on the definition of career success, as it is one element of human capital. This was not found to be the case, however, as will be discussed in more detail in Section 5.5.

\section{Objective career success factors}

This study also provides some support for the idea that objective career success is part of subjective career success. For example, Judge et al's (1995) and Ng et al's (2005) concept of objective career success - as both pay and promotions - was apparent in the participants' personal definitions of career success. This research also extends the 
conceptualization of objective career success by recognizing that employees use the concept of "having authority" as an indicator of hierarchical level in the organization. Other researchers could consider using authority as an indicator of career success in future studies.

\section{Self-referent and other-referent factors}

The literature also suggests that individuals define career success based on otherreferent and self-referent factors, such as those discussed by Heslin (2003) and Judge et al (1995). The grounded theory analysis in this study, however, suggests that the selfand other-referent categories are not distinct from the other categories, as a number of the themes identified in this study could be included in either the self- or other-referent grouping and in another grouping. For example, the sub-theme Making a Contribution (in the theme Outcomes of the Work) is similar to the job-related factors found in the literature. Listening to how participants describe this sub-theme, however, suggests that they also measure this theme based on other-referent factors. For example, individuals appear to judge their contribution by comparing themselves to rubrics based on their own (self-referent) and other people's (other-referent) contributions, as well as the contributions expected in the job (job-related). As such, it was decided that the Benchmarking themes found in this study were closest to the self- and other-referent categories found in the literature. The other themes found in this study (that could have been grouped in the self- or other-referent category) were placed in the other categories as appropriate. 
Job-related factors

Job-related factors were very important to participants and discussed in much more detail than in the literature. Dyke and Orser (2005) suggested rewarding work and community impact were important components of subjective career success, and these clearly line up with the responses given here. No other job-related variables were proposed by researchers. The literature is in stark contrast to this study, where the vast majority of themes related to definitions of career success fall within the job-related category (including the Outcomes of the Work, Experiences While Working, and Work Roles themes, as well as part of the Having Fit theme). Again, this appears to be an important contribution of this study as it expands our concept of subjective career success. It also suggests that researchers may make better progress in understanding subjective career success if they focus more on job-related variables. This finding also demonstrates the value of employing a grounded theory approach in this type of research.

\section{Work-life balance factors}

The Work-Life Balance sub-theme of the Having Fit theme found in this study is roughly similar to the work-life balance factors found in the literature. Work-life balance variables suggested by Dyke and Orser (2005) included balanced life and personal wellbeing. Participants in this study were concerned with ensuring a fit between their work and life, including reasonable workload and reasonable stress levels, although they did not discuss personal well-being in detail. 


\section{Organizational/regional/industrial factors}

Judge et al (1995) included organizational, regional, and industrial variables in their analysis. $\mathrm{Ng}$ et al (2005) included organizational variables in the form of organizational sponsorship, and Dyke and Orser (2005) included them in the form of organizational performance. None of these elements was particularly visible in the participants' comments, with one exception. This organization uses a generic pool model for placing its managers, such that they may be rotated to another area as needed. This organizational characteristic may have influenced the appearance of the sub-theme Having Control Over Placement sub-theme that was mentioned by five participants $(12.5 \%)$ in this study.

\subsubsection{Findings compared to the career decision-making literature}

This research supported most of the findings from the career decision-making literature, although it also resulted in a number of findings not previously reported in the literature. The literature did not provide an operational definition of the decision to seek a promotion, so it was not possible to compare this to the results of this study. Figure 5-8 shows how the decision to seek a promotion themes found in this study compare to the factors suggested by the literature. Most of the factors suggested in the literature were borne out by the study. It should be noted, however, that very few studies could be found that focussed on this issue specifically and not much is known about how the decision to seek a promotion is made. The grounded theory approach used here has resulted in a much more comprehensive understanding of the factors considered when seeking a promotion than what is available in the literature. 


\begin{tabular}{|c|c|c|}
\hline \multicolumn{3}{|c|}{$\begin{array}{l}\text { Figure 5-8: Comparison of Career Decision-making Factors Found In the Literature } \\
\text { to Themes and Sub-Themes Found In This Study }\end{array}$} \\
\hline \multirow{3}{*}{$\begin{array}{l}\text { FROM THE } \\
\text { LITERATURE }\end{array}$} & SUB-THEMES & THEMES \\
\hline & Input From Superiors & \multirow{3}{*}{ Input From Others } \\
\hline & Input From Peers/Staff/Etc & \\
\hline \multirow{2}{*}{$\begin{array}{l}\text { Demographic } \\
\text { Spouse }\end{array}$} & Input From Spouse/Family & \\
\hline & Gender will be excumined in Section 5.5 . & \\
\hline \multirow[t]{5}{*}{ Human capital } & Level will be examined in Section 5.5 . & \\
\hline & Feelings About Readiness & \multirow{4}{*}{ Benchmarking } \\
\hline & Seeking Equivalency With Peers & \\
\hline & Wanting to Meet Own Goals & \\
\hline & Feeling Pay Was a Factor & \\
\hline \multirow{8}{*}{ Job-related } & Making a Contribution & $\begin{array}{c}\text { Expected Outcomes } \\
\text { of the Work }\end{array}$ \\
\hline & Expectations About Enjoying the Work & \multirow{3}{*}{$\begin{array}{l}\text { Expected Experiences } \\
\text { While Working }\end{array}$} \\
\hline & Feelings About Challenge/Change & \\
\hline & Feeling What Job Will Be Like is Known/Unknown & \\
\hline & Wanting More Authority/Influence & \multirow{3}{*}{ Expected Work Roles } \\
\hline & Wanting More Respect/Recognition & \\
\hline & Wanting To Lead & \\
\hline & Feelings About Control Over Placement Fit & \multirow{4}{*}{ Expected Fit } \\
\hline \multirow{3}{*}{ Work-life balance } & Feelings About Timing/Rightness & \\
\hline & Feelings About Work-Life Balance Fit & \\
\hline & Feelings About Workload/Stress & \\
\hline \multirow{7}{*}{ Organizational } & Having Successes/Recognition & \multirow{2}{*}{$\begin{array}{l}\text { Expectation of } \\
\text { Getting the Job }\end{array}$} \\
\hline & Perceiving Opportunities/Signals & \\
\hline & Feelings About the Process & \multirow{3}{*}{$\begin{array}{l}\text { Strategic Decision- } \\
\text { Making }\end{array}$} \\
\hline & Comparison to Position Would Be Leaving & \\
\hline & Preventing Others From Getting the Job & \\
\hline & Giving It a Try & \multirow{2}{*}{$\begin{array}{l}\text { Importance of } \\
\text { Applying }\end{array}$} \\
\hline & Wanting the Job & \\
\hline
\end{tabular}




\section{Demographic/spouse variables}

The demographic variables suggested in the literature were found to some extent in this study. The marital status variables suggested by Cassirer and Reskin (2000) were supported by the participants' responses regarding their spouses' input into the decision to seek a promotion (Input From Spouse/Family sub-theme). Gender (which will be discussed in more detail in Section 5.5) was not found to be very influential overall. No other demographic variables were apparent in the data.

\section{Human capital factors}

Only one human capital factor predicted by the literature was seen in this study: level in the hierarchy. The literature predicts that level, as one aspect of human capital, should have an influence on the career-related decision-making. This was not found to be the case. Further details on the impact of level are given in Section 5.5. Powell and Mainiero (1992) also include work motivation and career choices in their human capital variables, and suggest that these would have an influence on decisions. This hypothesis was not supported by this study.

It is likely that these two factors found in the literature but not in the study (demographic and human capital variables), form part of the context that influences the relationship between subjective career success and the decision to seek a promotion. This study suggests, however, that employees are not objectively aware of the impact of these factors on their decisions to seek a promotion. 
Job-related factors

Job related factors were discussed in far more detail by the participants in this study than they were by researchers. There was, however, some support for those jobrelated themes that were identified in the literature. Liff and Ward (2001) suggested three variables that influence individuals' decisions: level of knowledge about what the job entailed, routes to promotion, and perceptions of commitment required. These items were all found in this study. In addition, there were a substantial number of themes that are linked to job characteristics, but were not covered in the literature. Participants appeared to consider many themes related to what the job would be like, as well as how it compared to the current job: the themes Expected Outcomes of the Work, Expected Experiences While Working, Expected Work Roles, and the Feelings About Control Over Place Fit sub-theme. As such, this study increases our understanding of how these types of decisions are made.

\section{Work-life balance factors}

The Feelings About Work-Life Balance Fit sub-theme from this study was found to be roughly similar to the findings in the literature. Liff and Ward (2001), for example, found that work-life balance factors were important in career decisions and Stone and Lovejoy (2004) found that the workplace regulations and culture surrounding flexible work was important. Both of these predicted variables were supported by the study. Hewlett and Luce (2005) found that home responsibilities were a significant theme in women's decisions to remain at a lower level. This was only mentioned a few times by the women in the current study, and not at all by the men. 


\section{Organizational factors}

The literature predicted that a number of organizational variables would influence the decision to seek a promotion. Cassirer and Reskin (2000) suggested several organizational structure variables, two of which were visible here: formalized evaluation

processes and past treatment by the employer. These findings are consistent with Liff and Ward's (2001) suggestion that respondents considered their "perceptions of the promotion process" in the promotion aspirations. These findings from the literature are similar to the Feelings About the Process sub-theme discussed by individuals in this study. Two other sub-themes could be related to organizational structures. One is the Feelings About Control Over Placement Fit sub-theme that participants mentioned in terms of considering the extent of control they would have over where they would be placed. As mentioned previously, this sub- theme may be partly an artifact of the "generic pool" used to place managers in this organization. Also, participants in this study mentioned the sub-theme Perceiving Opportunities/Signals, considering whether there were messages about available opportunities in the organization.

\section{Factors not found in the literature}

A variety of additional themes were identified in this study that were not seen in the literature. In particular, researchers to date have underestimated the impact of the following items on an individual's decision to seek a promotion:

- The opinions of colleagues and superiors

- Having acceptable fit with the job characteristics or requirements

- Desire for particular aspects of the work 
- Political maneuvering with respect to peers (either seeking to be equivalent to peers or seeking to prevent others from taking the position)

- Goal orientation of the individual (such as having a strong investment in the promotion, or simply giving the competition a try)

Some of these themes are similar to the self-referent and other-referent factors that were found in the subjective career success literature, but not in the decision to seek a promotion literature. The discrepancies between the findings of this study and the existing literature on career-related decision-making provide some directions for future research and also support the importance of conducting qualitative research in this area.

\subsection{To what extent does the relationship between subjective career success and the decision to seek a promotion depend on gender and level?}

This section will examine whether there are any statistically significant differences between the themes mentioned by the male and female groups, and between the feeder and executive management groups. For each comparison, the subjective career success and career-related decision-making themes will be examined separately. The impact of gender and of level on the overall model will then be discussed.

\subsubsection{To what extent does subjective career success depend on gender?}

As shown in Table 5-4, women listed more themes and sub-themes than men did when talking about how they define career success - a mean of 3.1 themes per woman, compared to only 2.3 per man, and 4.6 sub-themes compared to 3.0 . While gender difference in the number of themes mentioned was an interesting finding, it is difficult to 
determine exactly what this difference means. One hypothesis is that women mentioned more themes because they were more voluble in the interviews or because they considered a wider variety of elements in their definitions. It could also be some other unidentified difference.

Table 5-4: Frequency of Occurrences of Career Success Themes and Sub-themes by Gender

\begin{tabular}{|l|c|c|}
\hline & Themes & Sub-themes \\
\hline Mean number mentioned by women & 3.1 & 4.6 \\
\hline Mean number mentioned by men & 2.3 & 3.0 \\
\hline Mean number mentioned by both genders & 2.7 & 3.75 \\
\hline Total number of themes found in the study & 5 & 17 \\
\hline
\end{tabular}

As shown in Table 5-5, there were only four significant gender differences in subjective career success. The analysis indicates that women were more likely than men to define career success in terms of

- Experiences While Working $(\mathrm{p}=0.009)$

- Learning and Being Challenged $(\mathrm{p}=0.021)$

- Having Good Relationships $(\mathrm{p}=0.078)$

- Having Fit With Your Values $(\mathrm{p}=0.042)$

- Doing Something I Enjoy (very close to the statistical significance cut-off, at $\mathrm{p}=0.105$ )

The rest of the themes and sub-themes were noted equally often by men and women. Taken as a whole these findings support the following conclusion: women are more likely than men to define career success in terms of their values and their 
experiences at work (i.e. relationships, being challenged, doing enjoyable work). In all other respects, women and men appear to define career success similarly.

Table 5-5: Test for Significance of Gender on Themes and Sub-themes in Subjective Career Success Using Fisher's Exact Probability Test

\begin{tabular}{|c|c|c|c|c|c|}
\hline Factor & $\begin{array}{l}\text { Number of } \\
\text { Females }\end{array}$ & $\begin{array}{l}\text { Percent of } \\
\text { Females }\end{array}$ & $\begin{array}{l}\text { Number of } \\
\text { Males }\end{array}$ & $\begin{array}{l}\text { Percent of } \\
\text { Males }\end{array}$ & $\begin{array}{c}\text { P. } \\
\text { Value }^{12}\end{array}$ \\
\hline Experiences While Working & 19 & $100 \%$ & 14 & $67 \%$ & $.009^{*}$ \\
\hline Doing Something I Enjoy & 15 & $79 \%$ & 11 & $52 \%$ & .105 \\
\hline Learning and Being Challenged & 11 & $58 \%$ & 4 & $19 \%$ & $.021^{*}$ \\
\hline Having Good Relationships & 8 & $42 \%$ & 3 & $14 \%$ & $.078^{*}$ \\
\hline Benchmarking & 12 & $63 \%$ & 14 & $67 \%$ & 1.000 \\
\hline Benchmarking on Own Goals & 7 & $37 \%$ & 9 & $43 \%$ & .755 \\
\hline Benchmarking on Pay & 4 & $21 \%$ & 4 & $19 \%$ & 1.000 \\
\hline $\begin{array}{l}\text { Benchmarking on Doing a } \\
\text { Good Job }\end{array}$ & 4 & $21 \%$ & 3 & $14 \%$ & .689 \\
\hline $\begin{array}{l}\text { Benchmarking Self Against } \\
\text { Peers }\end{array}$ & 2 & $11 \%$ & 2 & $10 \%$ & 1.000 \\
\hline Benchmarking on Using Skills & 2 & $11 \%$ & 1 & $5 \%$ & .596 \\
\hline Outcomes of the Work & 12 & $63 \%$ & 11 & $52 \%$ & .538 \\
\hline Making a Contribution & 11 & $58 \%$ & 10 & $48 \%$ & .545 \\
\hline $\begin{array}{l}\text { Having Accomplishments or } \\
\text { Successes }\end{array}$ & 1 & $5 \%$ & 2 & $10 \%$ & 1.000 \\
\hline Work Roles & 8 & $42 \%$ & 6 & $29 \%$ & .510 \\
\hline Feeling Respected/Recognized & 6 & $32 \%$ & 5 & $24 \%$ & .727 \\
\hline Having Authority & 2 & $11 \%$ & 2 & $10 \%$ & 1.000 \\
\hline Leading Others & 2 & $11 \%$ & 1 & $5 \%$ & .596 \\
\hline Having Fit & 8 & $42 \%$ & 4 & $19 \%$ & .170 \\
\hline Having Work-Life Balance Fit & 3 & $16 \%$ & 4 & $19 \%$ & 1.000 \\
\hline Having Control Over Placement & 4 & $21 \%$ & 1 & $5 \%$ & .172 \\
\hline Having Fit With Your Values & 4 & $21 \%$ & 0 & $0 \%$ & $.042 *$ \\
\hline
\end{tabular}

${ }^{12}$ Considered significant at a p-value equal to or less than 0.10 for a two-tailed Fisher's Exact Probability Test using Minitab 15. 
It is interesting to compare these gender-related findings to those in the literature. A number of researchers expected men to be more focussed on objective career success then women (O’Connor \& Wolfe, 1987; Russo, Kelly \& Deacon, 1991; Powell \& Mainiero, 1992; Sturges, 1999; Dyke and Murphy, 2006). This was not supported, as there were no significant gender differences in the emphasis placed on the indicators of objective career success (i.e. pay or authority). Women were also expected to be more concerned with work-life balance and with life success (Powell \& Mainiero, 1992; Sturges, 1999; Dyke \& Orser, 2005; Dyke and Murphy, 2006). This prediction was not borne out by this study either, as there was not a significant difference in men's and women's focus on work-life balance as a part of the definition of career success.

Other researchers suggested that women were more likely to define career success by intangible criteria (Sturges, 1999), such as feelings about their careers (Powell \& Mainiero, 1992), personal fulfillment (Parker and Chusmir, 1992), or rewarding work (Dyke \& Orser, 2005). These predictions were somewhat supported, as women were more likely than men to consider intangible criteria such as experiences while working and their values.

Some researchers have suggested that women's differences in subjective career success definitions may be due to national or organizational cultures (Gallos, 1989; Gilligan, 1982; Davidson \& Cooper, 1992; Poole et al, 1993; Sturges, 1999). Since this study only examined one organization, it is not possible to say whether the gender differences found here were due to this reason or not. This study does provide some support for this idea, however, as the results are more in line with Dyke and Orser's (2005) finding of limited gender differences in career success. Since the latter study was 
conducted in Canada, while most of the other studies were conducted in the U.S., Great Britain, or Australia, this may point to the impact of national cultures on gender differences on subjective career success. It should be noted, however, that Dyke and Murphy's (2006) study, also with a Canadian sample (personal communication, May 31, 2007), did find many of the gender differences predicted by the literature.

\subsubsection{To what extent does the decision to seek a promotion depend on gender?}

In general, when explaining what they considered when deciding to seek a promotion, women listed a mean of 4.9 themes and 7.1 sub-themes, while men listed only 4.0 themes and 5.0 sub-themes (shown in Table 5-6). It is not clear from the data whether women mentioned more themes because they were more voluble in the interviews, or because they considered more themes as part of their decisions, or some other unidentified difference. Again, we cannot say for sure what causes this gender difference in the mean number of themes mentioned per participant, but it is likely to be the same factors that caused the gender differences with respect to the number of career success themes mentioned above.

Table 5-6: Frequency of Occurrences of Career Decision-making Themes and Subthemes by Gender

\begin{tabular}{|l|c|c|}
\hline & Themes & Sub-themes \\
\hline Mean number mentioned by women & 4.9 & 7.1 \\
\hline Mean number mentioned by men & 4.0 & 5.0 \\
\hline Mean number mentioned by both genders & 4.45 & 6.0 \\
\hline Total number of themes found in the study & 9 & 25 \\
\hline
\end{tabular}


As shown in Table 5-7, three of the decision to seek a promotion sub-themes had a statistically significant difference between men and women; none of the themes were significant. This analysis indicates that women were more likely than men to consider the following issues in their decision on whether or not to seek a promotion:

- Expectations About Enjoying the Work $(\mathrm{p}=0.014)$

- Feelings About Challenge/Change $(\mathrm{p}=0.078)$

- Feelings About Work-Life Balance Fit ( $\mathrm{p}=0.001)$.

The rest of the themes and sub-themes were noted equally often by men and women. These findings support the conclusion that when deciding to seek a promotion, women are more likely than men to consider their expectations about the new job in terms of work experiences and work-life balance. In all other respects, women and men appear to consider the same issues in their decisions to seek a promotion.

It is also interesting to note here that while eight women and no men mentioned a theme of needing to balance their work and home life, five men but only two women spoke about concerns regarding workload and stress in the new job. This may indicate a difference in the way that men and women talk about the increased demands of a new job. Women appear to be more concerned with how the increased work requirements will affect their home demands, while men conceptualize these increased requirements in terms of the workplace, as increased stress, workload, and responsibility. This could be an important subject for future research, since a difference in the way men and women conceptualize these issues could affect the findings of work-life balance studies. 
Table 5-7: Test for Significance of Gender on Themes and Sub-themes in Decision to Seek a Promotion, Using Fisher's Exact Probability Test

\begin{tabular}{|c|c|c|c|c|c|}
\hline Factor & $\begin{array}{l}\text { Number of } \\
\text { Females }\end{array}$ & $\begin{array}{l}\text { Percent of } \\
\text { Females }\end{array}$ & $\begin{array}{c}\text { Number of } \\
\text { Males }\end{array}$ & $\begin{array}{l}\text { Percent of } \\
\text { Males }\end{array}$ & $\begin{array}{c}\text { P. } \\
\text { Value }^{13}\end{array}$ \\
\hline Benchmarking - & 15 & $79 \%$ & 14 & $67 \%$ & .488 \\
\hline Feelings About Readiness & 13 & $68 \%$ & 10 & $48 \%$ & .216 \\
\hline Seeking Equivalency With Peers & 6 & $32 \%$ & 3 & $14 \%$ & .265 \\
\hline Feeling Pay Was a Factor & 1 & $5 \%$ & 5 & $24 \%$ & .186 \\
\hline Wanting to Meet Own Goals & 2 & $11 \%$ & 2 & $10 \%$ & 1.000 \\
\hline Expected Experiences While Working & 16 & $84 \%$ & 13 & $62 \%$ & .163 \\
\hline Expectations About Enjoying the Work & 14 & $74 \%$ & 7 & $33 \%$ & $.014^{*}$ \\
\hline Feellings About Challenge/Change & 8 & $42 \%$ & 3 & $14 \%$ & $.078^{*}$ \\
\hline $\begin{array}{l}\text { Feeling What Job Will Be Like is } \\
\text { Known/Unknown }\end{array}$ & 5 & $26 \%$ & 5 & $24 \%$ & 1.000 \\
\hline Expected Fit & 14 & $74 \%$ & 12 & $57 \%$ & .333 \\
\hline Feelings About Control Over Placement Fit & 9 & $47 \%$ & 7 & $33 \%$ & .520 \\
\hline Feelings About Timing/Rightness & 5 & $26 \%$ & 3 & $14 \%$ & .442 \\
\hline Feelings About Work-Life Balance Fit & 8 & $42 \%$ & 0 & $0 \%$ & $.001^{*}$ \\
\hline Feelings About Workload/Stress & 2 & $11 \%$ & 5 & $24 \%$ & .412 \\
\hline Expected Work Roles & 10 & $53 \%$ & 10 & $48 \%$ & 1.000 \\
\hline Wanting More Authority/Influence & 8 & $42 \%$ & 6 & $29 \%$ & .520 \\
\hline Wanting More Respect/Recognition & 3 & $16 \%$ & 6 & $29 \%$ & .457 \\
\hline Wanting to Lead & 3 & $16 \%$ & 2 & $10 \%$ & .654 \\
\hline Expectation of Getting the Job & 8 & $42 \%$ & 11 & $52 \%$ & .545 \\
\hline Perceiving Opportunities/Signals & 6 & $32 \%$ & 6 & $29 \%$ & 1.000 \\
\hline Having Successes/Recognition & 3 & $16 \%$ & 6 & $29 \%$ & .457 \\
\hline Input From Others & 9 & $47 \%$ & 10 & $48 \%$ & 1.000 \\
\hline Input From Superiors & 8 & $42 \%$ & 6 & $29 \%$ & .510 \\
\hline Input From Peers/Staff/Etc & 5 & $26 \%$ & 4 & $19 \%$ & .712 \\
\hline Input From Spouse/Family & 3 & $16 \%$ & 2 & $10 \%$ & .654 \\
\hline Expected Outcomes of the Work & 9 & $47 \%$ & 5 & $24 \%$ & .186 \\
\hline Feelings About Ability to Contribute & 9 & $47 \%$ & 5 & $24 \%$ & .186 \\
\hline Strategic Decision-Making & 9 & $47 \%$ & 6 & $29 \%$ & .328 \\
\hline Feelings About the Process & 5 & $26 \%$ & 3 & $14 \%$ & .442 \\
\hline Comparison to Position Would Be Leaving & 4 & $21 \%$ & 3 & $14 \%$ & .690 \\
\hline Preventing Others From Getting the Job & 2 & $11 \%$ & 2 & $10 \%$ & 1.000 \\
\hline Importance to Self of Applying & 3 & $16 \%$ & 4 & $19 \%$ & 1.000 \\
\hline Giving It a Try & 1 & $5 \%$ & 3 & $14 \%$ & .607 \\
\hline Wanting the Job & 2 & $11 \%$ & 1 & $5 \%$ & .596 \\
\hline
\end{tabular}

${ }^{13}$ Considered significant at a p-value equal to or less than 0.10 for a two-tailed Fisher's Exact Probability Test using Minitab 15. 
It is interesting to compare these gender-related findings to those in the literature. Both Stone and Lovejoy (2004) and Mainiero and Sullivan (2005) predicted that gender would lead to differences in career-related decision-making themes.

Mainiero and Sullivan (2005) expected women to consider whether the work decision was "true to who they are," whether it provided the desired "work/non-work balance" and whether the work was sufficiently challenging These predictions were largely supported by the findings, as statistically significant differences were found between men and women in Feelings About Work-Life Balance Fit (42\% of women, 0\% of men) and Feelings About Challenge/Change (42\% of women, $14 \%$ of men) in their decision to seek a promotion. Also, although being "true to who they are" was not a theme seen in women's decision making, the similar sub-theme Having Fit With Your Values was a statistically significant difference between men and women in their definitions of career success.

Stone and Lovejoy (2004) and Mainiero and Sullivan (2005) expected women to be more likely to consider the opinions of their spouses when deciding whether to seek a promotion; this dataset does not support this assumption as in this case women did not do this significantly more often than men. In addition, Stone and Lovejoy (2004) expected that women would be more likely to consider the work environment. Again this expectation was not supported as no significant differences were found in this area.

It is interesting to note, however, that this study identified one gender difference that has not been reported by other researchers: in that women were more likely than men to consider whether they would enjoy the work, when deciding whether or not to take a promotion. This is similar to the finding that in this study women were more likely 
than men to define career success in terms of enjoyment of the work. Mainiero and Sullivan (2005) expected men would be more likely than women to consider goal orientation, independent action, and career benefits. Again, this hypothesis was not supported as no significant gender differences were observed in this dataset for any of these factors.

\subsubsection{To what extent does the relationship between subjective career success and the decision to seek a promotion depend on gender?}

The sample size is not large enough to examine the impact of gender on the matching of subjective career success and career-related decision-making themes in a statistically meaningful manner. Nevertheless, as noted in the previous section, there is evidence that gender has some impact on both definitions of career success and the decision to seek a promotion. Most interestingly, in both subjective career success and the decision to seek a promotion, the gender differences were concentrated in the Experiences While Working theme and related sub-themes.

Taken overall, however, in this study gender appeared to have little to do with how an employee subjectively defined career success and made the decision to seek a promotion. This finding conflicts with the findings of researchers such as Powell and Mainiero (1992) or Cassirer and Reskin (2000) that women and men are significantly different in how they understand or approach these constructs. That being said, one gender difference is worthy of note, since it appeared in both subjective career success and the decision to seek promotion data: Experiences While Working. Women were more likely than men to define career success based on work experiences (including ideas such 
as learning, challenge, relationships with others, and doing enjoyable work). Women were also more likely than men to consider their expectations about the work experiences they would have in their new job when deciding on whether or not to seek a promotion (including ideas such as their feelings about challenge and whether they would enjoy the work).

Given the fact that this gender difference appeared and was significant for both constructs, it seems justified to conclude that a strong relationship between these constructs exists for women but not men. These gender differences provide some interesting avenues for future research.

\subsubsection{To what extent does subjective career success depend on level?}

As shown in Table 5-8, those at the management feeder group level (EXM1) listed more themes and sub-themes when defining career success than those in the executive cadre (EX). Individuals in the feeder group listed a mean of 2.7 themes and 4.3 sub-themes, comparison to individuals in the executive group who listed 2.7 themes and 3.3 sub-themes. It is not clear from the data why those at the lower level mentioned more sub-themes than those at the higher level, although this might be an avenue for future research. 
Table 5-8: Frequency of Occurrences of Career Success Themes and Sub-themes by Level

\begin{tabular}{|l|c|c|}
\hline & Themes & Sub-themes \\
\hline Mean number mentioned by EXM1s & 2.7 & 4.3 \\
\hline Mean number mentioned by EXs & 2.7 & 3.3 \\
\hline Mean number mentioned by both groups & 2.7 & 3.75 \\
\hline Total number of themes found in the study & 5 & 17 \\
\hline
\end{tabular}

As shown in Table 5-9, only one sub-theme was found to have a statistically significant difference between the levels. These results indicate that individuals in the feeder group (EXM1s) were more likely than the executive cadre (EXs) to define career success based on Benchmarking on Using Skills ( $\mathrm{p}=0.069)$. Also, Having Work-Life Balance Fit was close to significance $(\mathrm{p}=0.113)$. The rest of the themes and sub-themes were noted equally often by both groups. These findings support a conclusion that, by and large, there is no difference in how career success is defined by individuals in the feeder group compared to individuals in the executive cadre. 
Table 5-9: Test for Significance of Level on Themes and Sub-themes in Subjective Career Success Using Fisher's Exact Probability Test

\begin{tabular}{|c|c|c|c|c|c|}
\hline Factor & $\begin{array}{l}\text { Number of } \\
\text { EXM1s }\end{array}$ & $\begin{array}{l}\text { Percent of } \\
\text { EXM1s }\end{array}$ & $\begin{array}{l}\text { Number of } \\
\text { EXs }\end{array}$ & $\begin{array}{l}\text { Percent of } \\
\text { EXs }\end{array}$ & $\begin{array}{c}\text { P- } \\
\text { Value }\end{array}$ \\
\hline Experiences While Working & 14 & $82 \%$ & 19 & $83 \%$ & 1.000 \\
\hline Doing Something I Enjoy & 13 & $76 \%$ & 13 & $57 \%$ & .315 \\
\hline Learning and Being Challenged & 6 & $35 \%$ & 9 & $39 \%$ & 1.000 \\
\hline Having Good Relationships & 5 & $29 \%$ & 6 & $26 \%$ & 1.000 \\
\hline Benchmarking & 10 & $59 \%$ & 16 & $70 \%$ & .521 \\
\hline Benchmarking on Own Goals & 8 & $47 \%$ & 8 & $35 \%$ & .522 \\
\hline Benchmarking on Pay & 3 & $18 \%$ & 5 & $22 \%$ & 1.000 \\
\hline $\begin{array}{l}\text { Benchmarking on Doing a Good } \\
\text { Job }\end{array}$ & 2 & $12 \%$ & 5 & $22 \%$ & .677 \\
\hline Benchmarking Self Against Peers & 2 & $12 \%$ & 2 & $9 \%$ & 1.000 \\
\hline Benchmarking on Using Skills & 3 & $18 \%$ & 0 & $0 \%$ & $.069^{*}$ \\
\hline Outcomes of the Work & 10 & $59 \%$ & 13 & $57 \%$ & 1.000 \\
\hline Making a Contribution & 10 & $59 \%$ & 11 & $48 \%$ & .538 \\
\hline $\begin{array}{l}\text { Having Accomplishments or } \\
\text { Successes }\end{array}$ & 1 & $6 \%$ & 2 & $9 \%$ & 1.000 \\
\hline Work Roles & 7 & $41 \%$ & 7 & $30 \%$ & .521 \\
\hline Feeling Respected/Recognized & 5 & $29 \%$ & 6 & $26 \%$ & 1.000 \\
\hline Having Authority & 3 & $18 \%$ & 1 & $4 \%$ & .294 \\
\hline Leading Others & 2 & $12 \%$ & 1 & $4 \%$ & .565 \\
\hline Having Fit & 5 & $29 \%$ & 7 & $30 \%$ & 1.000 \\
\hline Having Work-Life Balance Fit & 5 & $29 \%$ & 2 & $9 \%$ & .113 \\
\hline Having Control Over Placement & 1 & $6 \%$ & 4 & $17 \%$ & .373 \\
\hline Having Fit With Your Values & 2 & $12 \%$ & 2 & $9 \%$ & 1.000 \\
\hline
\end{tabular}

${ }^{14}$ Considered significant at a p-value equal to or less than 0.10 for a two-tailed Fisher's Exact Probability Test using Minitab 15. 


\subsubsection{To what extent does the decision to seek a promotion depend on level?}

Individuals in the management feeder group level (EXM1) listed more themes and sub-themes as criteria in their decision to seek a promotion than those in the executive cadre (EX) did, as shown in Table 5-10. The EXM1 group listed a mean of 4.0 themes and 5.2 sub-themes, while those in the EX group listed a mean of 4.8 themes and 6.6 sub-themes. It is not clear from the data why individuals at a higher level listed more career decision-making themes than those at a lower level did. This is especially interesting given that individuals at a higher level listed fewer subjective career success themes than those at a lower level did. This difference may point to a subject for future research.

Table 5-10: Frequency of Occurrences of Career Decision-making Themes and Subthemes by Level

\begin{tabular}{|l|c|c|}
\hline & Themes & Sub-themes \\
\hline Mean number mentioned by EXM1s & 4.0 & 5.2 \\
\hline Mean number mentioned by EXs & 4.8 & 6.6 \\
\hline Mean number mentioned by both groups & 4.5 & 6.0 \\
\hline Total number of themes found in the study & 9 & 25 \\
\hline
\end{tabular}

As shown in Table 5-11, only one statistically significant difference was found between the two levels (EXM1 and EX). This difference was that those in the executive cadre were more likely to consider the sub-theme Feelings About Challenge/Change when deciding on whether or not to seek a promotion $(\mathrm{p}=0.079)$. No other statistically significant differences were found. This analysis supports the conclusion that, overall, individuals in the feeder group and individuals in the executive cadre make career decisions according to the same criteria. 
Table 5-11: Test for Significance of Level on Themes and Sub-themes in Decision to Seek a Promotion, Using Fisher's Exact Probability Test

\begin{tabular}{|c|c|c|c|c|c|}
\hline Factor & $\begin{array}{c}\text { Number of } \\
\text { EXM1s }\end{array}$ & $\begin{array}{l}\text { Percent of } \\
\text { EXM1s }\end{array}$ & $\begin{array}{c}\text { Number of } \\
\text { EXs }\end{array}$ & $\begin{array}{c}\text { Percent of } \\
\text { EXs }\end{array}$ & $\begin{array}{c}\text { P- } \\
\text { Value }^{15}\end{array}$ \\
\hline Benchmarking & 12 & $71 \%$ & 17 & $74 \%$ & 1.000 \\
\hline Feelings About Readiness & 9 & $53 \%$ & 14 & $61 \%$ & .749 \\
\hline Seeking Equivalency With Peers & 3 & $18 \%$ & 6 & $26 \%$ & .707 \\
\hline Feeling Pay Was a Factor & 3 & $18 \%$ & 3 & $13 \%$ & 1.000 \\
\hline Wanting to Meet Own Goals & 2 & $12 \%$ & 2 & $9 \%$ & 1.000 \\
\hline Expected Experiences While Working & 12 & $71 \%$ & 17 & $74 \%$ & 1.000 \\
\hline Expectations About Enjoying the Work & 11 & $65 \%$ & 10 & $43 \%$ & .216 \\
\hline Feelings About Challenge/Change & 2 & $12 \%$ & 9 & $39 \%$ & $.079^{*}$ \\
\hline $\begin{array}{l}\text { Feeling What Job Will Be Like is } \\
\text { Known/Unknown }\end{array}$ & 2 & $12 \%$ & 8 & $35 \%$ & .145 \\
\hline Expected Fit & 10 & $59 \%$ & 16 & $70 \%$ & .521 \\
\hline Feelings About Control Over Placement Fit & 6 & $35 \%$ & 10 & $43 \%$ & .747 \\
\hline Feelings About Timing/Rightness & 3 & $18 \%$ & 5 & $22 \%$ & 1.000 \\
\hline Feellngs About Work-Life Balance Fit & 4 & $24 \%$ & 4 & $17 \%$ & .702 \\
\hline Feelings About Workload/Stress & 2 & $12 \%$ & 5 & $22 \%$ & .677 \\
\hline Expected Work Roles & 8 & $47 \%$ & 12 & $52 \%$ & 1.000 \\
\hline Wanting More Authority/Influence & 6 & $35 \%$ & 8 & $35 \%$ & 1.000 \\
\hline Wanting More Respect/Recognition & 3 & $18 \%$ & 6 & $26 \%$ & .707 \\
\hline Wanting to Lead & 3 & $18 \%$ & 2 & $9 \%$ & .634 \\
\hline Expectation of Getting the Job & 6 & $35 \%$ & 13 & $57 \%$ & .216 \\
\hline Perceiving Opportunities/Signals & 3 & $18 \%$ & 9 & $39 \%$ & .179 \\
\hline Having Successes/Recognition & 4 & $24 \%$ & 5 & $22 \%$ & 1.000 \\
\hline Input From Others & 7 & $41 \%$ & 12 & $52 \%$ & .538 \\
\hline Input From Superiors & 5 & $29 \%$ & 9 & $39 \%$ & .739 \\
\hline Input From Peers/Staff/Etc & 3 & $18 \%$ & 6 & $26 \%$ & .707 \\
\hline Input From Spouse/Family & 1 & $6 \%$ & 4 & $17 \%$ & .373 \\
\hline Expected Outcomes of the Work & 6 & $35 \%$ & 8 & $35 \%$ & 1.000 \\
\hline Feelings About Ability to Contribute & 6 & $35 \%$ & 8 & $35 \%$ & 1.000 \\
\hline Strategic Decision-Making & 5 & $29 \%$ & 10 & $43 \%$ & .512 \\
\hline Feelings About the Process & 3 & $18 \%$ & 5 & $22 \%$ & 1.000 \\
\hline Comparison to Position Would Be Leaving & 2 & $12 \%$ & 5 & $22 \%$ & .677 \\
\hline Preventing Others From Getting the Job & 1 & $6 \%$ & 3 & $13 \%$ & .624 \\
\hline Importance of Applying & 2 & $12 \%$ & 5 & $22 \%$ & .677 \\
\hline Giving It a Try & 1 & $6 \%$ & 2 & $9 \%$ & 1.000 \\
\hline Wanting the Job & 1 & $6 \%$ & 3 & $13 \%$ & .624 \\
\hline
\end{tabular}

${ }^{15}$ Considered significant at a p-value equal to or less than 0.10 for a two-tailed Fisher's Exact Probability Test using Minitab 15. 
5.5.6 To what extent does the relationship between subjective career success and the decision to seek a promotion depend on level?

The sample size is not large enough to examine the impact of level on the matching of subjective career success and career-related decision-making themes in a statistically meaningful manner. For both the career success and decision to seek a promotion tests, only one significant difference was found between the executive cadre (EX) and feeder group to the executive cadre (EXM1). This indicates that there may be essentially no difference between these two groups in terms of how they define subjective career success and how they make the decision to seek a promotion (when all individuals are already managers). This supports the idea that level may not need to be included in the proposed model. It is possible that for groups that are more widely separated in the hierarchy, more differences might appear. Further studies could examine these hypotheses using confirmatory methodologies and a sample that spans more levels of the hierarchy, especially comparing groups before and after the jump into management. 


\section{CONCLUSIONS}

This section will present the key findings from this study, including the model of the relationship between subjective career success and the decision to seek a promotion. Next, the limitations of the study will be addressed. Finally, the implications for organizations and for researchers will be presented, including a number of suggestions for future research.

\subsection{Key findings}

This study has demonstrated how public servants, in particular those at the management level, define career success and what themes they take into account when deciding whether to seek a promotion. It has also shown evidence of a relationship between these two constructs. A model of this relationship has been developed and will be discussed in Section 6.1.4. Finally, the study has demonstrated, as hypothesized, that gender has some impact on subjective career success and career-related decision-making, although level does not appear to. The key findings will now be briefly reviewed.

\subsubsection{Subjective career success}

This study aimed to understand how public servants defined career success for themselves. The individuals in this study were found to define career success according to the following broad themes:

- Experiences While Working

- Benchmarking

- Outcomes of the Work 
- Work Roles

- Having Fit

These findings largely support the existing literature on subjective career success. They also highlight, however, the greater importance that researchers have placed on predictive factors (such as demographic, human capital, and organizational/regional/industrial themes) compared to employees, and the greater importance that employees place on job factors compared to researchers. Future research into subjective career success should bear in mind the difference in this perspective. These results support the value of doing exploratory research and using grounded theory methodology in this area.

\subsubsection{The decision to seek a promotion}

One of the primary goals of this study was to seek to better understand what motivates individuals to seek management jobs. The individuals in this study described the following themes and sub-themes as being part of the decision to seek a promotion:

- Benchmarking

- Experiences While Working

- Expected Fit

- Expected Work Roles

- Expectation of Getting the Job

- Receiving Input From Others

- Strategic Decision-Making

- Expected Outcomes of the Work 


\section{- Importance to Self of Applying}

It was found that some of these themes (and related sub-themes) encouraged the individual to seek a promotion, some were discouraging, and others could be encouraging or discouraging depending on the situation. This finding supports the assertion that individuals do not always seek a promotion without question. Even in this pool of individuals who did go on to seek and receive a promotion, the participants described a variety of factors that discouraged them from applying.

For the most part, this study supported the findings from the limited amount of research into career-related decision-making. It also extends this research by identifying factors that had not been predicted by previous research, namely factors that were related to expectations of success, input from others, strategic implications of the decision, the importance placed on applying for the job, and benchmarking on self- and other-referent criteria. Again, these findings reflected the greater emphasis that individuals place on job-related factors compared to researchers.

Individuals were also found to engage in a number of decision-making behaviours during the process of deciding to seek a promotion, including weighing the pros and cons of the decision, identifying some issues as more important than others, enlisting the advice or help of others, formulating a backup or escape plan in case they were unhappy with the outcome of their decision, and spending time considering the decision.

These findings point to the need for more research into career-related decisionmaking and to some interesting avenues for future research, as they highlight the gaps in the current understanding of this decision process in the literature. 


\subsubsection{The relationship between subjective career success and the decision to seek a} promotion

The results of this study support the existence of a relationship between subjective career success and the factors that individuals consider when deciding on whether or not to seek a promotion. In this relationship, the individual's definition of career success forms some of the decision-making criteria, but not all of them. It is believed that future studies with structured response items and a larger sample would provide statistically significant support for this finding.

However, it is also clear that a number of other themes go into the decision. In particular, it appears that individuals not only consider the job itself (such as experiences they would have in the job, whether it meets criteria for intrinsic and extrinsic rewards, and the work roles they would gain by achieving the management level); they also consider the likelihood of winning the position, how well it will fit with their life and needs, the opinions of others, political maneuvering, and the application process itself.

\subsubsection{A model of the relationship between the definition of career success and the decision to seek a promotion}

This thesis asked the question, What is the relationship between the definition of career success and the decision to seek a promotion? The result of this question is the model shown in Figure 6-1, showing the relationship between the definition of career success and the decision to seek a promotion. The elements of the model will now be discussed in detail. 


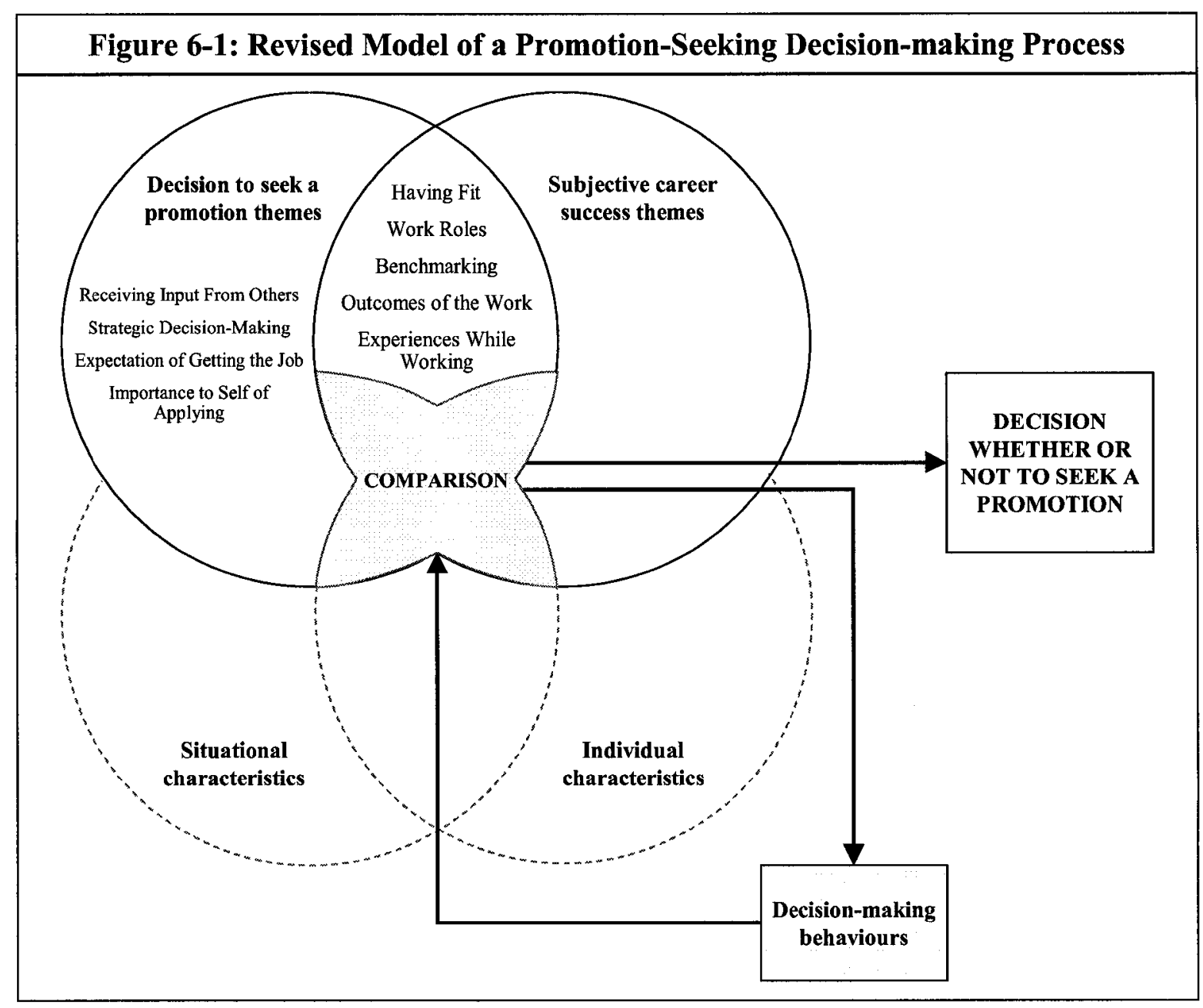

This model is radically different from the proposed model shown previously in Figure 3-1. Most notable is the move away from discrete iterative boxes to a depiction showing the overlapping and interrelated nature of the constructs examined in this thesis. This is because the grounded theory analysis of the data did not support the idea of making these constructs into separate steps in a process model approach. The complexity and richness revealed through the grounded theory analysis calls for a more intuitive model. This change is also in line with a tendency in process research away from linear progressions and toward models that recognize "the presence of multilayered and changing contexts, multidirectional causalities, and feedback loops" (Langley, 1999, p. 
694). The central relationship depicted by the model is still the way in which an individual compares various elements, leading to the individual deciding whether or not to seek a promotion. It is hoped that the model proposed in Figure 6-1 reveals the "effect of events on the state of an entity" as well as "the cognitions and emotions of individuals as they interpret and react to events" (Langley, 1999, p. 693).

The model contains seven elements. These include four influences on the individual (the decision to seek a promotion themes and the subjective career success themes, as well as individual and situational characteristics) and three actions taken by the individual (a comparison process, decision-making behaviours, and the final decision whether or not to seek a promotion).

This study found that the first construct shown in Figure 6-1, the decision to seek a promotion, included nine main themes: Receiving Input From Others, Strategic Decision-Making, Expectation of Getting the Job, Importance to Self of Applying, Having Fit, Work Roles, Benchmarking, Outcomes of the Work, and Experiences While Working. It was found that individuals considered a personal subset of these themes when making a decision on whether or not to seek a promotion.

Of these nine themes, five were also found to be themes in the second construct, subjective career success: Having Fit, Work Roles, Benchmarking, Outcomes of the Work, and Experiences While Working. As stated, all of these themes are considered by individuals when they make a decision on whether or not to seek a promotion. These five are shown in the overlap between subjective career success and the decision to seek a promotion. The five themes that appear in both the decision to seek a promotion and in subjective career success support the idea that individuals do rely on their personal 
definitions of career success when deciding whether to seek a promotion. The two constructs are still shown separately because some sub-themes were identified only in the subjective career success definitions, and not in the factors considered as part of the decision to seek a promotion. It is believed that this indicates these two constructs are still distinct.

Four additional themes have been identified in the decision to seek a promotion construct that appear to be separate from the individual's notion of career success. These additional four themes illustrate a key finding of this study: when making the decision to seek a promotion, individuals also consider issues such as the opinions of others, strategic impacts of the decision, whether they expect to get the job, and the importance they attach to applying. This is an important finding, as most of these elements were not previously identified in the literature

The figure also shows the influence of individual and situational characteristics. The focus of this study limits how much it is possible to say about the influence of these characteristics, but the figure recognizes their importance. These constructs are shown in the background, since the data showed that they influence the other elements (as demonstrated by the contextualizing statements examined in Sections 5.1.1 and 5.2.1). Future grounded theory research is needed to flesh out importance of these constructs.

At the centre of the diagram is the comparison process that the individual goes through as they weigh the various elements of their decision to seek a promotion and are influenced by various aspects of the situation. This is shown at the intersection of four constructs to reflect the fact that the data suggests the subjective career success themes, 
decision-making themes, and the individual and situational characteristics all influence the comparison (and each other) in an iterative fashion.

Decision-making behaviours are also shown as a unique construct in the diagram, as these are hypothesized to influence the comparison process. For example, the individual might compare the various elements of their decision, decide that he or she does not have enough information, and seek advice. With that additional information, he or she can re-do their comparison and hopefully be able to make a decision.

Finally, the diagram shows that the individual will complete the comparison and make a yes or no decision on whether or not to seek a promotion.

It was noted above that there is a need for testable models of the career decision process in general that could be applied to specific types of career decisions. The model developed in this exploratory study could form the basis for such research.

\subsubsection{The impact of gender and level}

The existing literature predicted that gender and level should have an impact on both the definition of career success and on the decision to seek a promotion. This was largely contradicted by the results. In general, the women and men in this study were found to be very similar, as were the executive cadre and management feeder groups. There was one notable exception, however. Women were found to place more importance on experiences while working, both in the way they defined career success and in the factors they considered when deciding to seek a promotion. This is a significant finding, and future research should test these results with different populations 
and should study whether this difference has an impact on women's career-related decisions and objective career success.

\subsection{Limitations}

There are a number of limitations inherent in this study. These include the potential effects of qualitative methodologies, repeated statistical measures, observation or contamination effects from the study format, and effects due to the organizational culture or job types of the participants. It is believed that the impact of these potential limitations has been minimized as much as possible by the methodologies used by the researcher. These limitations will be addressed here.

Qualitative research in general has been accused of being subjective, and systematic methods are required to counteract any researcher bias (Goulding, 2002). In this study, the appropriate grounded theory techniques, such as fracturing of data, constant comparisons, and use of Strauss and Corbin's (1998) coding paradigm, have been used to reduce the influence of any potential researcher bias. It is felt that even with a secondary dataset, the grounded theory analysis was able to reach a reasonable level of saturation.

Repeated statistical measures such as are used in this study can result in a number of false positives (and false negatives). The researcher has the most confidence in the finding of gender influencing the importance of work experiences on subjective career success and the decision to seek a promotion, since there were multiple significant results on these themes and sub-themes. Also, since there is so much similarity between the themes and sub-themes identified in subjective career success and in the decision to seek 
a promotion, it is believed that future confirmatory analysis studies would find stronger statistical evidence of participants mentioning the same sub-themes for both research categories.

The participants' results may be skewed by the fact that they are aware of being observed, and they may show preferences in their answers as well as experimenterinterviewer interaction effects (Web et al, 1966). The effect may be stronger in this case because the participants were aware that the results of the study were being provided to their employer. Even though participants were assured that their results were anonymous, they may still have self-censored.

There are also a number of other possible limitations related to the study format. The data for this study was drawn from a project on a related but different topic, and responses could have been contaminated by other questions in the study. It is also possible that the ordering of the questions in the interviews could have had an impact on the match rate found in this analysis. This is believed to be unlikely, as there were a number of other questions in between the two directly related to subjective career success and the decision to seek a promotion (questions $\mathrm{A}$ and $\mathrm{F}$ as shown in Section 4.3.1). Finally, the questions asked individuals to look back at the past, so responses may be subject to some recall bias.

This research focussed on a group with certain homogenous characteristics: all of the participants were managers in one department of the Canadian Public Service, all were knowledge workers with university training, all had decided to seek the promotion being studied, and all had succeeded in achieving that promotion. 
This study took place in an organization with a very strong culture. Thus, individuals in this organization may define career success and make career decisions in ways that are homogenous within the organization, but unique compared to other organizations (Tsui \& Gutek, 1984; Schneider, Smith \& Paul, 2001; Heslin, 2005). In addition, the study took place in a Public Service environment with a specific promotion process, which may operate differently from environments in the private sector or smaller public organizations. Future studies should expand on this research to examine the decision to seek a promotion in organizations with more informal promotion processes.

\subsection{Implications of the research}

These findings have implications for organizations (including the one where this study was performed) and for the state of research in this area. These will be discussed in more detail, with a list of suggested areas for future research.

\subsubsection{Implications for organizations and human resource professionals}

The results of this research can assist organizations in making management positions more attractive and accessible to employees. Although this study was undertaken with a specific and somewhat unique population, this research provides some important indications about what factors employees consider when deciding on whether or not to seek a promotion.

Organizations can make use of these results to guide the development of human resources policies and practices intended to encourage employees to seek management positions. The individual definitions of career success held by employees appear to have 
a substantial relationship to the themes they consider when deciding on whether or not to seek a promotion. Thus, organizations should seek to understand how their employees define career success, and whether management positions in the organization complement those definitions.

Although future research in other venues might have different results, it is believed that organizations (particularly organizations in the Canadian Public Service) can still be guided by the findings of this study, such as the themes and sub-themes that were most commonly mentioned by the participants who participated in this research.

The broad themes found in this study indicate that employees consider benchmarking on various factors; the experiences, fit, work roles, and outcomes they expect to have in the new position; whether they are likely to get the job; the opinions of others; a strategic evaluation of the impact of obtaining vs. not obtaining the position; and the importance they personally place on applying. These findings indicate that organizations need to consider not only how employees feel about the job characteristics and the objective career success they might obtain from the position, but also how situational and political factors may impact the employee's decision.

In this study participants commonly mentioned sub-themes such as whether they were ready for the position, would enjoy the work, would have additional authority, perceived positive signals from the environment or from superiors, and would be able to contribute in the position. Organizations may wish to pay particular attention to whether their human resources practices provide sufficient information about the job characteristics and about readiness for promotions (in the form of both self-evaluations and signals from others). 
Finally, organizations should take note of the important gender difference found in this study: the greater emphasis that women place on the experiences they would have while working. In order to encourage more women to seek management positions, organizations will need to confirm both that these positions will provide experiences that will appeal to their female employees, and that their female employees are aware of what the day-to-day experiences of these positions are like. Human resources programs and practices could emphasize making more information available about what the management job entails.

\subsubsection{Implications for researchers}

This study has produced a number of valuable findings that confirm, contradict, or expand on the literature. Also, a number of suggestions for future research have been identified in this study.

\section{Subjective career success}

This study has helped to address the lack of exploratory studies examining how individuals define career success for themselves. These findings largely support the existing literature on subjective career success. They also highlight, however, the greater importance that researchers have placed on predictive factors (such as demographic, human capital, and organizational/regional/industrial themes) compared to employees, and the greater importance that employees placed on job factors, compared to researchers. Future research into subjective career success should bear in mind the difference in this perspective and how it may affect study findings. 
Some directions for research that should be considered by researchers include the following items:

- The themes and sub-themes identified in this study could be used to develop a subjective career success instrument with structured response items that could be tested for validity and reliability.

- A number of participants in this study had trouble answering the question about career success, while others did not. Future research could examine whether individuals have articulated a definition of career success for themselves, and whether they use it consciously when making career-related decisions. It would also be interesting for researchers to investigate the possibility that triggering events may cause individuals to articulate (for the first time) or re-evaluate (and possibly change) their definitions of career success.

- Participants also appeared to be aware of organizational or national cultural norms in the definition of career success. Researchers might investigate this idea more thoroughly and whether it affects how individuals define career success and whether they make career-related decisions to fit these perceived norms.

- There has been some suggestion in the literature that career and job satisfaction alone may not be adequate constructs for measuring subjective career success. This was borne out by this study, as the definitions of career success used by the participants go beyond the idea of satisfaction. It would be useful for future research to study how well career and job satisfaction predict satisfaction on the various elements of subjective career success found in this study. 
- This study found that participants tended to use the concept of "having authority" as a proxy for describing level in the hierarchy (i.e. one facet of objective career success). It could be useful for researchers to study whether other employees might use this concept to measure objective career success, and if so, why.

\section{Decision to seek a promotion}

This research did not directly address the question of whether an individual will always seek, or accept, a promotion if one is available, since all of the participants did ultimately seek, and receive, the position they discussed for this study. Nevertheless, the results supported the researcher's hypothesis that individuals do not simply seek any promotion that might be available: the participants went through an extensive thought process in considering whether to seek the promotion, and they saw both negative and positive themes.

Studying these constructs in an organization where the promotion-seeking process is quite transparent has made it easier to examine. Further research, however, should expand on this to examine whether promotion-seeking decisions are similar in organizations with more fluid promotion processes.

Future research could consider the following issues:

- Additional research into the factors that affect career-related decision-making is clearly needed, based on the scarcity of literature in this area.

- It would be useful for a cohort study to be conducted, in order to examine the relationship between subjective career success definitions and career-related 
decision-making while the participants are in the process of considering the decision.

- The themes and sub-themes identified in this study could be used to develop a career-related decision-making instrument with structured response items that could be tested for validity and reliability.

- Additional grounded theory research into the decision-making behaviours that individuals engage in when deciding to seek a promotion could be particularly beneficial to organizations, since human resources practices could be developed to best complement these behaviours. Overall, decision-making behaviours appear to be under-represented in the career-related decision models found in the literature.

- Future studies should examine the decision to seek a promotion in private organizations with more informal promotion processes to see if the findings differ significantly from those found in the organization studied here.

- Participants in this study considered a variety of positive and negative themes when deciding whether to seek a promotion. In this case, on average the participants considered more positive themes than negative ones, and did go on to seek the promotion. Future research could examine whether the number of positive and negative themes considered by individuals is related to their decision on whether or not to seek the promotion.

- It appears from this study that employees practice some benchmarking based on self- and other-referent criteria when deciding on whether or not to seek a promotion. The literature on career-related decision-making could be expanded 
by applying the self-referent and other-referent concepts used by Heslin (2003) with subjective career success.

The relationship between subjective career success and the decision to seek a promotion The model developed in this study for the Public Service, shown in Figure 6-1, is a valuable contribution that can form the basis for future research into the relationship between subjective career success and the decision to seek a promotion. Such research might address the following questions:

- The results of this study could be used to develop an instrument with structured response items to test for a statistically significant relationship between subjective career success and the decision to seek a promotion.

- It is believed that subjective career success and the decision to seek a promotion are separate constructs, despite the fact that most of the themes and sub-themes found in career success definitions could be subsumed in the themes and subthemes found in the decision to seek a promotion. Further studies should seek to confirm that these constructs are distinct.

- Future studies with larger samples should address the impact of individual and situational characteristics on the relationship between subjective career success and the decision on whether or not to seek a promotion.

\section{Impact of gender}

One of the important goals of this study was to examine the impact of gender on subjective career success and the decision to seek a promotion. Much research has been 
conducted into gender differences over the past decades, but workplace gender imbalances are still widespread. It is hoped that continued study of this issue can help to narrow this gap. Research into the following items may prove valuable:

- Studies with a larger sample size should be undertaken to examine the impact of gender on the relationship between subjective career success and career-related decision-making themes in a statistically meaningful manner.

- In particular, the finding that women place more importance on experiences while working than men do should be studied with larger, more heterogeneous samples.

- Future research should also investigate whether this difference has an impact on the career-related decisions that women make.

- Additional studies should investigate the impact of national cultures on gender differences on subjective career success.

- This study resulted in some curious findings regarding the number of themes and sub-themes mentioned by participants of different genders. This discrepancy bears additional research, as a difference in the number of responses given by each gender could impact the findings of research in this area.

- It was noted in this study that when considering issues of work demands, women appeared to consider them in terms of the impact on their home lives (i.e. worklife balance) while men considered them in the sphere of the workplace (i.e. workload, stress). This could be an important subject for future research, since such a difference in the way men and women conceptualize or describe these issues could affect the results of work-life balance research. 
Impact of level in the hierarchy

Finally, the literature predicted that human capital factors, such as level in the hierarchy, should have an impact on the results in this study. This was not found to be the case. Future studies could address this interesting finding by considering the following points:

- It is possible that a study with participants who are more widely separated in the hierarchy (such as those who have entered management ranks and those who have not) would identify more differences in subjective career success and/or in the criteria considered when deciding on whether or not to seek a promotion.

- A discrepancy in number of themes and sub-themes mentioned by participants was also noticed for different levels in the hierarchy. This discrepancy could affect the results of future studies comparing employees at different levels.

This thesis used grounded theory methodology and exploratory research techniques to develop a model that illustrates how individuals' definitions of career success are linked to their decisions about whether or not to pursue a promotion. In the process, this study has extended the literature with a number of valuable findings. It is hoped that researchers will be able to employ this research to better understand subjective career success, the decision to seek a promotion, and the relationship between the two constructs, and that organizations will be able to use these findings to address the succession planning issues that they face. 
Appendix A: Comparison of presence of Positive and negative sub-themes

\begin{tabular}{|c|c|c|c|}
\hline & Total & $\begin{array}{c}\text { Positive } \\
\text { (encouraging theme) }\end{array}$ & $\begin{array}{c}\text { Negative } \\
\text { (discouraging theme) }\end{array}$ \\
\hline Benchmarking & 29 & & \\
\hline Feelings About Readiness & 23 & $\begin{array}{c}20 \\
\text { (feeling ready) }\end{array}$ & $\begin{array}{c}9 \\
\text { (feeling unsure l'm ready) }\end{array}$ \\
\hline Seeking Equivalency With Peers & 9 & 9 & $n / a$ \\
\hline Feeling Pay Was a Factor & 6 & 6 & $n / a$ \\
\hline Wanting to Meet Own Goals & 4 & 4 & $n / a$ \\
\hline $\begin{array}{l}\text { Expected Experiences While } \\
\text { Working }\end{array}$ & 29 & 28 & 3 \\
\hline Expectations About Enjoying the Work & 21 & 21 & $n / a$ \\
\hline Feelings About Challenge/Change & 11 & 11 & $n / a$ \\
\hline $\begin{array}{l}\text { Feeling What Job Will Be Like is } \\
\text { Known/Unknown }\end{array}$ & 10 & $\begin{array}{c}7 \\
\text { (feeling job is known) }\end{array}$ & $\begin{array}{c}3 \\
\text { (feeling job is unknown) }\end{array}$ \\
\hline Expected Fit & 26 & 21 & \\
\hline $\begin{array}{l}\text { Feelings About Control Over } \\
\text { Placement Fit }\end{array}$ & 16 & $\begin{array}{l}12 \\
\text { (likely to have input or go } \\
\text { somewhere specific) }\end{array}$ & $\begin{array}{c}8 \\
\text { (losing mobility and control, few } \\
\text { positions / wanted) }\end{array}$ \\
\hline Feelings About Timing/Rightness & 8 & $\begin{array}{c}7 \\
\text { (feeling it was the good, right time) }\end{array}$ & $\begin{array}{c}1 \\
\text { (feeling unsure about timing) }\end{array}$ \\
\hline Feelings About Work-Life Balance Fit & 8 & $\begin{array}{c}4 \\
\text { (feeling WL fit will be good) }\end{array}$ & $\begin{array}{c}5 \\
\text { (feeling WL fit will be bad) }\end{array}$ \\
\hline Feelings About Workload/Stress & 7 & $\begin{array}{c}2 \\
\text { (feeling workload is the same or } \\
\text { manageable) }\end{array}$ & $\begin{array}{c}5 \\
\text { (feeling workload is higher) }\end{array}$ \\
\hline Expected Work Roles & 20 & 20 & $\mathrm{n} / \mathrm{a}$ \\
\hline Wanting More Authority/Influence & 14 & 14 & $n / a$ \\
\hline Wanting More Respect/Recognition & 9 & 9 & $n / a$ \\
\hline Wanting to Lead & 5 & 5 & $n / a$ \\
\hline Expectation of Getting the Job & 19 & 19 & 2 \\
\hline Perceiving Opportunities/Signals & 12 & $\begin{array}{c}12 \\
\text { (perceiving positive signals) }\end{array}$ & $\begin{array}{c}2 \\
\text { (not perceiving positive signals, or only } \\
\text { negative ones) }\end{array}$ \\
\hline Having Successes/Recognition & 5 & 5 & $n / a$ \\
\hline $\begin{array}{l}\text { Receiving Input From Others } \\
\text { Input From Superiors }\end{array}$ & $\begin{array}{l}19 \\
14\end{array}$ & $\begin{array}{c}19 \\
14 \\
\text { (encouragement by superiors) }\end{array}$ & $\begin{array}{c}3 \\
2 \\
\text { (discouragement by superiors) }\end{array}$ \\
\hline
\end{tabular}




\begin{tabular}{|c|c|c|c|}
\hline $\begin{array}{l}\text { Input From Peers/Staff/Etc } \\
\text { Input From Spouse/Family }\end{array}$ & $\begin{array}{c}\text { Total } \\
9 \\
5\end{array}$ & $\begin{array}{c}\text { Positive } \\
\text { (encouraging theme) } \\
9 \\
5 \\
\text { (encouragement by spouse, family) }\end{array}$ & $\begin{array}{c}\text { Negative } \\
\text { (discouraging theme) } \\
n / a \\
2 \\
\text { (discouragement by spouse, family) }\end{array}$ \\
\hline $\begin{array}{l}\text { Expected Outcomes of the Work } \\
\text { Feelings About Ability to Contribute }\end{array}$ & $\begin{array}{l}14 \\
14\end{array}$ & $\begin{array}{c}13 \\
13 \\
\text { (feeling / will be able to contribute) } \\
\end{array}$ & $\begin{array}{c}1 \\
1 \\
\text { (fearing / will not be able to contribute) }\end{array}$ \\
\hline Strategic Decision-making & 15 & 7 & 11 \\
\hline Feelings About the Process & 8 & $\begin{array}{l}1 \\
\text { (Positive feelings about the } \\
\text { process) }\end{array}$ & $\begin{array}{l}\quad 7 \\
\text { (Negative feelings about the process) }\end{array}$ \\
\hline $\begin{array}{l}\text { Comparison to Position Would Be } \\
\text { Leaving }\end{array}$ & 7 & $\begin{array}{c}5 \\
\text { (Negative feelings about positive I } \\
\text { was leaving) }\end{array}$ & $\begin{array}{c}4 \\
\text { (Positive feelings about positive / was } \\
\text { leaving) }\end{array}$ \\
\hline $\begin{array}{l}\text { Preventing Others From Getting the } \\
\text { Job }\end{array}$ & 4 & 4 & $n / a$ \\
\hline Importance to Self of Applying & 7 & 7 & $n / a$ \\
\hline Giving It a Try & 4 & 4 & $n / a$ \\
\hline Wanting the Job & 3 & 3 & $n / a$ \\
\hline
\end{tabular}




\section{Appendix B: Initial Model of Subjective Definitions of Career Success Process Resulting from Axial Coding Phase}

This model was developed as part of using Strauss and Corbin's (1998) coding paradigm. It is shown here to demonstrate the researcher's analytical process.

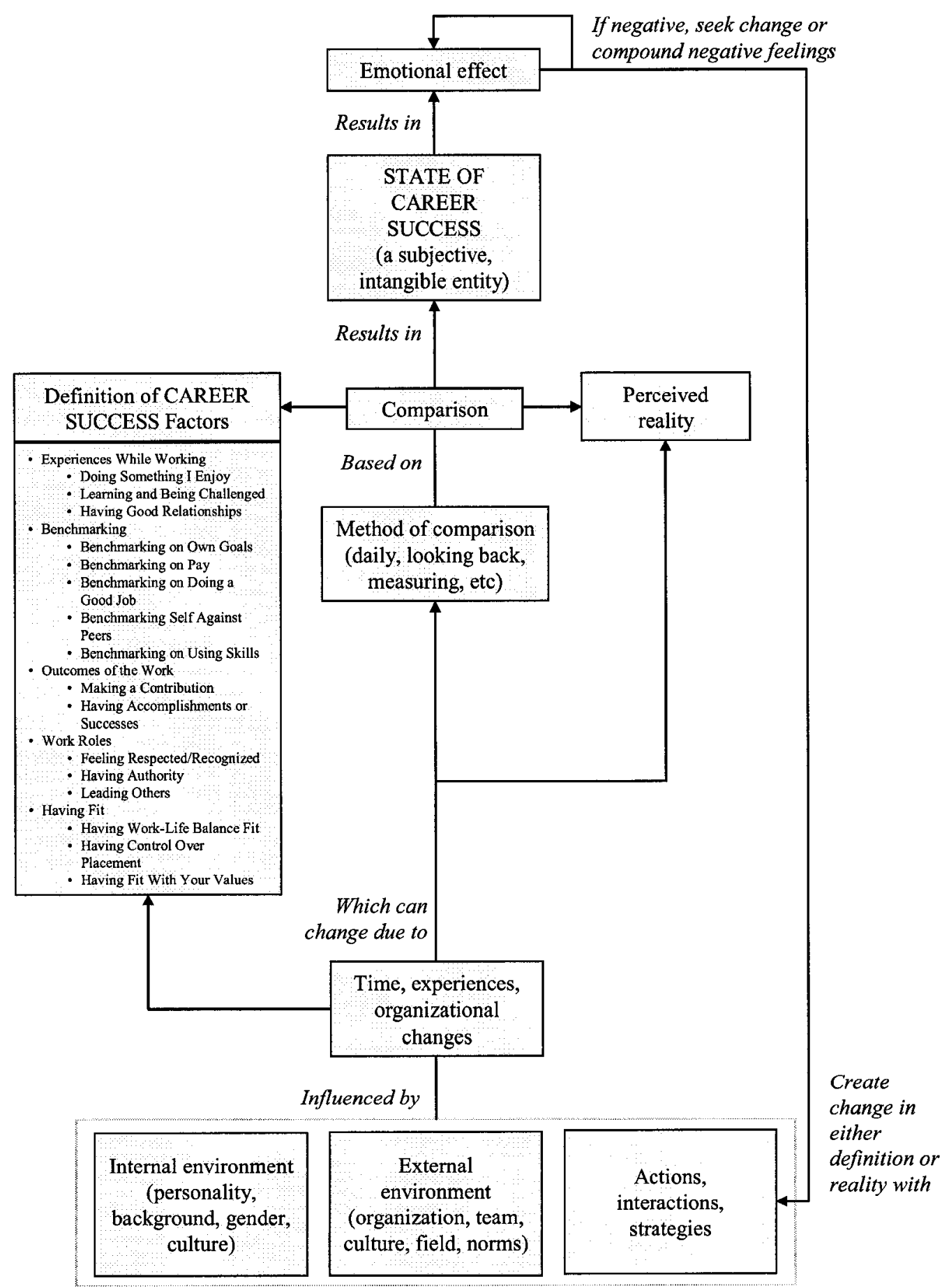




\section{Appendix C: Initial Model of Decision to Seek a Promotion Process Resulting from Axial Coding Phase}

This model was developed as part of using Strauss and Corbin's (1998) coding paradigm. It is shown here to demonstrate the researcher's analytical process.

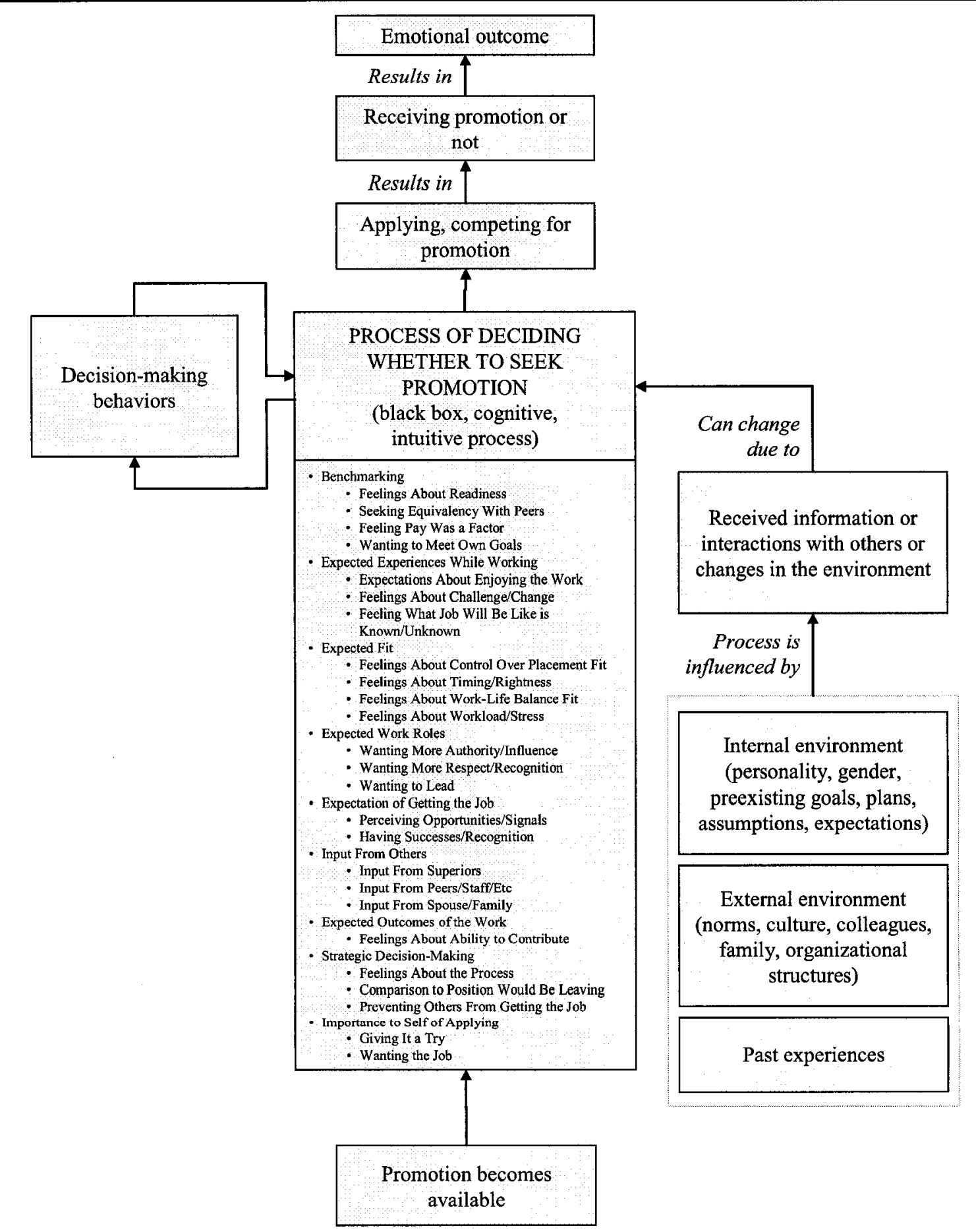




\section{REFERENCES}

Acker, J. (1990). Hierarchies, jobs, bodies: a theory of gendered organizations. Gender \& Society, 4(2), 139-158.

Astin, H. S. (1984). The meaning of work in women's lives: a sociopsychological model of career choice and work behavior. The Counseling Psychologist, 12: 117-126.

Auster, E. (2001). Professional women's midcareer satisfaction: toward an explanatory framework. Sex Roles, 44, 719-750.

Bailyn, L. (1980). The slow burn way to the top: Some thoughts of the early years of organizational careers. In C. B, Derr (Ed.), Work, family and the career: New frontiers in theory and research. New York: Praeger.

Barnett, R. \& Lundgren, L. (1998). Dual-earner couples and the decision to work less: A conceptual model. Community, Work and Family, 1, 273-295.

Bateman, T. \& Crant, J. (1993). The proactive component of organizational behavior. Journal of Organizational Behavior, 14, 103-118.

Belkin, L. (2003, October 26). The opt-out revolution. The New York Times. [Electronic version]. Retrieved November 20, 2006 from http://www.nytimes.com/ 2003/10/26/magazine/26WOMEN.html?ex=1382500800\&en=02f8d75eb63908e0 \&ei=5007\&partner=USERLAND

Bielby, W. T., \& Baron, J. N. (1986). Men and women at work: Sex segregation and statistical discrimination. American Journal of Sociology, 91, 759-799. 
Bray, D. \& Howard, A. (1980). Career success and life satisfactions of middle-aged managers. In Bond LA, Rosen JC (Eds.), Competence and coping during adulthood. Hanover, NH: University Press of New England.

Bringer, J., Johnston, L., \& Brackenridge, C. (2004). Maximising transparency in a doctoral thesis: The complexities of writing about the use of QSR*NVIVO within a grounded theory study. Qualitative Research, 4(2), 247-265.

Burke R. (2001). Managerial women's career experiences, satisfaction and well-being: A five country study. Cross Cultural Management, 8, 117-133.

Cannings K. \& Montmarquette, C. (1991). Managerial momentum: A simultaneous model of the career progress of male and female managers. Industrial and Labor Relations Review, 44, 212-228.

Cannings, K. (1988). Managerial promotion: the effects of socialization, specialization, and gender. Industrial and Labor Relations Review, 42(1), 77-88.

Cannings. K. (1988). Managerial promotion: The effect of socialization, specialization, and gender. Industrial and Labor Relations Review, 42, 77-88.

Cardozo, A. (1986). Sequencing: having it all but not all at once. A new solution for women who want marriage, career, and family. New York: Athenaeum Press.

Cassirer \& Reskin. (2000). High Hopes Organizational Position, Employment Experiences, and Women's and Men's Promotion Aspirations. Work and Occupations 27 (November): 438-463.

Cattell, R. (1970). Handbook for the 16 PF. Champaign. IL: Institute for Personality and Ability Testing. 
Charmaz, K. (2006). Constructing grounded theory: a practical guide through qualitative analysis. London: Sage

Chênevert, D., \& Tremblay, M. (2002). Managerial career success in Canadian organizations: is gender a determinant? International Journal of Human Resource Management, 13, 920-942.

Corbin, J., \& Strauss, A. (1990). Grounded theory research: Procedures, canons, and evaluative criteria. Qualitative Sociology, 13(1), 3-21.

Costa, P. \& McCrae, R. (1992). Revised NEO personality inventory and NEO five-factor inventory professional manual. Odessa, FL: Psychological Assessment Resources.

Cox T. \& Harquail, C. (1991). Career paths and career success in the early career stages of male and female MBAs. Journal of Vocational Behavior, 39, 54-75.

Cramer, D. (2004). The Sage Dictionary of Statistics: A Practical Resource for Students in the Social Sciences. London: Sage Publications Ltd.

Cutler, M. M. \& Jackson, A. L. (2002). A 'glass ceiling' or work/family conflicts? The Journal of Business and Economics Studies, 8(2), 73-85.

Davidson, M. \& Cooper, C. (1992). Shattering the glass ceiling: the woman manager. Paul Chapman: London.

Davis, J. A., \& Smith, T. W. (1991). General social surveys [Machine-readable data file]. Chicago, IL: National Opinion Research Corporation [Producer]. Storrs, CT: The Roper Center for Public Opinion Research, University of Connecticut [Distributor].

Diener, E. (1984). Subjective well-being. Psychological Bulletin, 95, 542-575. 
Dyke, L \& Murphy, S. (2006). How we define success: a qualitative study of what matters most to women and men. Sex Roles (in press).

Dyke, L. \& Orser, B. (2005) “Gender differences in corporate mangers perceptions of success." Proceedings from the Administrative Sciences Association of Canada Annual Conference, Toronto: Ryerson Polytechnic University, May 28-31. Retrieved November 12, 2006 from http://luxor.acadiau.ca/library/ ASAC/v26/11/26_11_p036.pdf

Eisenhardt, K. (1989). Building theories from case study research. Academy of Management Review, 14(4), 532-550.

Fels, A. (2004). Do women lack ambition? Harvard Business Review, April, 50-60.

Gallos, J. (1989). Exploring women's development: Implications for career theory, practice, and research. In M. B. Arthur, D. T. Hall, \& B. S. Lawrence (Eds.), Handbook of career theory. Cambridge, England: Cambridge University Press.

Gattiker, U. \& Larwood, L. (1989). Career success, mobility and extrinsic satisfaction of corporate managers. Social Science Journal, 26, 75-92.

Gattiker, U. E. \& Larwood, L., (1986). Subjective career success: a study of managers and support personnel. Journal of Business and Psychology, 1(2), 78-94.

Gerund. (2006). In C. Soanes \& A. Stevenson (Eds.), The Concise Oxford English Dictionary $\left(11^{\text {th }}\right.$ ed. revised) [Web]. Oxford University Press. Retrieved April 29, 2007, from Oxford Reference Online: http://catalogue.library.carleton.ca/search/ Xoxford + english + dictionary \&searchscope $=3 \&$ SORT $=\mathrm{D} /$ Xoxford + english + dictio nary\&searchscope=3\&SORT=D\&extended=0\&SUBKEY=oxford $\% 20$ english $\% 2$ 
Odictionary/1,24,24,B/1856 b2319618\&FF=Xoxford+english+dictionary\&SORT $=\mathrm{D} \& 1,1,1,0$

Gilligan, C. (1982). In a Different Voice. Cambridge, MA: Harvard University Press.

Gould, S. (1979). Characteristics of career planners in upwardly mobile occupations. Academy of Management Journal, 22, 539-550.

Goulding, C. (2002). Grounded theory: a practical guide for management, business and market researchers. London: Sage.

Gourman J. (1993). The Gourman Report. Los Angeles; National Education Standards.

Greenberg, J. \& McCarty, C. (1990). Comparable worth: A matter of justice. In Ferris GR, Rowland KM (Eds.), Research in personnel and human resources management, Vol. 8, Greenwich, CT: JAI Press.

Greenhaus, J., Parasuraman, S., \& Wormley, W. (1990). Effects of race on organizational experiences, job performance evaluations, and career outcomes. Academy of Management Journal, 33, 64-86.

Hall, D. \& Moss, J. (1998). The new protean career contract: helping organizations and employees adapt. In Osland, J., Kolb, D. \& Rubin, I., Eds. The Organizational Behavior Reader, $7^{\text {th }}$ Ed. (2001). Upper Saddle River, NJ: Prentice Hall.

Hardesty, S. \& Jacobs, N. (1986). Success and betrayal: The crisis of women in corporate America. New York: Franklin Watts.

Harrell, T. (1969). The personality of high earning MBA's in big business. Personnel Psychology, 22, 457-463,

Hartwig, F. \& Dearing, B. (1979). Exploratory Data Analysis. Newbury Park: Sage Publications. 
Hastie, R. \& Dawes, R. (2001). Rational choice in an uncertain world: The psychology of judgment and decision-making. Thousand Oaks, CA: Sage Publications.

Herriot, P., Gibbons, P., Pemberton, C. \& Jackson, P. (1994). An empirical model of managerial careers in organizations. British Journal of Management, 5, 113-121.

Heslin, P. (2003). Self- and other-referent criteria of career success. Journal of Career Assessment, 11, 262-286.

Heslin, P. (2005). Conceptualizing and evaluating career success. Journal of Organizational Behavior, 26, 113-136.

Hewlett \& Luce. (2005). Off-ramps and on-ramps: keeping talented women on the road to success. Harvard Business Review, 83(3), 43-6.

Hoffmann, C., \& Reed, J. S. (1981). Sex discrimination? The XYZ affair. Public Interest, $62,21-39$

Howard, A., \& Bray, D. (1988). Managerial lives in transition: Advancing age and changing times. New York: Guilford Press.

Hughes, E. C. (1937). Institutional office and the person. American Journal of Sociology, 43, 404-413.

Hughes, E. C. (1958). Men and their work. Glencoe: Free Press.

Institute for Personality and Ability Testing (1972). Manual for the 16PF. Champaign, IL: IPAT.

Jaskolka, G. Beyer, J. \& Trice, H. (1985). Measuring and predicting managerial success. Joumal of Vocational Behavior, 26,189-205.

Judge, T. \& Bretz, R. (1994). Political influence behavior and career success. Journal of Management, 20, 43-65. 
Judge, T., Cable, D., Boudreau, J. \& Bretz, R. (1995). An empirical investigation of the predictors of executive career success. Personnel Psychology, 48, 485-519.

Kanter, R. M. (1977). Men and women of the corporation. New York: Basic Books. Kirchmeyer C. (2002). Gender differences in managerial careers: Yesterday, today, and tomorrow. Journal of Business Ethics, 37, 5-24.

Langley, A. (1999). Strategies for theorizing from process data. Academy of Management Review, 24(4), 691-710.

Levinson, D. (1978). The Seasons of a Man's Life, Alfred A. Knopf, New York, NY.

Liff, S. \& Ward, K. (2001). Distorted views through the glass ceiling: the construction of women's understandings of promotion and senior management positions. Gender, Work and Organization, 8(1), $19-36$.

Lillis, A. (1999). A framework for the analysis of interview data from multiple field research sites. Accounting and Finance, 39, 79-105.

Locke, E. (1976). The nature and causes of job satisfaction. In Dunnette, M. D. (Ed.), Handbook of industrial and organizational psychology (pp. 1297-1343). Chicago: Rand McNally.

London, M. (1983). Toward a theory of career motivation. The Academy of Management Review, 8(4), 620-630.

London, M. \& Stumpf, S. (1982). Managing careers. Reading, MA: Addison-Wesley. Loxley, W. (2001). Drowning in words? using NUDIST to assist in the analysis of long interview transcripts from young injecting drug users. Addiction Research and Theory, 9(6), 557-573. 
Lyness, K. \& Thompson, D. (1997). Above the glass ceiling? A comparison of matched samples of female and male executives. Journal of Applied Psychology, 82, 359375.

Mainiero, L. \& Sullivan, S. (2005). Kaleidoscope careers: An alternate explanation for the "opt-out" revolution. Academy of Management Executive, 19(1), 106-123.

May, K. (2006, November 6). Universities getting ready for post-boomer PS job rush. The Ottawa Citizen, pp. A1.

Melamed, T. (1996). Career success: An assessment of a gender-specific model. Journal Of Occupational And Organizational Psychology 69: 217-242 .

Merriam, S. (1997). Qualitative Research and Case Study Applications in Education. San Francisco: Jossey Bass.

Mihal, W. L., Sorce, P. A., \& Comte, T.E. (1984). A process model of individual career decision making. Academy of Management Review, 9(1), 95-103.

Miles, M. \& Huberman, A. (1994). Qualitative data analysis : an expanded sourcebook. Thousand Oaks: Sage.

Mintzberg, H. (1979). An emerging strategy of "direct" research. Administrative Science Quarterly, 24, 582-589.

Morrison, A., White, R. P., \& Van Velsor, E. (1992). Breaking the glass ceiling. Reading, MA: Addison-Wesley.

Morse, J. (1994). Emerging from the data: the cognitive processes of analysis in qualitative inquiry. In J. Morse (Ed.), Critical issues in qualitative research methods. Thousand Oaks, C: Sage. 
MOW International Research Team. (1987). The meaning of working. London: Academic Press.

Ng, T., Eby, L. \& Sorensen, K, \& Feldman, D. (2005). Predictors of objective and subjective career success: A meta-analysis. Personnel Psychology, 58 (2), 367408.

O’Connor, D. \& Wolfe, D. (1987). On managing mid-life transitions in career and family. Human Relations, 40(12), 799-816.

O'Reilly, C. \& Caldwell, D. (1981). The commitment and job tenure of new employees: some evidence of postdecisional justification. Administrative Science Quarterly, 26(4), 597-616.

Parker, B. \& Chusmir, L. (1992). A comparison of men and women managers' and nonmanagers' perceptions of success. Human Resource Development Quarterly, 3, 73-84.

Poole, M., Langan-Fox, J., \& Omodei, M. (1993). Contrasting subjective and objective criteria as determinants of perceived career success: A longitudinal study. Journal of Occupational and Organizational Psychology, 66, 39-54.

Powell, G., Mainiero, L.. (1992). Cross-currents in the river of time: Conceptualizing the complexities of women's careers. Journal of Management, 18, 215-237.

Priest, H., Roberts, P., \& Woods, L. (2002). An overview of three different approaches to the interpretation of qualitative data. Part 1: Theoretical issues. Nurse Researcher, 10(1), 30-42.

Public Service Commission of Canada. (2002). The road ahead: Recruitment and retention challenges for the public service. [Electronic version]. 
Rosin, H. \& Korabik, K. (1989). Marital and family correlates of women managers' attrition from organizations. Journal of Vocational Behavior, 37, 104-120.

Russo, N., Kelly, R.-M. \& Deacon, M. (1991). Gender and success-related attribution: beyond individualistic conceptions of achievement. Sex Roles, 25(5-6), 331-350.

Scarpello, V. \& Campbell, J. P. (1983). Job satisfaction: Are all the parts there? Personnel Psychology, 36, 577-600.

Schultz, V. (1990). Telling stories about women and work: Judicial interpretations of sex segregation in the workplace in Title VII cases raising the lack of interest argument. Harvard Law Review, 103, 1750-1843.

Seibert, S., Kraimer, M. (2001). The five-factor model of personality and career success. Journal of Vocational Behavior, 58, 1-21.

Stone, P. \& Lovejoy, M. (2004). Fast-track women and the "choice" to stay home. The Annals of the American Academy of Political and Social Science, 596(1), 62-83.

Strauss, A. (1987). Qualitative analysis for social scientists. Cambridge: Cambridge University Press.

Strauss, A. \& Corbin, J. (1994). Grounded theory methodology: An overview. In N.K. Denzin \& Y.S. Lincoln (Eds.), Handbook of qualitative research. Thousand Oaks, CA: Sage.

Strauss, A. \& Corbin, J. (1998). Basics of qualitative research: techniques and procedures for developing grounded theory. Thousand Oaks : Sage Publications.

Stroh, L., Brett, J. \& Reilly, A. (1992). All the right stuff: A comparison of female and male managers' career progression. Journal of Applied Psychology, 77, 251-260. 
Sturges, J. (1999). What it means to succeed: personal conceptions of career success held by male and female managers at different ages. British Journal of Management, 10, 239-252.

Tharenou, P. (2001). Going up: Do traits and informal social processes predict advancing in management? Academy of Management Journal, 44, 1005-1017.

Tsui, A. S., \& Gutek, B. A. 1984. A role set analysis of gender differences in performance, affective relationships, and career success of industrial middle managers. Academy of Management Journal, 27, 619-635.

Vroom, V. H. (1964). Work and motivation. New York: Wiley.

Weber, R. (1990). Basic Content Analysis. $2^{\text {nd }}$ Ed. Newbury Park, CA: Sage Publications.

White, B. L. \& Cooper, C. L. (1995). The career development of successful women. Proceedings of The British Psychological Society. 3(1) February, 10. 